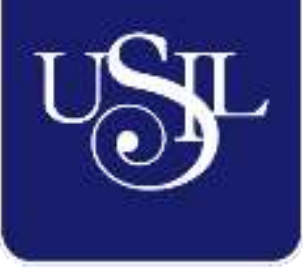

UNIVERSIDAD

SAN IGNACIO

DE LOYOLA

FACULTAD DE CIENCIAS EMPRESARIALES

Carrera de Administración y Emprendimiento

\title{
DETERMINACIÓN DE LA INFLUENCIA DEL MARKETING DIGITAL EN LA DECISIÓN DE COMPRA DE PRODUCTOS FITNESS EN USUARIOS DE GIMNASIOS DE LIMA MODERNA
}

Tesis para optar el Título Profesional de Licenciado en Administración y Emprendimiento

\section{RICHARD MADGE MEDINA DIEGO AMERICO CHAVEZ MACURI}

\author{
Asesor: \\ Jenny Vega Mondragon \\ Lima, Perú \\ 2020
}




\section{Índice}

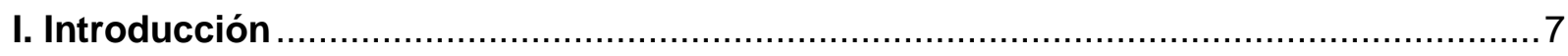

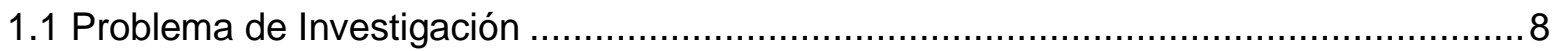

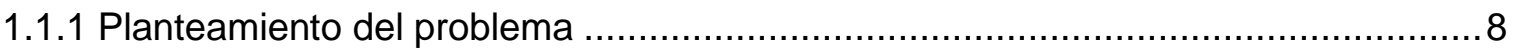

1.1.2 Formulación del problema..................................................................... 10

1.1.3 Justificación de investigación ................................................................ 10

1.1.4 Delimitación de la investigación ................................................................. 12

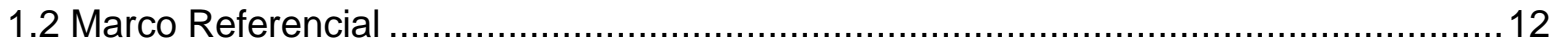

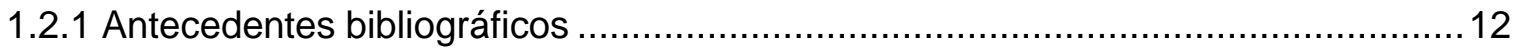

1.2.2 Marco teórico ............................................................................................ 16

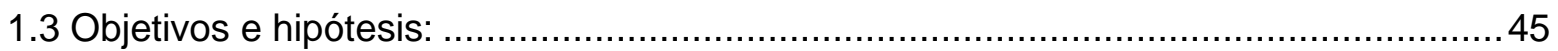

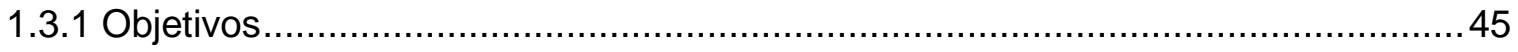

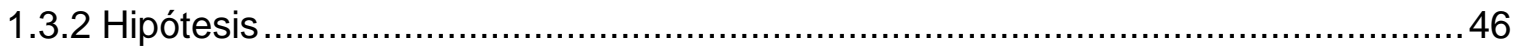

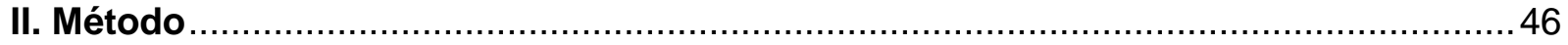

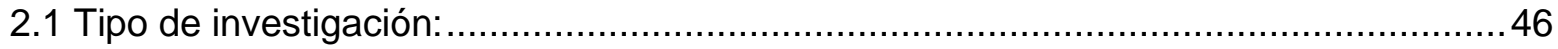

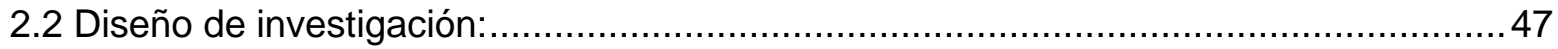

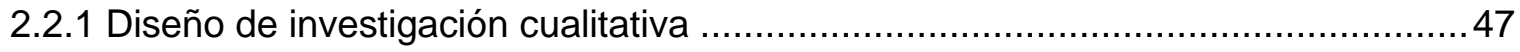

2.2.2 Diseño de investigación cuantitativa ...................................................... 47

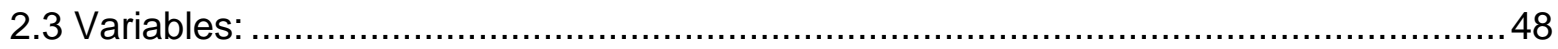

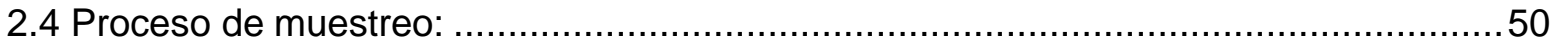

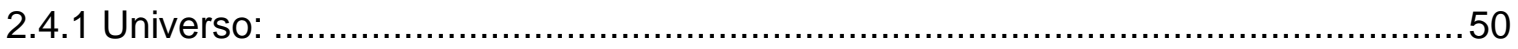

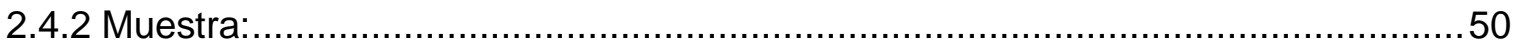

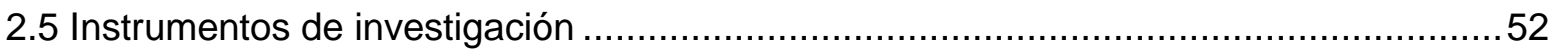

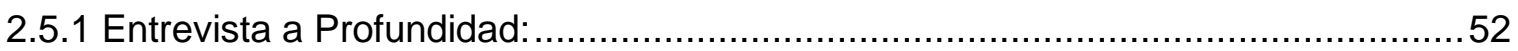

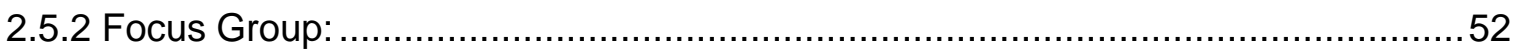

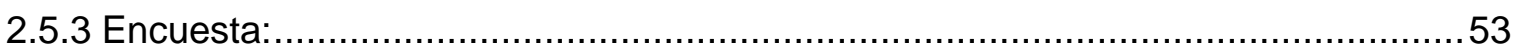

2.6 Procedimiento de recolección de datos ......................................................56

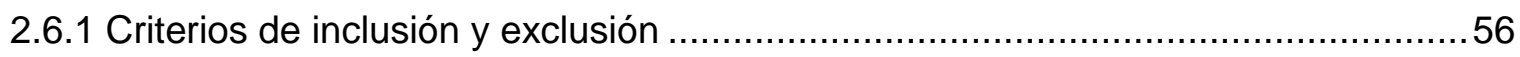

2.7 Procedimiento de recolección de información cualitativa ........................................5 57

2.7.1 Resumen de información obtenida del estudio cualitativo ....................................58

2.8 Procedimiento de recolección de información cuantitativo.......................................59

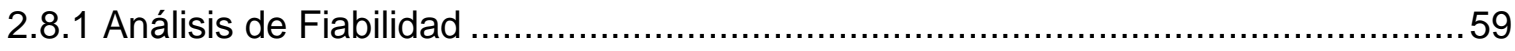




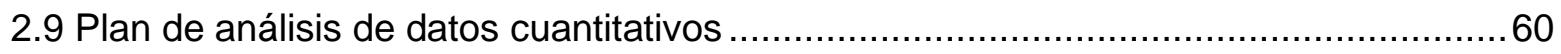

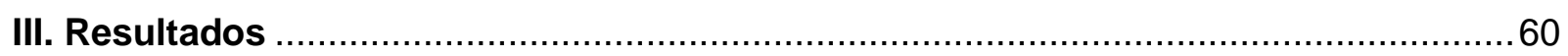

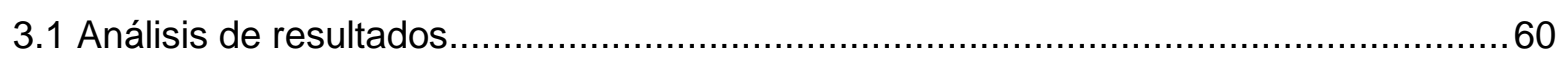

3.1.1 Análisis de resultados del estudio cualitativo: ............................................60

3.1.2 Análisis de resultados de estudio cuantitativo: ............................................67

3.1.3 Análisis de tablas de contingencia del estudio cuantitativo ............................... 104

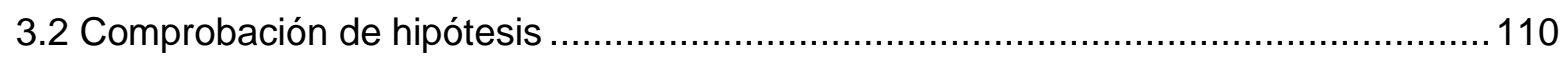

3.2.1 Prueba Rho-spearman.................................................................... 110

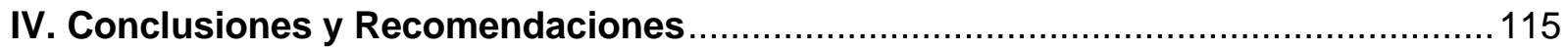

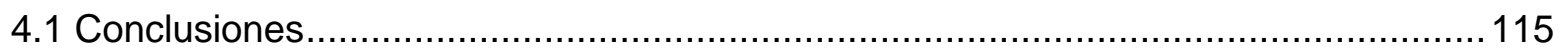

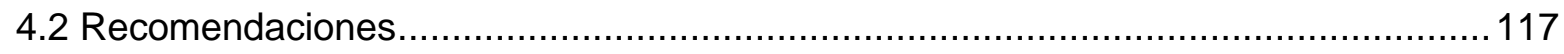

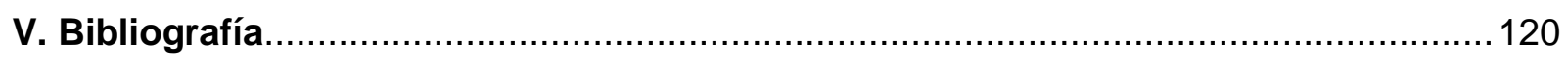

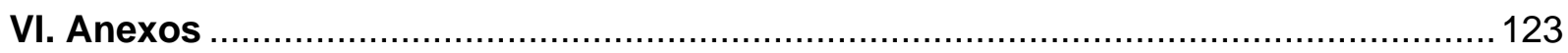


Índice de tablas

Tabla 1: Factores que influyen en el comportamiento del consumidor..........................18

Tabla 2: Proceso de toma de decisiones del consumidor. .............................................19

Tabla 3: Tendencias de consumo peruano...................................................................21

Tabla 4: Clasificación digital de usuarios peruanos 2018. ..........................................22

Tabla 5: Porcentaje de los medios sociales en Latinoamérica.........................................33

Tabla 6: 5 maneras de como utilizan los peruanos las redes sociales............................33

Tabla 7: Descripción y operacionalización de las variables de estudio. ........................48

Tabla 8: Tamaño de muestra.....................................................................................51

Tabla 9: Las dimensiones teóricas de afirmaciones del instrumento de investigación.54

Tabla 10: Fiabilidad del instrumento. ..........................................................................57

Tabla 11: Participantes focus group ............................................................................63

Tabla 12: Análisis de resultados del primer objetivo específico..................................74

Tabla 13: Análisis de resultados del segundo objetivo específico. ...............................84

Tabla 14: Análisis de resultados del tercer objetivo específico. ...................................92

Tabla 15: Tabla cruzada 1 Marketing digital * Decisión de compra............................... 104

Tabla 16: Tabla cruzada 2 dimensión de atracción * decisión de compra....................105

Tabla 17: Tabla cruzada 3 dimensión de difusión* decisión de compra.......................107

Tabla 18: Tabla cruzada 4 dimensión de retención * decisión de compra.................... 108

Tabla 19: Prueba Rho de Spearman hipótesis general. ..............................................111

Tabla 20: Prueba Rho de Spearman primera hipótesis específica................................112

Tabla 21: Prueba Rho de Spearman para la segunda hipótesis específica..................113

Tabla 22: Prueba Rho de Spearman tercera hipótesis específica................................114 


\section{Indice de figuras}

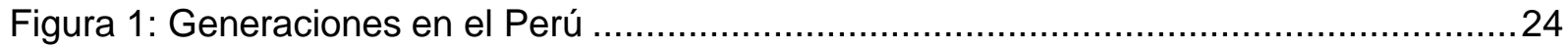

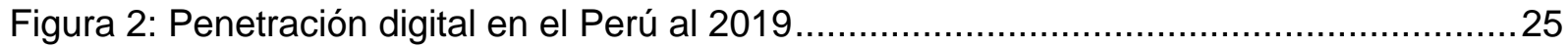

Figura 3: Crecimiento anual digital entre los años 2018 y 2019.......................................26

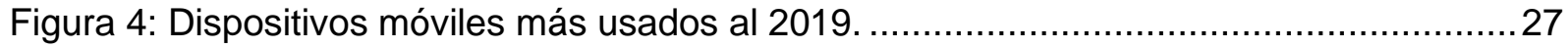

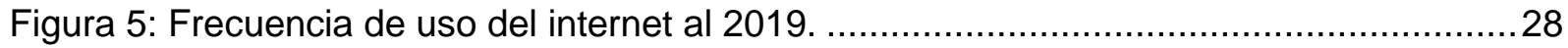

Figura 6: Audiencias de medios sociales de publicidad al 2019......................................29

Figura 7: Crecimiento en el último trimestre de audiencias de medios sociales al 2019........30

Figura 8: Perfil de la audiencia en medios sociales al 2019............................................

Figura 9: Frecuencia de actividad en Facebook al 2019. ...............................................

Figura 10: Evolución de la inversión publicitaria en el Perú...............................................38

Figura 11: Magnitud de inversión del marketing por internet en el Perú................................39

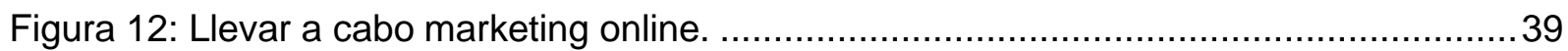

Figura 13: Análisis de la pregunta 1 del instrumento cuantitativo......................................68

Figura 14: Análisis de la pregunta 2 del instrumento cuantitativo.......................................69

Figura 15: Análisis de la pregunta 3 del instrumento cuantitativo......................................70

Figura 16: Análisis de la pregunta 4 del instrumento cuantitativo..................................... 71

Figura 17: Análisis de la pregunta 5 del instrumento cuantitativo.....................................72

Figura 18: Análisis de la pregunta 6 del instrumento cuantitativo. ..........................................73

Figura 19: Análisis de la pregunta 7 del instrumento cuantitativo...................................... 75

Figura 20: Análisis de la pregunta 8 del instrumento cuantitativo. .........................................

Figura 21: Análisis de la pregunta 9 del instrumento cuantitativo....................................

Figura 22: Análisis de la pregunta 10 del instrumento cuantitativo...................................78

Figura 23: Análisis de la pregunta 11 del instrumento cuantitativo. ......................................79

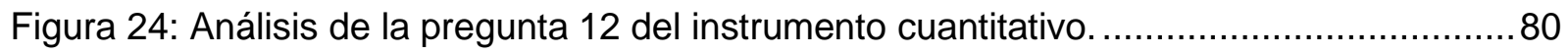

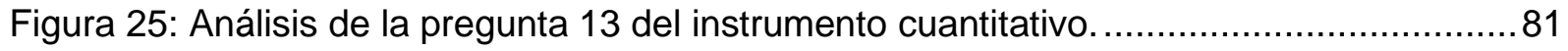

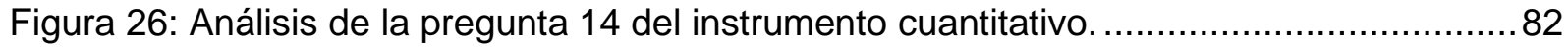

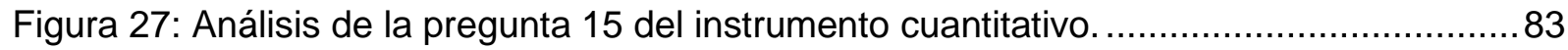

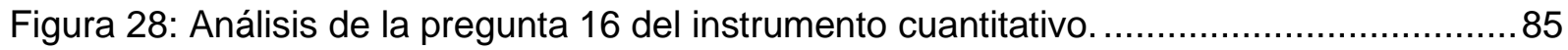

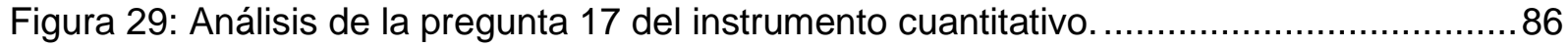

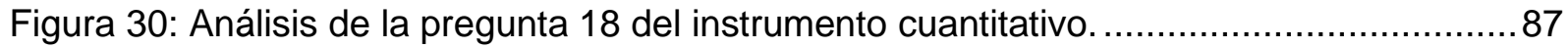

Figura 31: Análisis de la pregunta 19 del instrumento cuantitativo. ......................................8

Figura 32: Análisis de la pregunta 20 del instrumento cuantitativo. .......................................89 
Figura 33: Análisis de la pregunta 21 del instrumento cuantitativo. ...................................90

Figura 34: Análisis de la pregunta 22 del instrumento cuantitativo...................................91

Figura 35: Análisis de la pregunta 23 del instrumento cuantitativo. ...................................93

Figura 36: Análisis de la pregunta 24 del instrumento cuantitativo. ...................................94

Figura 37: Análisis de la pregunta 25 del instrumento cuantitativo..................................95

Figura 38: Análisis de la pregunta 26 del instrumento cuantitativo...................................96

Figura 39: Análisis de la pregunta 27 del instrumento cuantitativo. ................................97

Figura 40: Análisis de la pregunta 28 del instrumento cuantitativo. ..................................98

Figura 41: Análisis de la pregunta 29 del instrumento cuantitativo...................................99

Figura 42: Análisis de la pregunta 30 del instrumento cuantitativo.................................100

Figura 43: Análisis de la pregunta 31 del instrumento cuantitativo................................. 101

Figura 44: Análisis de la pregunta 32 del instrumento cuantitativo. .................................. 102

Figura 45: Análisis de la pregunta 33 del instrumento cuantitativo. ................................... 103

Figura 46: Análisis cruzado variable dependiente e independiente.................................. 105

Figura 47 Análisis cruzado 2 dimensión de atracción * decisión de compra.......................106

Figura 48: Análisis cruzado 3 dimensión de difusión * decisión de compra.......................108

Figura 49: Análisis cruzado 4 dimensión de retención * decisión de compra. ....................109

\section{Indice de Anexos}

Anexo A: Matriz de consistencia. ........................................................................... 123

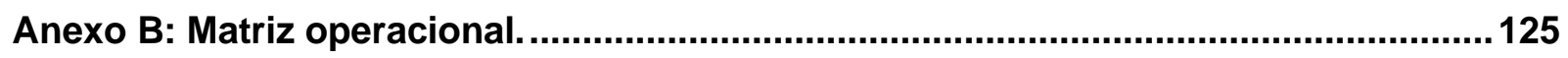

Anexo C: Guía de pauta de la entrevista de profundidad ...........................................128

Anexo D: Entrevistas de profundidad ......................................................................130

Anexo E: Guía de pauta del FOCUS GROUP ............................................................137

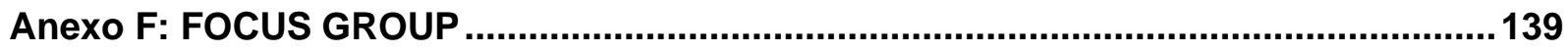

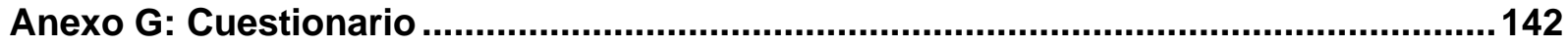




\section{Introducción}

En el siguiente trabajo demostraremos la relación de la influencia que tiene el marketing digital en la decisión de compra de productos fitness en usuarios de gimnasios en la zona delimitada de Lima moderna, siendo este estudio impulsado por la falta de publicidad de productos fitness en los canales tradicionales de marketing (televisión, radio, etc.) limitándose a publicaciones en plataformas de Internet; teniendo como meta justificar la inversión en este tipo de publicidad al promocionar productos fitness desde la perspectiva de un negocio pequeño y mediano; así como delimitando el concepto de productos fitness a suplementos ergogénicos (vitaminas, minerales, aminoácidos, etc.) los cuales se encuentran en venta sin receta médica (KidsHealth redacción, 2015). Por ello el primer capítulo hace hincapié en los fundamentos que impulsan esta investigación, define los términos base de ésta y plantea la problemática que se busca resolver al finalizar la investigación.

En la publicación “Una tendencia para llegar más al público del sector fitness es el canal digital" (Redacción Gestión, 2015), Marcela Garcés gerente comercial de Bodytech, afirma que el marketing digital no es el medio más tradicional de publicidad; sin embargo, su impacto es el más medible en el momento, además que la comunicación es más personalizada mientras no sea invasiva, y es posible llegar a una gran audiencia en un tiempo respetable. Teniendo en cuenta esta perspectiva, el capítulo dos propone un método de investigación en la cual se procede a recolectar datos de un estudio cualitativo y cuantitativo, siendo el segundo exclusivamente digital, buscando demostrar la efectividad de este tipo de publicidad a través de la tarea de recopilación de datos.

Este trabajo de investigación, incluye entrevistas de profundidad, además de un focus group y de manera cuantitativa con el uso de encuestas. En el capítulo tres se analiza los resultados obtenidos de todos los estudios aplicados y permite hallar conclusiones respaldadas por los datos estadísticos de prueba, usados en la investigación.

El capítulo cuatro da a conocer sus conclusiones y recomendaciones basadas en los hallazgos de los capítulos anteriores, consiguiendo entender la valides real de marketing digital en este mercado, guiando al pequeño y mediano empresario a invertir recursos de tiempo, 
dinero o personal según sea conveniente; encontrando así la influencia del marketing digital frente a la decisión de compra de productos fitness.

\subsection{Problema de Investigación}

En este capítulo se procede a presentar y explicar de manera concisa este proyecto de investigación. Dividido en las siguientes secciones: Planteamiento del problema, formulación de la problemática con sus respectivas interrogantes y la justificación de la investigación.

\subsubsection{Planteamiento del problema}

La industria de productos fitness "genera más de 150 millones de soles al año solo en el Perú" (Front Consulting, 2016), sin embargo esta industria no es pública o difunde propaganda en medios de comunicación tradicionales, como televisión o radio; por el contrario "los peruanos que realizan compras por internet adquieren en un $37 \%$ de todo el comercio digital; la ropa, calzado, accesorios y productos de consumo fitness en general" según (Arellano Marketing, 2017), lo que demostró un gran interés propio por parte de la población de la adquisición de este tipo de productos por canales modernos incentivando así, el desarrollo de este estudio el cual se enfocó en determinar si el marketing digital tiene un impacto positivo para este tipo de industria y ¿cuáles de sus componentes producen mayores beneficios?, esto en gran medida motivado por la afirmación de que "hasta un $56 \%$ de las ventas en tienda están influenciadas por las interacciones a través de las redes sociales" (Deloitte, 2016) resultado obtenido de su investigación titulada "La nueva brecha digital" de la cual se puede resaltar la transformación e importancia de las tendencias de consumo digital así como de su beneficio para las MYNPES "las que conforman más del $90 \%$ de la fuerza comercial de productos fitness" (Ministerio de la producción - Gobierno del Perú, 2017).

Al mismo tiempo el marketing digital es una herramienta que sirve para alcanzar los objetivos comerciales de las empresas sin importar su tamaño, ya que minimiza los costos publicitarios al combinar conveniencia y exposición al estar disponible para toda persona con conexión a internet, ya que "más del 85\% de empresas modernas tienen presencia en redes sociales; sin embargo, esta presencia no basta si no se genera un vínculo de participación interactiva con el usuario promedio la cual se puede traducir a una venta" (Turró, 2017). Por ello, el uso de marketing digital genera conveniencia para las MYNPES las cuales obtienen la 
oportunidad de llegar a sus mercados objetivos, usando canales virtuales de acceso al público que gozan de gran popularidad (redes sociales), especialmente en el caso de productos fitness; mercado que posee un nicho de consumidores muy definido. Al día de hoy el potencial de crecimiento de este mercado es uno de los más grandes de todo el país, al soló tener el $2 \%$ de limeños inscritos en el gimnasio (Front Consulting, 2016).

En pocas palabras las MYNPES dedicadas al comercio de productos fitness no han logrado obtener todo los beneficios del marketing digital evitando asi, alcanzar su crecimiento potencial, por ello en este trabajo se busca determinar cuáles son las dimensiones del marketing digital que realmente influyen en la decisión de compra de productos fitness y poder así refinar las estrategias más relevantes para captar de manera eficiente la atención del mercado objetivo y generar impactos que se traduzcan en ventas, por ese motivo y por la falta de investigaciones previas sobre este tema, comenzamos la investigación con un estudio cualitativo el cual se encuentra conformado por entrevistas de profundidad a expertos con el fin de generar un panorama sobre el tipo de consumidor fitness moderno, seguido de un FOCUS group que permita determinar los temas más relevantes que conciernen a los consumidores de este mercado y así generar los cimientos de un estudio cuantitativo, el cual aporte al desarrollo y crecimiento de las MYNPES de este sector. 


\subsubsection{Formulación del problema}

\subsubsection{Problema general:}

La interrogante principal es ¿El marketing digital influye en la decisión de compra de productos fitness en usuarios de gimnasios de Lima moderna?

\subsubsection{Problemas específicos: Los cuales incluyen determinar}

- ¿La dimensión de la atracción del marketing digital influye en la decisión de compra de productos fitness en usuarios de gimnasios de Lima moderna?

- ¿La dimensión de la difusión del marketing digital influye en la decisión de compra de productos fitness en usuarios de gimnasios de Lima moderna?

- ¿La dimensión de la retención del marketing digital influye en la decisión de compra de productos fitness en usuarios de gimnasios de Lima moderna?

\subsubsection{Justificación de investigación}

Este trabajo de investigación se basa en la necesidad de proporcionar información a pequeñas y medianas empresas sobre la importancia del marketing digital en la actualidad, esto en gran medida, debido a que "el marketing digital en el Perú al 2017 solo abarcaba el $12 \%$ de lo gastado en la inversión de publicidad en general" (Miyoshi, 2017). Así mismo, presentar información sobre la relación de dependencia en la toma de decisión de la compra de productos fitness, frente al marketing digital en usuarios de gimnasios de Lima moderna, y confirmar si éste influye en la mentalidad del consumidor, al ser un mercado que publicita muy poco en medios de comunicación tradicionales. Por ello, este tema tiene un gran potencial práctico y aplicativo, debido a los pocos estudios realizados sobre este mercado en el Perú, siendo el mismo dominado por micro comercializadores. En el Perú "el 92.6\% de empresas formales son microempresas y el 3.2\% pequeñas empresas, dejando así un margen extremadamente pequeño a las medianas y grandes empresas" (Ministerio de la producción Gobierno del Perú, 2017), los cuales al ser un tamaño reducido no cooperan compartiendo información con otras empresas de este tipo; creando una mayor dificultad al intentar obtener información de este mercado. Al mismo tiempo, también se puede apreciar el desinterés por 
parte de las grandes empresas, demostrando la necesidad de realizar este estudio, bajo la noción de que la comprensión del valor de los aportes del marketing digital a la pequeña y mediana empresa la ayudarían significativamente a desarrollarse, mejorando sus ingresos, solidificando su existencia y evitando su fracaso en el tiempo.

Desde el enfoque actual en tiempos de pandemia, el interés por el éxito del mercado fitness peruano, desde el punto de vista de los stakeholders (partes interesadas), es mucho mayor debido a la presión constante de una economía mundial severamente golpeada para la cual se vaticina una larga recuperación ya que en el Perú se perdieron más de 6 millones de puestos laborales solo en el segundo trimestre del presente año 2020 (Anadolu Agency, 2020). $\mathrm{Y}$, siendo este sector considerado como lujo, empresas como Universe Nutricion la productora de suplementos fitness más grande del Perú con un $85 \%$ de presencia nacional (Perú21, 2018), esperan el éxito de ventas de los micro comercializadores en la red debido a que sus productos se comercializaban principalmente en gimnasios, solo en Lima comercializando sus productos en los más de 1600 gimnasios, los cuales se encuentran cerrados en casi todo el mundo como parte de las medidas gubernamentales enfocadas en contrarrestar la pandemia.

\subsubsection{Parte teórica:}

Debido al crecimiento económico y a la alta competitividad empresarial, según (Torres, Rivera, Cabarcas, \& Castro, 2017) de la Universidad Simón Bolívar, Barranquilla de Colombia, concluyen que el marketing digital es una herramienta bastante accesible para las pequeñas y medianas empresas, muchas de las cuales no poseen el capital para operar en la escala de las grandes corporaciones en materia de publicidad. Esto es importante para la industria fitness, debido a que muchas veces está conformada por productos de gran valor nutricional, creados por negocios emergentes o pequeños grupos que se dedican a la importación de productos altamente especializados, aquellos que no son comercializados directamente por el fabricante en el Perú.

\subsubsection{Parte práctica:}


La necesidad de las pequeñas y medianas empresas es crecer poco a poco, para conseguir ser rentables y no desaparecer en el tiempo; por ese motivo una herramienta como el marketing es muy relevante, sin embargo al tener costos muy elevados por parte de los canales tradicionales, este trabajo de investigación busca otorgar una alternativa viable para ofertar sus productos fitness y llegar a su público deseado con todas las promociones y novedades que estos anhelan, sin embargo para ser efectivas no todas las estrategias de marketing digital deben ser usadas, debido que al hacerlo conllevaría a esfuerzos infructuosos y desperdicio de capital, "las micro y pequeñas empresas no terminan de asimilar el perfil de su cliente objetivo, conformándose por estrategias de marketing genéricas en ineficientes" (Marroquín, Negrón, \& Solano, 2019). Por ello, se busca que los esfuerzos de marketing digital sean efectivos basados en los resultados de la investigación, demostrando su verdadera influencia, justificando así invertir en este medio y no solo poseer una presencia pasiva en este.

\subsubsection{Delimitación de la investigación:}

Se delimitó concretamente al usuario de gimnasio de Lima moderna, agrupado en 12 distritos: Jesús María, Barranco, San Miguel, La Molina, Lince, Magdalena, Miraflores, Surquillo, Pueblo Libre, San Isidro, Surco y San Borja (Ipsos, 2018), conformados principalmente por niveles socioeconómicos $\mathrm{A}$ y $\mathrm{B}$, siendo estos sectores poseedores de la afluencia monetaria, para realizar gastos adicionales a gastos de primera necesidad y cuyo periodo de tiempo fue comprendido entre el año 2019 e inicios del 2020.

\subsection{Marco Referencial}

\subsubsection{Antecedentes bibliográficos}

\subsubsection{Nacionales:}

En el estudio titulado "La aplicación del modelo Inbound marketing para incrementar las ventas de bebida de Camu Camu en el distrito de Santiago de Surco, 2015" (Cabrera \& Torres, 2016), cuyo objetivo central fue demostrar los resultados del uso de un modelo de Marketing Inbound a la empresa Agroindustrial del Perú S.A.; llegó a sus conclusiones 
mediante cuestionarios realizados a compradores, los cuales tuvieron una experiencia vivencial debido a que, esta estrategia se aplicó por parte de la empresa en el periodo de la investigación; presentando la conclusión que con el uso de varias técnicas Inbound, se consigue alcanzar a los consumidores deseados de Santiago de Surco; consiguiendo así ventas y lo más importante fidelización de clientes. Este estudio demuestra la importancia de entender el perfil del consumidor debido a que los productos nicho pueden florecer en el mundo digital si se conoce exactamente la mentalidad y hábitos de consumo del cliente, sin realizar costosas campañas de marketing sectorizado. Así, se crea esfuerzos de marketing más económicos y efectivos, ya que la publicidad no es invasiva o incómoda para el usuario permitiendo una mejor relación con la empresa. Lo que conlleva a una fidelización más sencilla y al mismo tiempo reconociendo que estas técnicas son accesibles para un pequeño empresario, mediante el uso de herramientas automatizadas en línea.

En el estudio "Relación entre las estrategias de marketing digital de empresas de moda y/o entretenimiento arequipeño, y la decisión de compra de sus clientes, usuarios de Facebook" (Llave, 2016), tenía como principal objetivo determinar la influencia del marketing digital en la red social conocida como Facebook, perteneciente a empresas de moda y entretenimiento, intercediendo así en la decisión de compra de los posibles clientes. Esta investigación se realizó por medio de encuestas, resolviendo así su hipótesis y por medio de sus resultados, se confirmó que el marketing digital tiene un impacto significativo y positivo en la decisión de compra de los usuarios de Facebook. Para la investigación, estos resultados incentivan un estudio más sectorizado del uso de marketing digital, permitiendo considerar estrategias de publicidad direccionada en redes sociales sin ser limitadas a una sola red social como Facebook.

El estudio titulado "Grado de eficacia de la estrategia de personalización de marketing digital de la empresa Pinkberry Perú en la red social Instagram, Trujillo 2016” (Malpica, 2017), tenía como objetivo principal, determinar la eficacia de la estrategia de personalización del marketing digital de la empresa a estudiar en Instagram; por ese motivo realizó medición de métricas de interacción de la página web de este grupo en esta red social, dando como conclusión que la estrategia de personalización influye positivamente, debido a la publicación de contenidos exclusivos de esta pequeña tienda para sus consumidores que asisten al Mall Aventura Plaza; mejorando así el nivel de interacción de los seguidores, gracias a la 
publicación de contenidos personalizados, los cuales reconocieron las necesidades y gustos de los consumidores de manera correcta, generando empatía con la tienda, considerándose como una de las mejores campañas de esta cadena de restaurantes. Creando la interrogante que incluso tiendas de cadenas pueden ser autónomas en sus esfuerzos de marketing sectorizado, las cuales, por su tamaño, no cuentan con grandes presupuestos en comparación de la marca principal; sin embargo, estas son exitosas por los conocimientos especializados de los profesionales que trabajan con la marca y desarrollan protocolos flexibles para ejecutar estos esfuerzos de marketing.

En "Estrategias de marketing digital para la internacionalización del hotel Huanchaco Paradise en el año 2019. Trujillo, Perú" (Esquiven, 2016), este trabajo tuvo como objetivo buscar las estrategias más eficaces del marketing digital con el fin de internacionalizar el Hotel Huanchaco Paradise. Así mismo, se contó con información de fuentes primarias por medio de entrevistas a expertos en marketing digital y como información secundaria se usó informes, papers, etc, concluyendo que el hotel ejecuta un marketing digital sin estrategias bien definidas y rápidamente desactualizadas dentro de las plataformas virtuales en donde se exponen. Esta problemática es muy común en negocios relativamente pequeños los cuales tienden a no tomar en cuenta las características que hacen a sus negocios atractivos en particular. Delimitando así sus posibilidades de crecimiento, que es una parte vital de los esfuerzos de marketing digital el cual invita a experimentar y encontrar el perfil del consumidor a través de sus campañas.

Este trabajo nos presenta un problema directo de una empresa, cuyo objetivo era generar una campaña de lanzamiento internacional, la cual sería en el marketing tradicional un proyecto costoso y extenso; sin embargo, gracias a las plataformas digitales, solo falta conocer que estrategias de marketing digital se debe utilizar para poder conseguir los resultados deseados, a un menor precio, llegando a lugares con un potencial de consumo inesperado. Demostrando así que las facilidades del marketing digital radican principalmente en la existencia de plataformas de captación de clientes más prácticas y estandarizadas, aquellas que no son difíciles de acceder, pero sí de dominar. 


\subsubsection{Internacionales:}

En la investigación de tesis titulada "Las redes sociales virtuales y su influencia en los hábitos saludables de alimentación y ejercicio, en los jóvenes universitarios en la ciudad de Cali" (Montoya, 2017), se usó el instrumento de la encuesta para examinar la influencia que ejercen los Influencers (líderes de opinión) sobre temas fitness: hábitos saludables relacionados con el ejercicio y la alimentación en jóvenes universitarios que usan la red social Instagram, demostrando por los resultados, que las redes sociales tienen la capacidad para influenciar en millones de personas, realizando cambios en la vida de aquellos expuestos al mensaje en el corto plazo. Se halló también que la influencia de las redes sociales como Instagram en hábitos de conducta es cierta, si las personas ya tienen un mínimo de interés en el tema, por lo cual se pudo confirmar que las personas pusieron en práctica las recomendaciones de los líderes de opinión; confirmando así sin importar que siguieran un consejo, la influencia ya estaba presente en la mente de los usuarios, siendo capaz de cambiar sus hábitos de comportamiento y consumo. Este trabajo nos presenta la respuesta psicológica del consumidor sectorizado frente a iniciativas de marketing digital correctamente usadas, en donde se puede considerar que los clientes potenciales son los que buscan la publicidad inconscientemente, al seguir a líderes de opinión quienes, gracias a las plataformas digitales, pueden ser cualquier persona con un smatphone y una idea atractiva.

En su publicación "Tendencias de la industria de los medios de América del Sur en la transición digital" (Campos-Freire, Yaguache, \& Ulloa, 2017), los autores tuvieron como objetivo exponer la tendencia de los medios en la evolución tecnológica en la era digital. A través de la data recolectada, llegaron a la conclusión que la tendencia de relevancia de los medios digitales está en ascenso, debido a que los medios impresos no consiguen llegar tan fácilmente a su público objetivo como antes. Esta investigación da claros indicios que el futuro del marketing, así como de muchas otras prácticas de comunicación masiva es digital, por ende, para el mundo de los negocios es una herramienta de vital importancia, ya que permite a entidades que no poseen los recursos económicos poder llegar a su público objetivo por una fracción de lo que costaría en medios tradicionales, al mismo tiempo es la transición natural en cuanto a ideología de consumo para una sociedad tecnológicamente moderna, al igual que los medios impresos la televisión y la radio en su época. 
En The Digital Experience (Jacobsen, 2016), la meta de la investigación propuesta por la autora fue explicar el impacto del marketing digital en las distintas industrias comerciales. Debido a ello se realizó un trabajo que demuestra cómo los medios digitales logran generar lazos con sus consumidores por medio de las estrategias del marketing digital. Se utilizó para este fin un método de valoración de empresas, así como la respuesta a los clientes. En ese sentido la información recabada demostró la efectividad del uso del marketing digital en múltiples industrias ya que es muy flexible. Este trabajo da entender que correctamente aplicado el marketing digital es una herramienta versátil y que en las manos de un usuario capacitado, puede lograr trasmitir ideas complejas que se transformarán en consumo sin importar la industria en la que se desarrolla.

\subsubsection{Marco teórico}

Para entender el Marketing digital de productos fitness se debe entender los conceptos que engloban el estímulo que se produce en las personas cuando estas son expuestas a los incentivos de compra a través de medios digitales.

\subsubsection{Decisión de compra}

Se refiere a la conducta de compra de los consumidores finales: individuos y hogares que deciden comprar bienes y servicios para su beneficio propio. Todos estos consumidores finales se combinan para hacer el mercado de consumo, según el libro (Kotler \& Armstrong, Fundamentos de marketing, Edicion 13, 2017).

La decisión de compra puede verse influenciada de muchas formas. Una de las más relevantes es a través del uso de ventajas competitivas. Para esto, las empresas buscan implementar estrategias comerciales que en la mentalidad del consumidor se puedan percibir como valor agregado y el cual tiene una gran capacidad de persuasión en la toma de decisiones de un cliente que se encuentra rodeado de muchas alternativas similares (Sonora, 2017).

Debido a que la toma de decisiones es considerada parte de nuestro libre albedrio, el marketing para ser efectivo, debe tomar una estrategia no invasiva. En pocas palabras, debe ser manipulador en las interacciones rápidas que tendrá con el consumidor en línea, 
asegurando un $61 \%$ de intención de compra si el cliente percibe la idea del consumo del producto o servicio como propia (Soto, 2019).

El fin de todo esfuerzo de marketing es el de generar ventas al influenciar los comportamientos de compra del consumidor; por ese motivo debemos entender los elementos que la conforman:

- Elementos culturales

- Clase Social

- Cultura

- Sub-cultura

- Social

- Estigma Sociales

- Familia

- Grupos y redes sociales

- Personal

- Edad y ciclo de vida

- Profesión

- Ego

- Situación económica

- Psicológico

- Percepción

- Educación

- Credo

- Motivación

- Actitud

\subsection{Factores que influyen en la decisión de compra}

Las compras del consumidor reciben la influencia de las características culturales, sociales, personales y psicológicas, como se explica en la tabla 1. 
Tabla 1:

Factores que influyen en la decisión de compra.

\begin{tabular}{|c|c|c|}
\hline Tipo & Factor & Descripción \\
\hline \multirow{3}{*}{$\begin{array}{l}\text { Factores } \\
\text { culturales }\end{array}$} & Cultura & $\begin{array}{l}\text { Conjunto de percepciones, deseos, valores, } \\
\text { comportamientos básicos y preferencias que un miembro de } \\
\text { la sociedad aprende de su familia y de otras instituciones } \\
\text { importantes. }\end{array}$ \\
\hline & Subcultura & $\begin{array}{l}\text { Grupo de personas que tienen distintos estilos de vida y } \\
\text { valores, basados en situaciones y experiencias comunes a } \\
\text { sus vidas. }\end{array}$ \\
\hline & Clases sociales & $\begin{array}{l}\text { Divisiones de una sociedad relativamente ordenada y } \\
\text { permanente, cuyos intereses, valores y conductas } \\
\text { comparten similitudes entre los miembros. }\end{array}$ \\
\hline \multirow{3}{*}{$\begin{array}{l}\text { Factores } \\
\text { Sociales }\end{array}$} & Grupos y redes sociales & $\begin{array}{l}\text { Dos o más personas que interactúan para alcanzar tanto } \\
\text { metas colectivas como individuales, estas interacciones no } \\
\text { necesitan ser en persona y pueden realizarse en el mundo } \\
\text { virtual. }\end{array}$ \\
\hline & Familia & $\begin{array}{l}\text { La familia es la organización de consumo más importante } \\
\text { de la sociedad. Los mercadólogos se interesan en la compra } \\
\text { de los distintos bienes y servicios a través de los roles y la } \\
\text { influencia del esposo, la esposa y los hijos. }\end{array}$ \\
\hline & Roles y estatus & $\begin{array}{l}\text { Un rol se basa en las distintas actividades que se espera } \\
\text { que ejecute la persona, acorde a la gente que la rodea. } \\
\text { Cada rol implica un estatus que refleja la estima general que } \\
\text { le asigna la sociedad. }\end{array}$ \\
\hline \multirow{3}{*}{$\begin{array}{l}\text { Factores } \\
\text { Personales }\end{array}$} & $\begin{array}{l}\text { Edad y etapa en el ciclo } \\
\text { de vida }\end{array}$ & $\begin{array}{l}\text { A lo largo de la vida las personas van cambiando los bienes } \\
\text { y servicios, gustos respecto a la ropa, los muebles, la } \\
\text { comida y las actividades recreativas suelen estar } \\
\text { relacionados con la edad. }\end{array}$ \\
\hline & Ocupación & $\begin{array}{l}\text { La ocupación de una persona influye en la compra que } \\
\text { realiza con respecto a bienes y servicios. Los operativos } \\
\text { suelen comprar ropa de trabajo más resistente, en cambio } \\
\text { los ejecutivos compran más trajes para actividades de } \\
\text { negocios. }\end{array}$ \\
\hline & Situación económica & $\begin{array}{l}\text { La situación económica afecta la elección de productos de } \\
\text { una persona. Los mercadólogos de bienes que dependen } \\
\text { de los ingresos, observan las tendencias en las tasas de } \\
\text { interés personales, los ingresos y en el de ahorros. }\end{array}$ \\
\hline
\end{tabular}




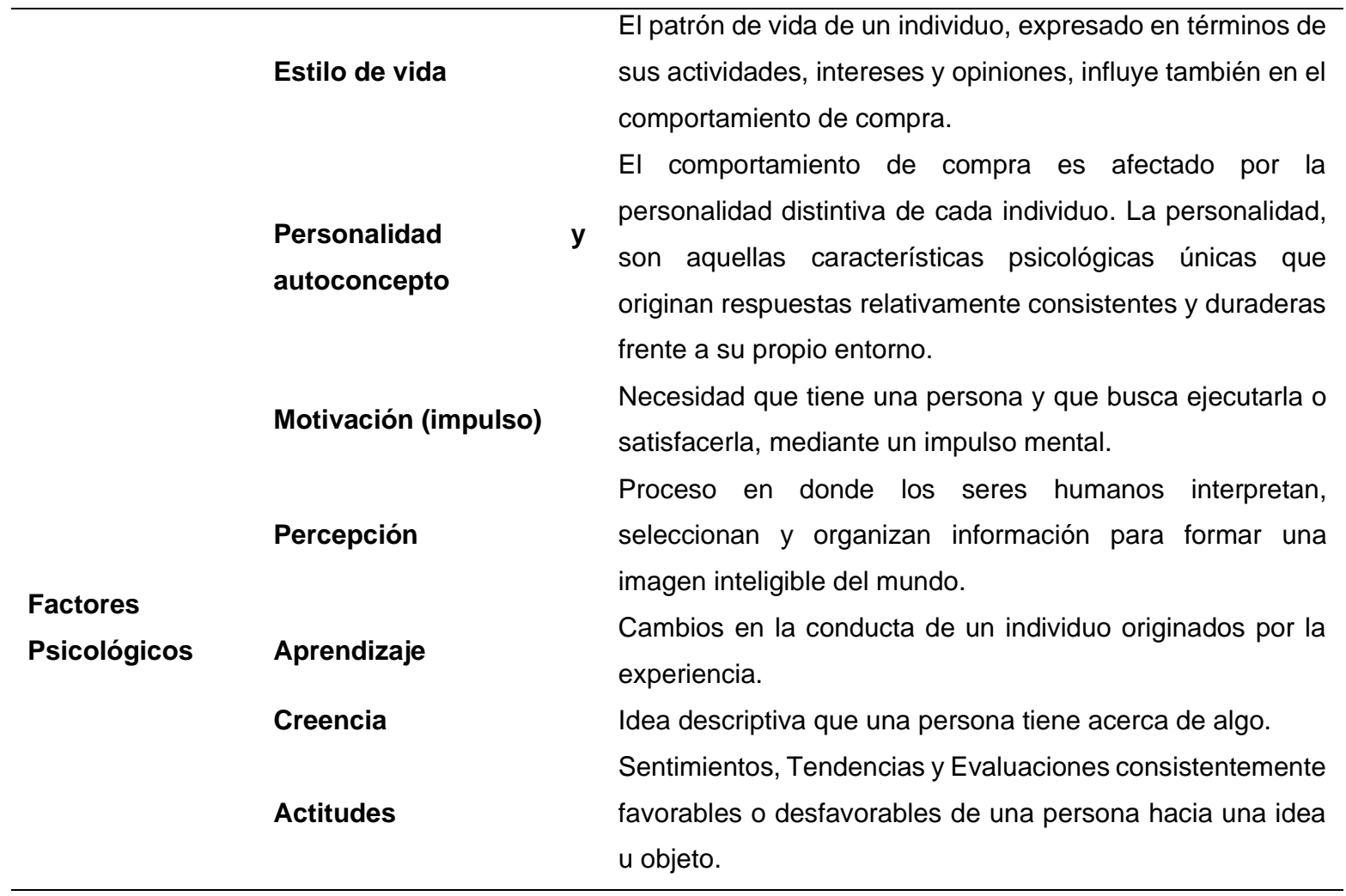

Fuente: Elaboración propia, (Escalante, 2016) "Los principales factores que influyen en la conducta del consumidor".

\subsection{Proceso de toma de decisiones del consumidor}

Estos explican el comportamiento de compra como un proceso de toma de decisiones; con el fin de satisfacer alguna necesidad del consumidor:

Tabla 2:

Proceso de toma de decisiones del consumidor.

\begin{tabular}{cl}
\hline Conciencia del problema & $\begin{array}{l}\text { Es la respuesta a un estímulo natural el cual } \\
\text { genera la búsqueda de una satisfacción para una } \\
\text { necesidad, que puede ser aprovechada para } \\
\text { presentar y comunicar un producto que cumpla con } \\
\text { la resolución de la necesidad. }\end{array}$ \\
\hline Reunión de información & $\begin{array}{l}\text { Consiste en la recopilación de datos } \\
\text { relacionados a comprar con el } \\
\text { conocimiento previo y las expectativas de } \\
\text { rango de precios y productos, información }\end{array}$
\end{tabular}


que hoy en día es más fácil de encontrar gracias al internet.

Basado en múltiples criterios, se puede realizar

Evaluación de soluciones alternativas(productos)

Selección de una solución apropiada (producto) evaluaciones con el fin de comparar marcas y productos para poder así hallar características deseables en una sola compra.

Al momento de realizar la selección, múltiples criterios pueden ser tomados en cuenta, el más común es el precio, seguido de factores como estatus y la psicología del comprador, todo esto tomado en cuenta facilita la decisión del consumidor ya que abarca todos los aspectos relacionados con la compra deseada.

Dependiendo de los beneficios obtenidos al realizar una compra, el cliente puede evaluar personalmente si mantendrá una relación de fidelidad con el producto o marca.

Fuente: Elaboración propia, (Teruel, 2019) en su artículo "Las 8 etapas en el proceso de toma de decisiones de la empresa".

Gracias a la globalización, el consumidor peruano ha podido acceder a mayor información debido a la disponibilidad y baja barrera de entrada del internet móvil, obteniendo como resultado inesperado, el incremento de la exigencia del consumidor, por ese motivo su opinión puede llegar a afectar la opinión de otros posibles compradores y en casos extremos sabotear a un producto o marca. En el Perú se han identificado cinco principales tendencias de consumo. 


\subsection{Tendencias de consumo peruano}

\section{Tabla 3:}

Tendencias de consumo peruano.

Se basa en que el consumidor puede buscar en más de una plataforma un producto o servicio, con la finalidad de encontrar un producto similar o incluso el mismo con características más

Consumo multicanal

Internet de las cosas

Mayor consumo E-commerce

Mayor consumo de programas de Recompensas

Tendencia del publico millennial ventajosas, por ese motivo el objetivo de las marcas y canales de venta es mantener la atención del consumidor enfocada en ellos.

Hoy en día la recopilación de datos de las empresas que forma parte de un ecosistema digital no es solamente legal, sino que una excelente forma de incentivar el consumismo debido al constante aprendizaje de las empresas sobre las preferencias del consumo de los usuarios, por ese motivo la interconexión de todos los aparatos electrónicos permite moldear a la industria moderna.

El consumidor peruano está empezando a perder el miedo a realizar compras por internet, en gran medida gracias a la aparición de pasarelas de pago las cuales dan mayor seguridad a los consumidores al ser intermediarias que protegen los intereses tanto de los compradores como de los vendedores; al mismo tiempo eliminando la tienda física, se reducen en gran medida los costos de venta, los cuales se ven traducidos en menores precios para los consumidores.

El secreto de muchas empresas peruanas para su crecimiento es la fidelización de cliente con una estrategia enfocada en programas de recompensas de consumo, un gran ejemplo de esto son la acumulación de millas cada vez que se realiza un viaje, esto permite que el cliente siga viajando para aprovechar sus millas obtenidas con la promesa de "ahorrar dinero".

Son la generación económicamente más activa del momento, crecieron con la tecnología la cual avanza a una velocidad enorme y son la primera 
generación en experimentar todos los efectos del marketing digital, por ello son un mercado muy importante para las empresas que están ofertando sus productos por medios digitales.

Fuente: Elaboración propia, (Sanchez, 2017) “Las cinco principales tendencias del consumidor peruano".

\subsection{Clasificación digital de usuarios peruanos:}

Tabla 4:

Clasificación digital de usuarios peruanos 2018.

- $\quad$ Moderno 35\%

- Formal $28 \%$

- Sofisticado $23 \%$

- Progresista 9\%

Estilo de vida

- Conservador $3 \%$

- Austero $2 \%$

- $\quad$ Entre 25 y 34 años (37\%)

- De 18 a 24 años (25\%)

Edad

- De 35 a 45 años (24\%)

- De 46 años a más (14\%)

Sexo

- Mujeres $54 \%$

- Hombres $46 \%$

- NSE A $19 \%$

Nivel Socio Económico

- NSE B $45 \%$

- NSE C $36 \%$

Fuente: Elaboración propia, (Aptitus, 2017) en su publicación "Cuál es el perfil del consumidor peruano digital".

Gracias a esta información podemos apreciar que, sin importar la edad, estilo de vida, sexo o NSE, el peruano tiene cierta participación ya sea por necesidad de usar el internet, de manera que sin importar el producto que se ofrezca hay un consumidor en línea para éste. 


\subsubsection{Internet, redes sociales y marketing digital}

\subsection{Internet y el consumo digital}

El Internet es el medio perfecto para llegar a todo tipo de audiencia, en especial aquella que no es fácil de alcanzar. Al mismo tiempo, es un medio eficaz para llevar mensajes a madres que laboran fuera del hogar, ejecutivos de alto nivel. Estas personas tienen perfiles bien definidos en línea y pueden ser ubicados según su ritmo de vida y disponibilidad de tiempo. (Kotler \& Armstrong, Fundamentos de marketing, Edicion 13, 2017) pág. 114. El internet ha cambiado fundamentalmente las nociones de los clientes acerca de comodidad, velocidad, precio, información de producto y servicio, otorgándole así más poder al consumidor.

En la figura 1 se muestra el perfil de las generaciones en el Perú y su respectiva relación con el internet, redes sociales, celulares, educación, trabajo, entre otros.

Se dividió y se distribuyó la población en tres segmentos, los cuales son:

- Generación Z:

- Personas de 13 a 20 años de edad que representan el $15 \%$ de la población equivalente a 4.6 millones de personas, en donde el $47 \%$ utiliza ávidamente los teléfonos inteligentes.

- Generación Y (o millennials):

- Personas de 21 a 35 años de edad que representan el $25 \%$ de la población equivalente a 8 millones, de los cuales el $62 \%$ utiliza ávidamente los teléfonos inteligentes.

- Generación X:

- Personas de 36 a 59 años de edad que representan el $27 \%$ de la población equivalente a 8.7 millones, en donde el $42 \%$ utiliza ávidamente los teléfonos inteligentes. 


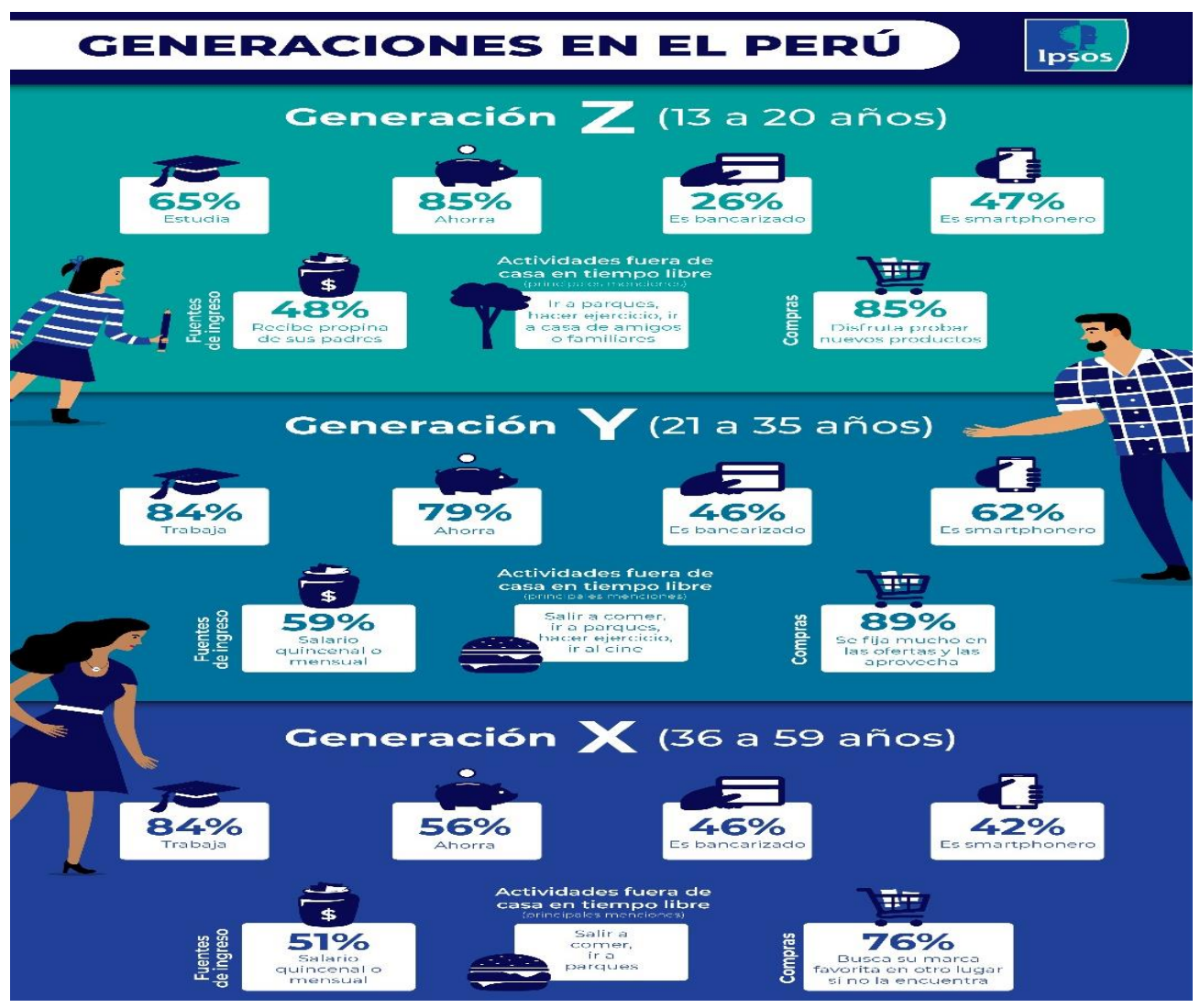

Figura 1: Generaciones en el Perú

Fuente: (IPSOS, 2019) en su publicación "Generaciones en el Perú"

Las empresas para lograr sus objetivos comerciales han usado canales poderosos como son las redes sociales. En el caso de Perú, hubo un crecimiento en el consumo digital. 


\subsection{Penetración digital en el Perú}

Como se observa en la figura 2, se muestra los datos de la penetración digital en el Perú, al contar con 32.74 millones de población, en donde más de 24 millones de usuarios están conectados a internet, así como más de 24 millones de usuarios son activos en redes sociales. Así mismo se tiene más de 39 millones de suscriptores móviles.

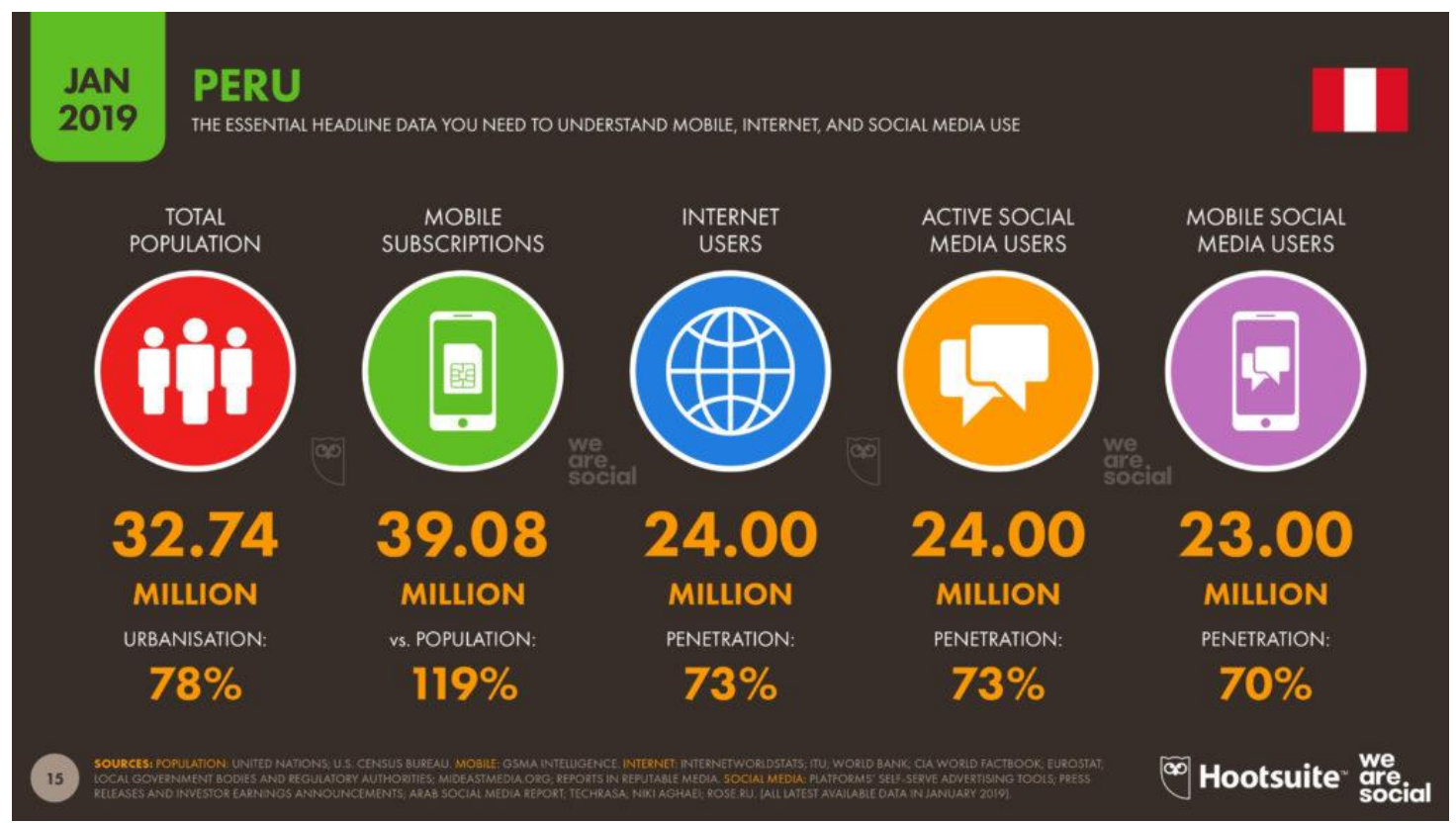

Figura 2: Penetración digital en el Perú al 2019

Fuente: (Hootsuite, 2019) en la publicación "Estadísticas de consumo digital Perú 2019" 
En la figura 3, se muestra el crecimiento anual digital entre los años 2018 y 2019 en el Perú, en donde se observa el incremento de más de 2 millones entre los usuarios internet y los usuarios activos en medios sociales, de la misma manera un incremento del $15 \%$ en el uso de teléfonos móviles de medios sociales que representa a 3 millones de personas.

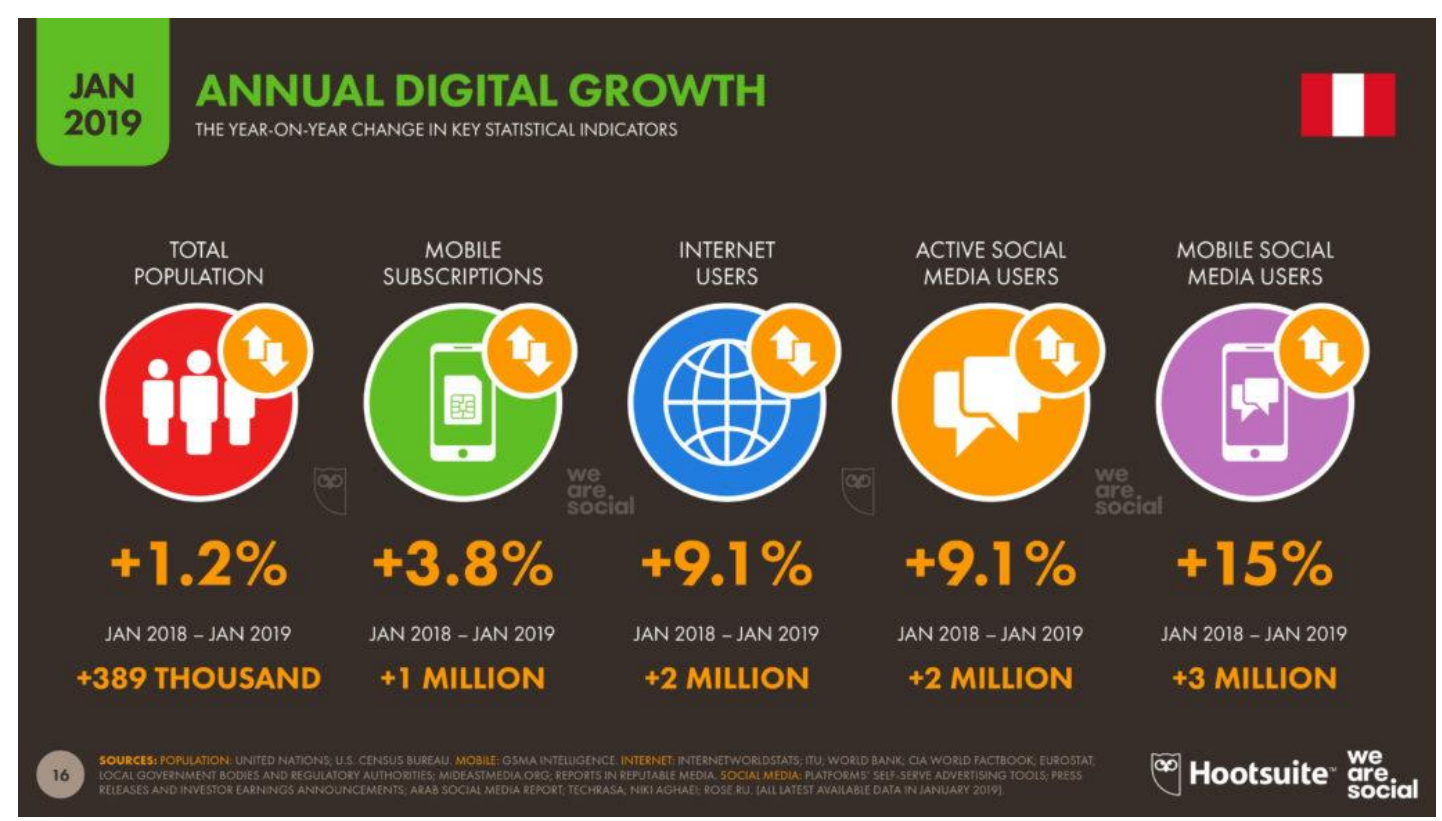

Figura 3: Crecimiento anual digital entre los años 2018 y 2019.

Fuente: (Hootsuite, 2019) en la publicación "Estadísticas de consumo digital Perú 2019" 
En la figura 4 se observa los dispositivos electrónicos más usados, donde la TV, con un $96 \%$ es la más utilizada por las personas. Desde otra perspectiva, el $56 \%$ de personas utiliza cualquier tipo de teléfono móvil. Por último, aquellas personas que usan teléfonos inteligentes, computadoras y laptops representan un $58 \%$.

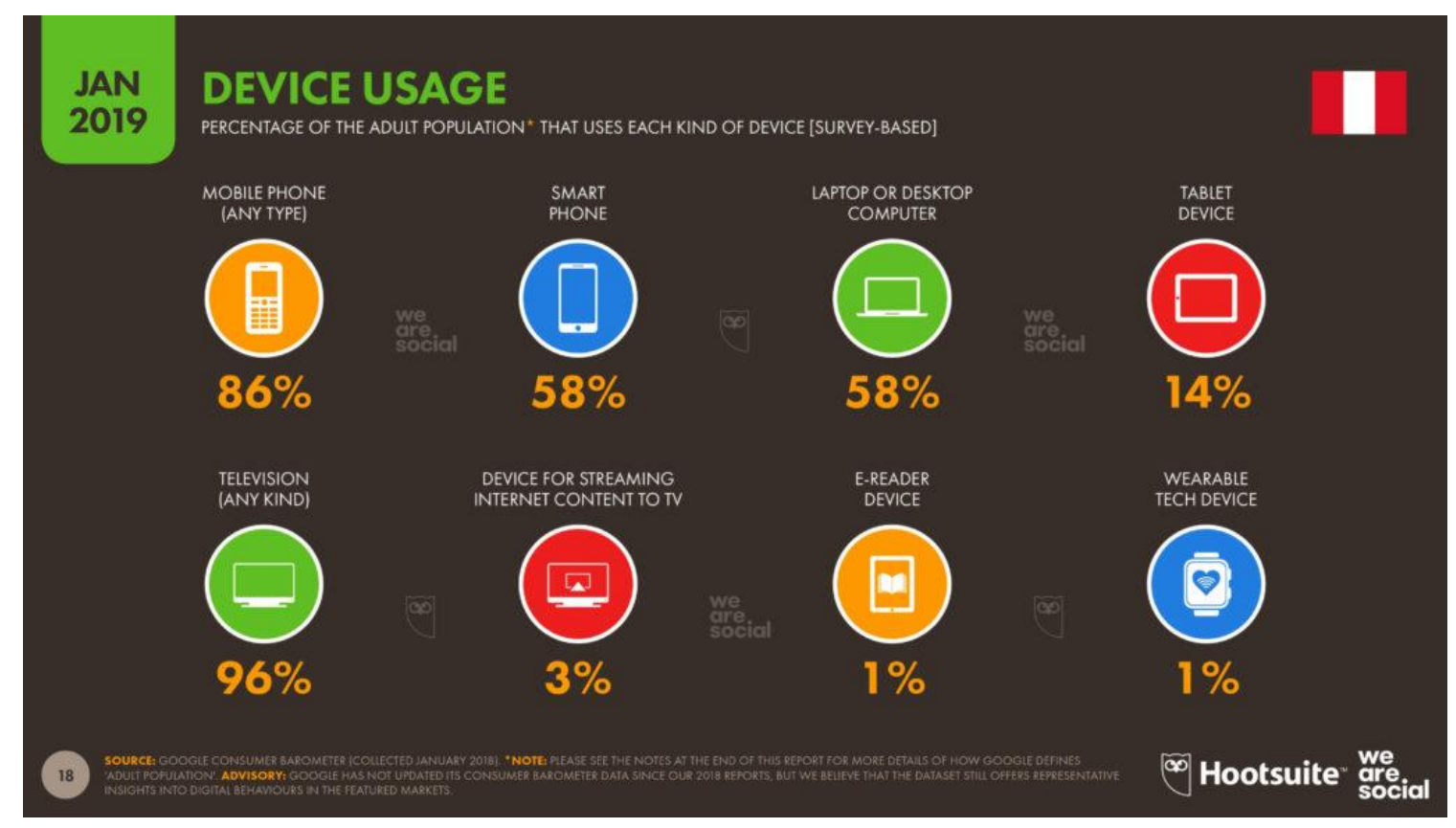

Figura 4: Dispositivos móviles más usados al 2019.

Fuente: (Hootsuite, 2019) en la publicación "Estadísticas de consumo digital Perú 2019" 
En la figura 5, se muestra la frecuencia de uso de Internet, observando que el $71 \%$ de las personas lo utilizan de manera diaria, el $20 \%$ solo una vez por semana y el $7 \%$ lo usa al menos una vez por semana.

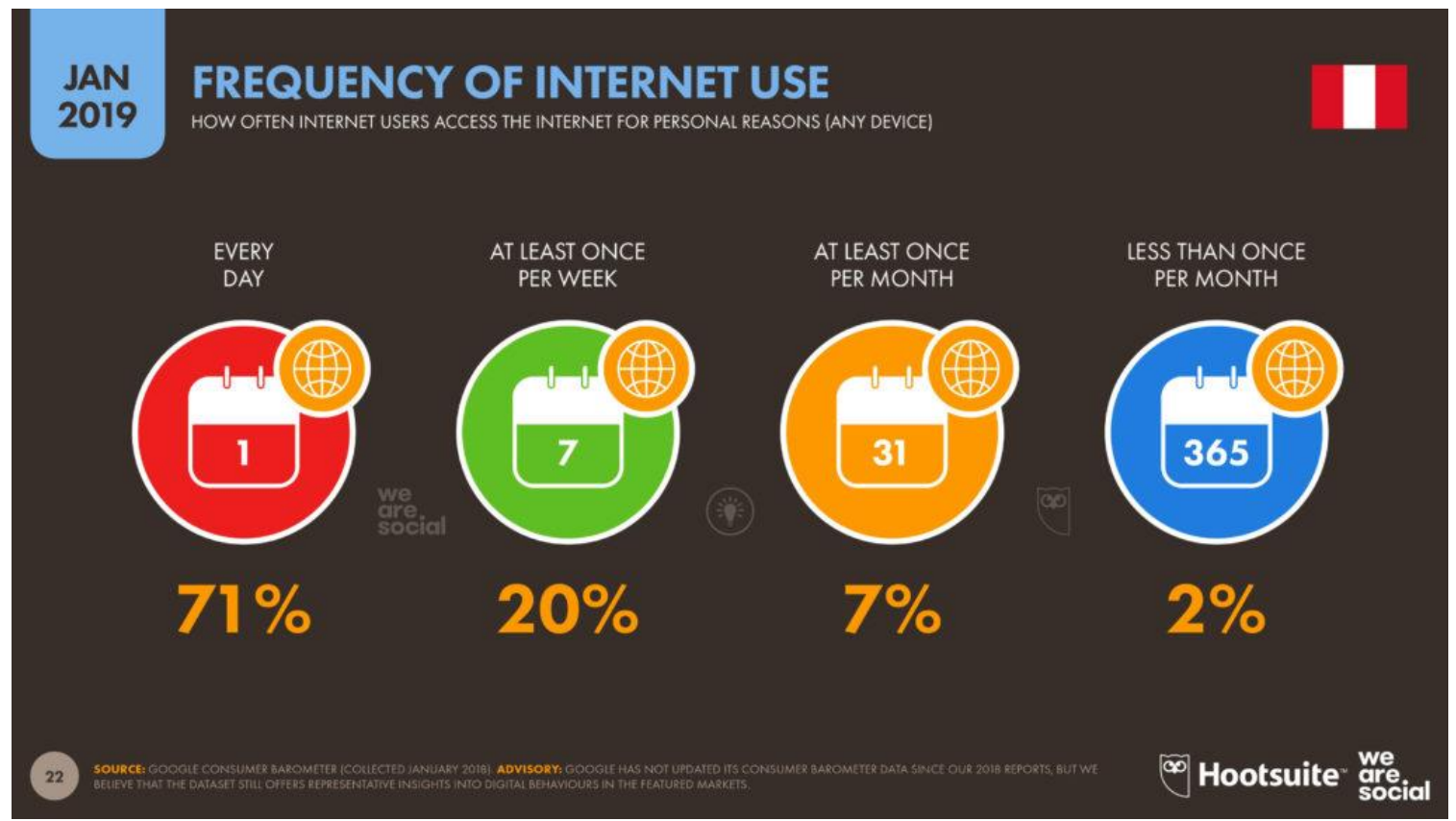

Figura 5: Frecuencia de uso del internet al 2019.

Fuente: (Hootsuite, 2019) en la publicación “Estadísticas de consumo digital Perú 2019"

\subsection{Redes sociales}

Son comunidades online (sitios web de redes sociales, blogs, incluso mundos de realidad virtual), donde las personas se congregan, se informan, se entretienen, socializan e intercambian puntos de vista e información. (Kotler \& Armstrong, Fundamentos de marketing, Edicion 13, 2017) pág. 24.

Las redes sociales de mayor importancia comercial para las PYMES latinoamericanas son Facebook e Instagram, ya que abarcan toda la población económicamente activa que se encuentra en línea. Además, su efectividad en relación al costo beneficio de anunciar en estas redes es bastante alto, permitiendo a las empresas de menor tamaño florecer y generar su propia leal audiencia (Gómez \& Neri, 2017). 
Las redes sociales suponen un cambio en la comunicación, así como en las estrategias usadas por compañías y grupos de interés de informar o desinformar a la población. Así, considerando que, gracias a estas redes, el ciudadano promedio se convierte en protagonista de los medios más relevantes de comunicación y ello acompañado de algoritmos los cuales buscan generar reacciones en los internautas, estas pueden generar o exacerbar problemáticas sociales, o por el contrario ayudar a resolver problemas demostrando el gran poder de esta herramienta digital en la mente humana (Rodríguez, 2018).

\subsection{Crecimiento de los medios sociales}

En la figura 6, se muestran las audiencias de medios sociales de publicidad, dando como resultado que 24 millones de usuarios activos son aquellos que ven publicidad en Facebook, así mismo un 5.2 millones en Instagram y 5 millones en Linkedln.

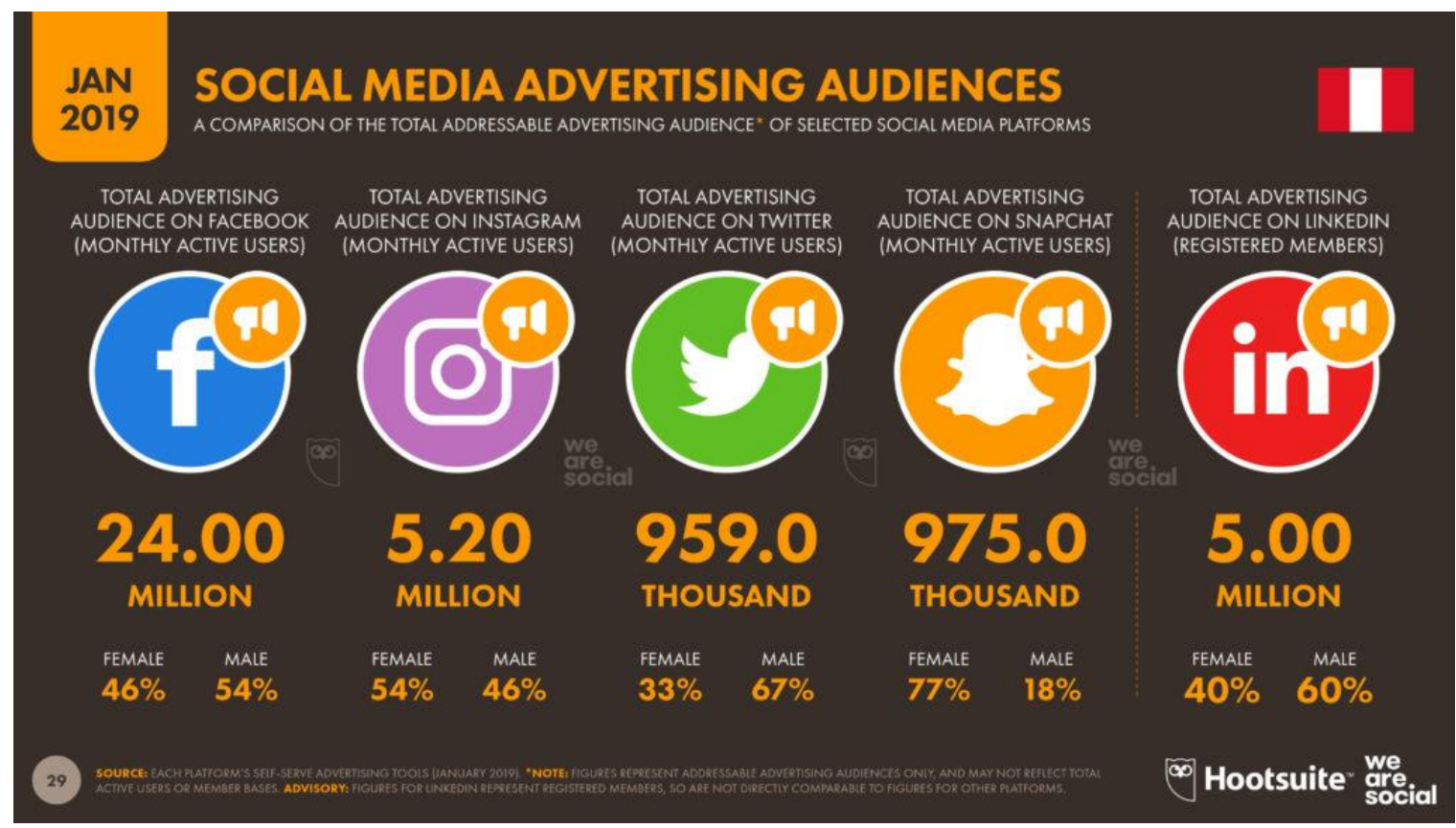

Figura 6: Audiencias de medios sociales de publicidad al 2019.

Fuente: (Hootsuite, 2019) en la publicación “Estadísticas de consumo digital Perú 2019” 
En la figura 7, se muestra el crecimiento en el último trimestre del 2019, en donde Linkedln creció en $8.7 \%$ en usuarios activos en publicidad, así mismo Facebook en un $4.3 \%$ e Instagram en $4 \%$.

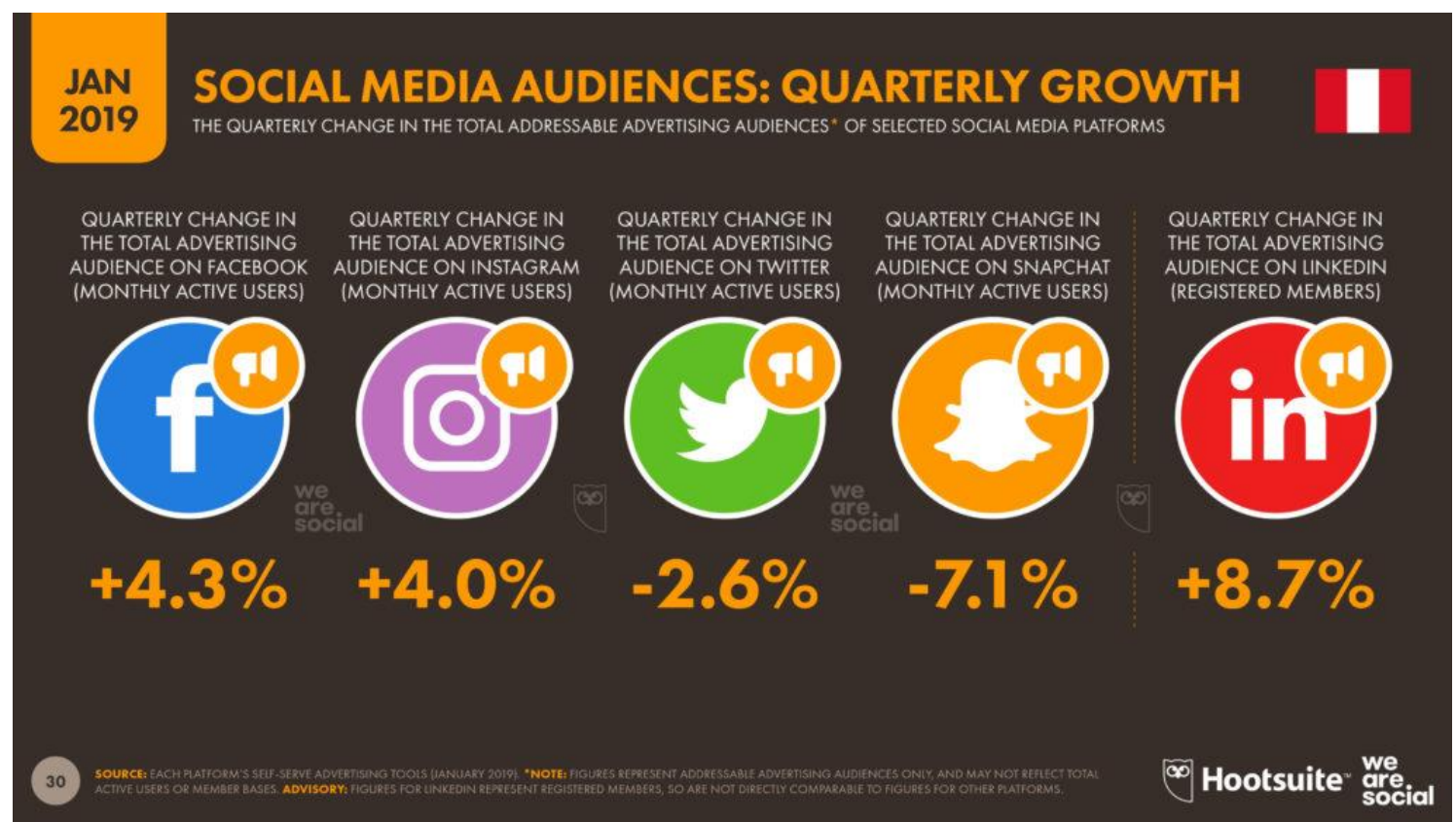

Figura 7: Crecimiento en el último trimestre de audiencias de medios sociales al 2019. Fuente: (Hootsuite, 2019) en la publicación "Estadísticas de consumo digital Perú 2019" 


\subsection{Perfil de los usuarios y frecuencia de actividad}

En la figura 8 se muestra el perfil de la audiencia en medios sociales entre los que destacan los usuarios de Facebook, Facebook Messenger e Instagram. Las edades entre los 18 hasta los 34 años son aquellas que tienen más presencia en los medios sociales, esto representa al $61 \%$ de las comunidades.

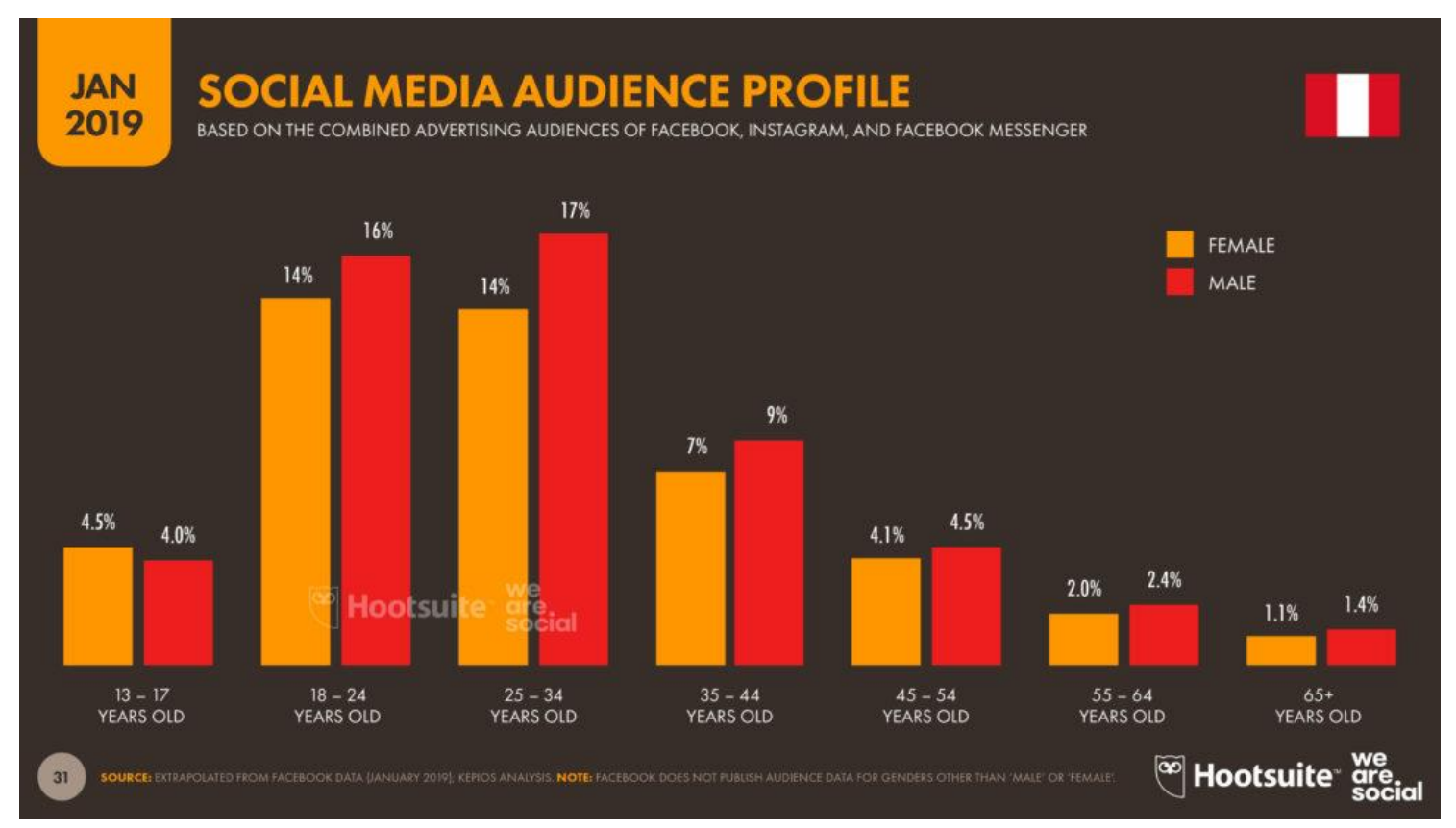

Figura 8: Perfil de la audiencia en medios sociales al 2019.

Fuente: (Hootsuite, 2019) en la publicación "Estadísticas de consumo digital Perú 2019" 
En la figura 9 se observa la frecuencia de actividad de Facebook que realizan los usuarios dentro de la red social. Así mismo, los usuarios mensualmente dan 9 likes, realizan comentarios 5 veces, comparten 2 veces alguna publicación y realizan 6 clicks a las publicidades en promedio.

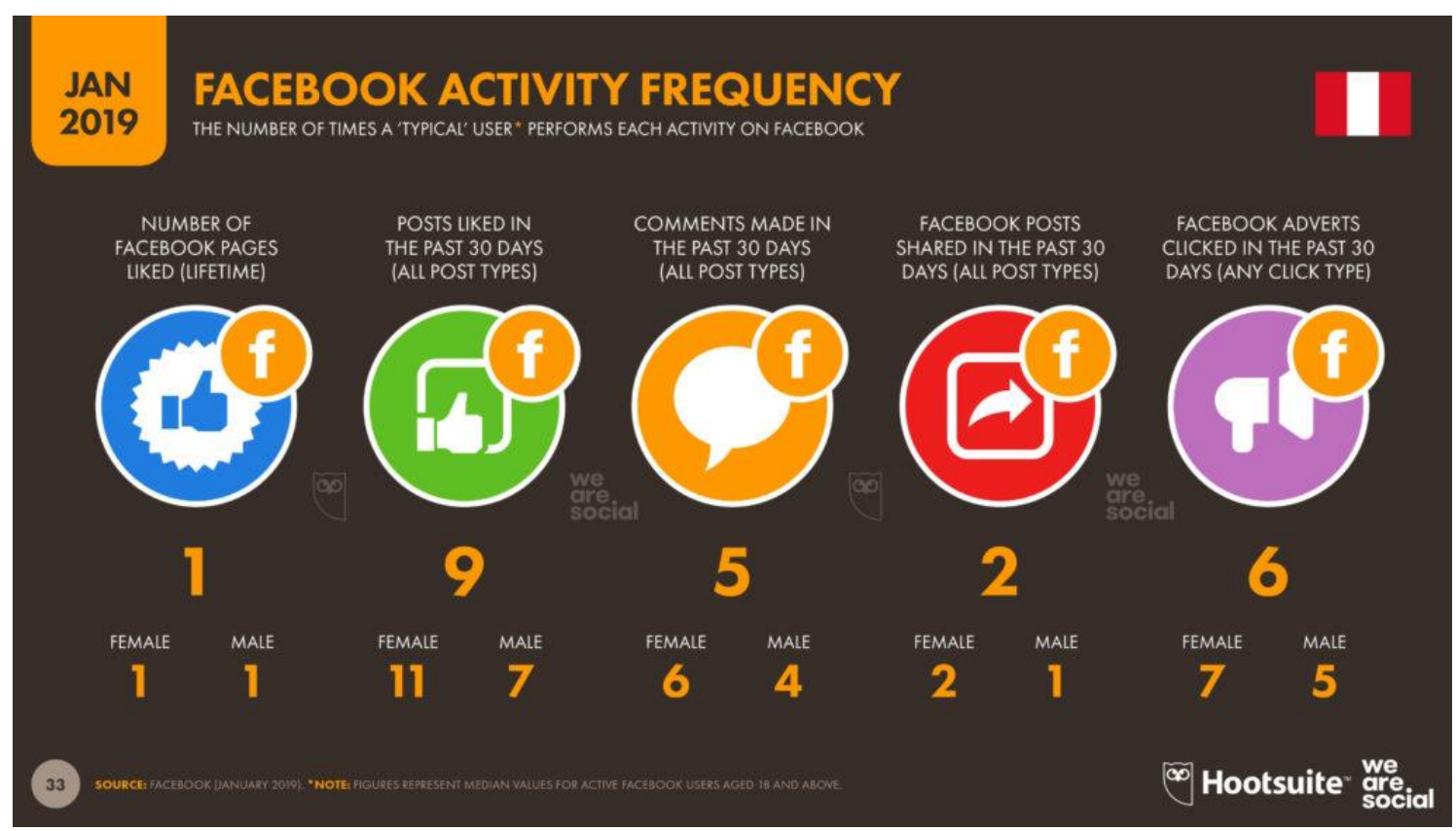

Figura 9: Frecuencia de actividad en Facebook al 2019.

Fuente: (Hootsuite, 2019) en la publicación "Estadísticas de consumo digital Perú 2019"

\subsection{Alcance de las redes sociales}

El Alcance digital en redes sociales, es la cantidad de personas que llegan a recibir el contenido que se compartió en una red social, además favorece para saber qué tipo de contenido es mejor recibido por los usuarios y en qué tipo de plataforma social fue captado, ya que esto permitirá modificar y conservar estrategias en redes sociales exitosas.

La tabla 5 muestra el porcentaje de los medios sociales en Latinoamérica, realizado por la firma ComScore (Compañía de investigación de Marketing en internet), destacando el Perú con un $93.2 \%$, siendo el país mejor posicionado con el mayor porcentaje de toda la región, reflejado en 20 millones de perfiles sociales y un promedio de 12.578 .000 minutos invertidos mensualmente en compras y entretenimiento. 
Tabla 5:

Porcentaje de los medios sociales en Latinoamérica.

\begin{tabular}{ll}
\hline Países & Alcance en medios sociales \\
\hline Perú & $93.2 \%$ \\
Brasil & $89.1 \%$ \\
México & $87.7 \%$ \\
Colombia & $83.8 \%$ \\
Argentina & $83.2 \%$
\end{tabular}

Fuente: Elaboración Propia, Alcance de los medios sociales en Latinoamérica (ComScore, 2019) en su publicación "Social Media: Perú es el primer país de la región con mayor porcentaje de alcance de redes sociales"

\subsection{Peruanos en las redes sociales}

A continuación, se describirá las 5 maneras de como utilizan los peruanos las redes sociales según ComScore.

Tabla 6:

5 maneras de como utilizan los peruanos las redes sociales.

\begin{tabular}{ll}
\hline & La Plataforma social para publicar e interactuar \\
& más preferida por las personas es Facebook, ya \\
Plataformas Sociales & que se lleva las publicaciones con un $44.5 \%$, \\
& seguido por Twitter con $31.5 \%$. Con respecto a las \\
& interacciones, el $48.6 \%$ representa Facebook, \\
& seguido con un $28.9 \%$ en Instagram. \\
\hline Consumo PC y Laptop & En promedio un peruano utiliza las redes sociales \\
& a través de su PC o laptop al mes unos 409.2 \\
& minutos, esto quiere decir, un aproximado de 7 \\
& horas, esto comparado con la media de \\
& Latinoamérica de 247.0 minutos, Perú se \\
& encuentra por encima. \\
& Las reacciones (Me gusta, Me divierte, Me \\
Formatos de representación de contenido & entristece, Me enoja) gustan más al obtener el $66 \%$ \\
& de las publicaciones con imágenes y/o texto, en \\
& cambio las publicaciones de video solo tienen un \\
& $36 \%$ de reacciones. No obstante, las publicaciones \\
& de videos si sobresalen con un $52 \%$ en \\
compartidos.
\end{tabular}




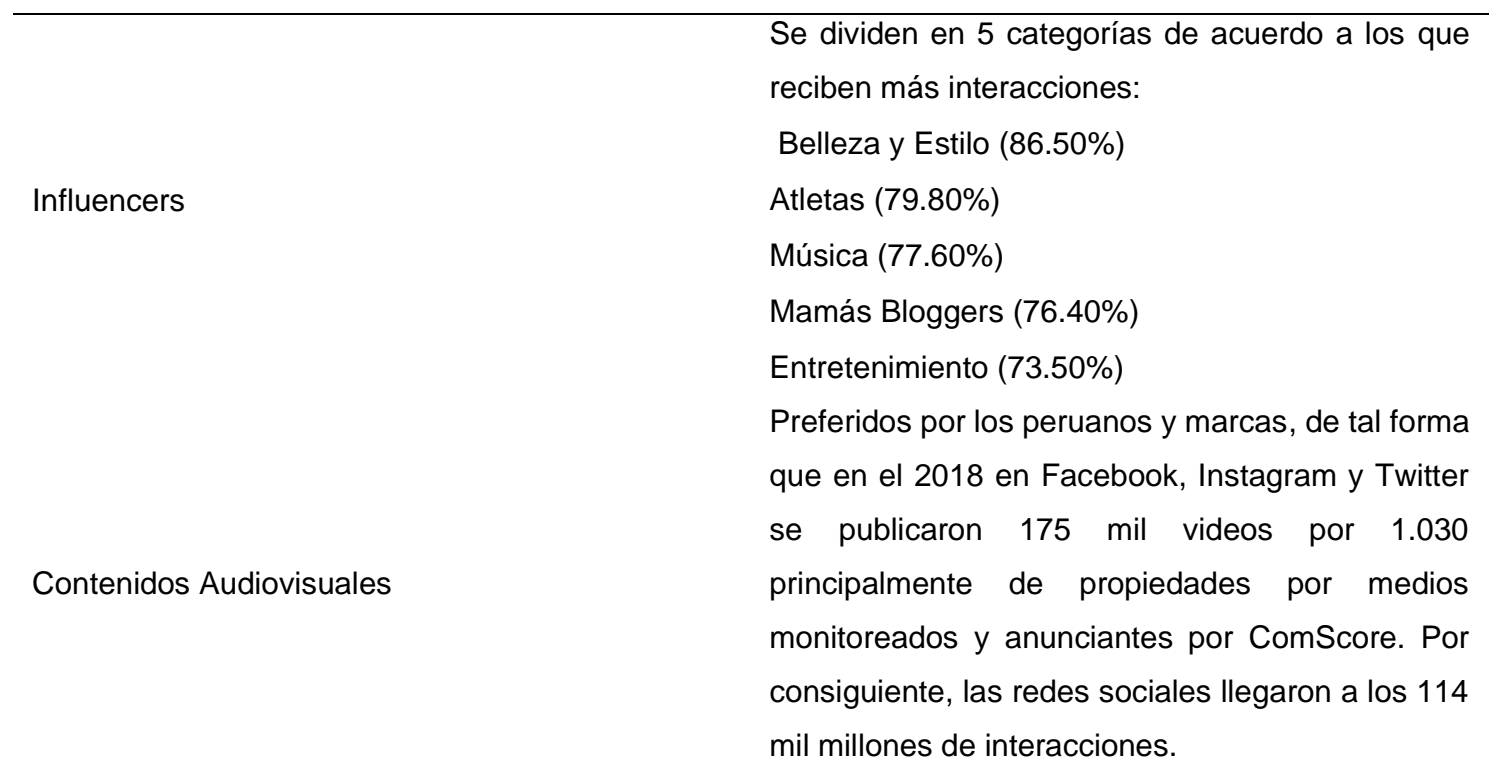

Fuente: Elaboración Propia, (ComScore, 2019) en su publicación “¿Cómo utilizan los peruanos las redes sociales los peruanos?"

\subsection{Marketing digital}

Son las estrategias de comercialización traducidas al nuevo contexto comercial de la era de la comunicación digital, en donde se usan todas las técnicas off-line adaptándolas a este nuevo medio, con el fin de comunicar productos y servicios de forma más interactiva y evolucionar con el consumidor, ya que en caso de no ser atractivas serán ignoradas con un simple ad-block.

Las empresas antes preocupadas por un crecimiento economico y tangible, como la posesion de varias tiendas y un gran numero de empleados, ahora se encuentran motivadas a tener una marca que pueda ser reconocida por el consumidor facilmente impulsando asi una evolución hacia el entorno digital donde el valor empresarial se encuentra en el poder disuasorio de la marca en la mentalidad del consumidor (Osorio, Restrepo, \& Muños, 2016).

El error comercial de muchas marcas, en especial de productos fitness, es subestimar al marketing digital. Tener una amplia participacion en esta nueva práctica de mercadeo no asegura el éxito de una venta ya que el error más común es no conocer al mercado objetivo y tratar de anunciar a todos por igual. Esto es algo completamente imperdonable en la era digital puesto que se nos permite en la actualidad direccionar toda la publicidad a un público muy 
especifico; ahorrando tiempo, dinero y asegurando resultados reales (Loza \& Cobarrubias, 2017), generando así una desconfianza innesesaria por esta nueva práctica por aquellos que desconocen cómo funciona y cuáles beneficios pueden traer cuando esta es correctamente implementada.

El marketing digital consiste en los esfuerzos de un ente comercial en darse a conocer, promover y principalmente verder sus productos o servicios por medio del internet, este medio cobra cada vez más fuerza debido a que al 2017 el $42 \%$ de la poblacion mundial tiene acceso al internet (Kotler \& Armstrong, Fundamentos de marketing, Edicion 13, 2017) pág. 24.

Experimentos de marketing, un concepto netamente académico y que en el pasado requeriría de una gran inversión de dinero y la participación de una gran cantidad de voluntarios. En la actualidad, puede realizarse por un estudiante promedio de pregrado a través de las herramientas digitales de acceso público, en donde, por una fracción de lo que tomaría en el pasado, se puede estudiar el comportamiento del consumidor a profundidad exponiéndolo a diferentes tipos de incentivos visuales, auditivos e interactivos; consiguiendo así realizar un mapeado de las técnicas de marketing digital más efectivas por producto o servicio (Gioshvili, 2019). De esta manera, se demuestra la facilidad con la cual se puede dominar las nuevas herramientas de marketing digital que nos ofrecen las plataformas sociales más actuales permitiendo a los interesados experimentar hasta encontrar a su publico objetivo y entender cómo mejorar sus ventas sin la necesidad de tener un gran equipo de mercadotecnia.

La transición a anunciar en medios digitales es una práctica recibida con resistencia por los tradicionalistas, pero los beneficios son innegables ya que además de poder enfocar los esfuerzos de marketing directamente al público deseado, también los gastos relacionados son minimizados obteniendo personal con la capacidad de responder a los clientes las 24 horas del día y los 7 días de la semana por menos dinero de lo que costaría implementar una robusta campaña en el marketing tradicional (Abdullah, 2019). En algunas culturas más que en otras es más complicado convencer a las compañías más tradicionales a implementar y posteriormente reemplazar el marketing tradicional por el digital; sin embargo, en el actual contexto de la pandemia podemos observar que una transición que llegaría con el tiempo se 
transformaría en la nueva normalidad, ya que al día de hay quienes temen aceptar un papel en la calle por el miedo al contagio.

\subsection{Ventajas del marketing digital}

Definiciones obtenidas de (Cañizales, 2018) en su publicación "marketing digital: Aprende Todo lo que Necesitas Saber Hoy"

1) Comunicación:

A diferencia del marketing tradicional, permite una comunicación inmediata y muy barata entre el cliente y el comprador, sin importar la hora y el lugar de residencia del cliente.

2) Alcance global:

Este marketing puede ser visto por cualquier persona en cualquier parte del mundo, eliminando así la tradicional plaza de las 4 P's del marketing tradicional, en donde elegir el lugar de la publicación era clave y aumentaba los costos, dependiendo de la conveniencia de la zona además de los materiales necesarios para el anuncio.

3) Interacción:

Permite una interacción en tiempo real, lo cual lo transforma en un canal de más de un solo sentido, permitiendo usar un código interactivo, ofreciendo experiencias como mini juegos o animaciones con la intención de sorprender y enganchar al consumidor en potencia.

4) Datos:

El beneficio más relevante del marketing digital es ahorrar dinero llegando específicamente al usuario con el perfil deseado, información que es vendida por redes sociales, las cuales gracias a diferentes líneas de códigos conocidos como "cookies", recopilan información en la red como preferencias de consumo, que personalidades web siguen, etc.

Esto debido a que, en gran parte, si un servicio digital es gratis entonces el "usuario" es el producto.

Lo cual nos permite crear campañas que aseguran llegar al público más propenso a realizar la compra del producto o servicio.

5) Segmentación:

Con la data obtenida en campañas anteriores o en la misma campaña actual, se puede hacer inversiones más fuertes de marketing dirigidas a un público, que, 
según la data obtenida por el comportamiento frente a la campaña analizada, responde de mejor manera permitiendo así invertir más dinero sin perderlo en una posible incertidumbre.

6) Tiempo real:

Debido a su naturaleza digital, este tipo de marketing puede monitorear en tiempo real la respuesta del público expuesto a la campaña en la red, permitiendo así cortar lo que no sirve, en caso de que una campaña este fallando, evitando perder dinero y replantear la estrategia digital para conseguir mejores resultados. Lo cual sería imposible de lograrse en medios tradicionales, donde sí se comete algún error será una perdida sin posibilidad de corrección, a menos que esta venga acompañada de sobre gastos en la campaña de marketing.

\subsection{Dimensiones del marketing digital}

El marketing digital es complejo pero no complicado, es simplemente la digitalización del marketing y su versión online, que se da en tres dimensiones como efectiva estrategia del mismo: la difusión, atracción y retención (Malhotra N. , 2020) en su libro "Investigación de mercados".

- Difusión de contenidos: Esta difusión general se da través de la web, en buscadores y sobre todo en las redes sociales más usadas, con contínuas repeticiones de publicidad emergente atractivas al público y de esta manera generar una mayor cantidad de vistas captando así el interés del usuario.

- $\quad$ Atracción de clientes: Esta dimensión se genera en el público objetivo captado a través de la difusión de contenidos, logrando que este público de clic, y de esta manera ingresen a la publicidad, visiten las redes sociales de la empresa (Facebook, twitter, YouTube, blogs), así como la página web convirtiéndose en un cliente potencial al obtener sus datos de contacto.

- Fidelización (retención) de clientes: Un cliente fidelizado es más propenso a volver a consumir los productos o servicios que ofrece la empresa, sin embargo, desde el punto de vista del marketing digital, este tipo de cliente es más propenso a estar atento a las promociones y ofertas anunciadas por canales digitales, 
generando ventas seguras, en especial cuando hay introducción de nuevos inventarios.

\subsection{Marketing por internet en el Perú}

Se observa en la figura 10 el tamaño de la inversión publicitaria en el Perú. En el 2018 se llegó a la cifra de 620 millones de dólares, 7.2\% menos que el año anterior según el reporte de (CPI, 2018) (Compañía Peruana de Estudios de Mercados y Opinión Pública S.A.C.) Con este resultado se mantuvo la caída de la inversión que se obtuvo entre los años 2016 y 2018.

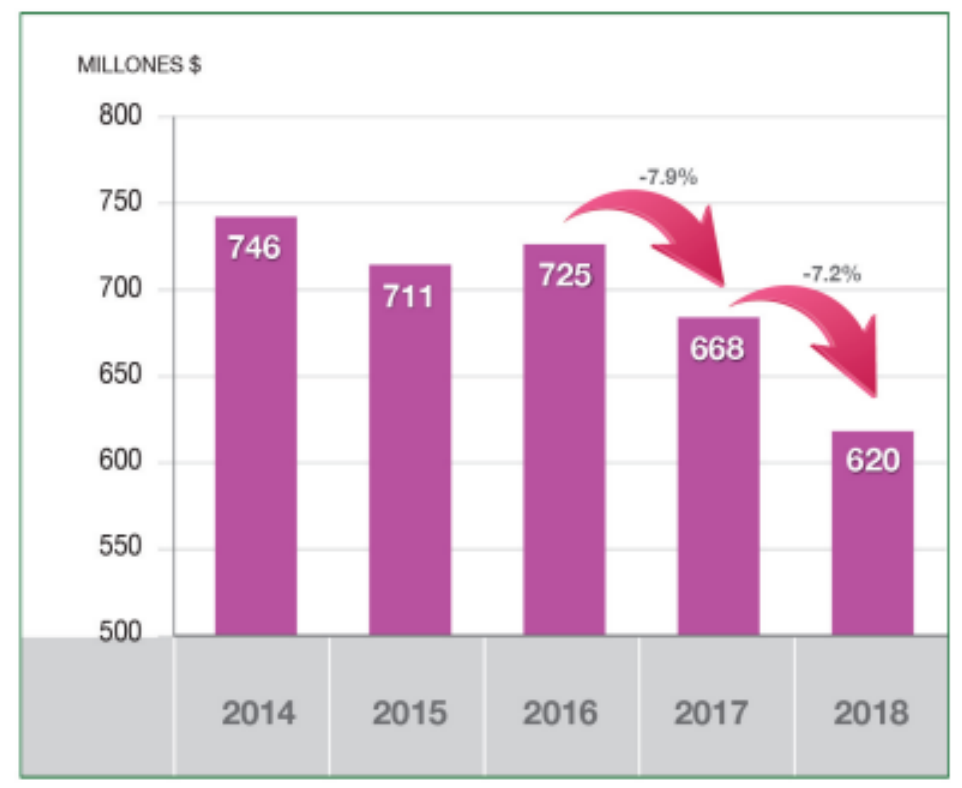

Figura 10: Evolución de la inversión publicitaria en el Perú.

Fuente: (CPI, 2018) - Market Report

La figura 11 explica la magnitud de lo que se invierte en marketing por internet en el Perú, en donde las estrategias publicitarias están siendo más empleadas a base del internet, llegando en el 2018 a un 17.3\%, esto quiere decir que el internet creció $12 \%$ y le ha restado inversiones a los demás medios masivos (CPI, 2018) 


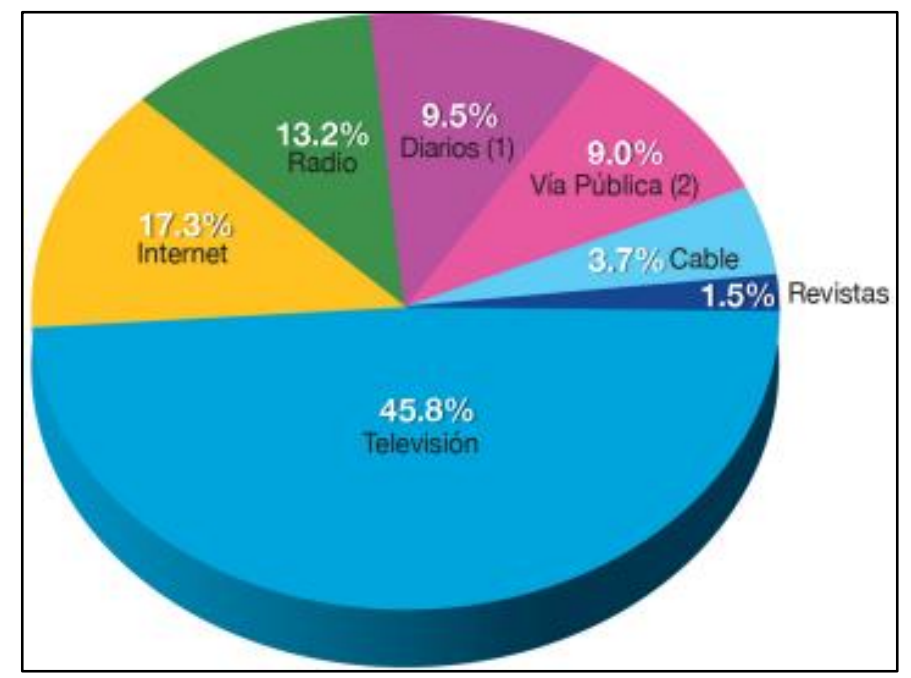

Figura 11: Magnitud de inversión del marketing por internet en el Perú. Fuente: (CPI, 2018) - Market Report

\subsection{Tipos de marketing digital}

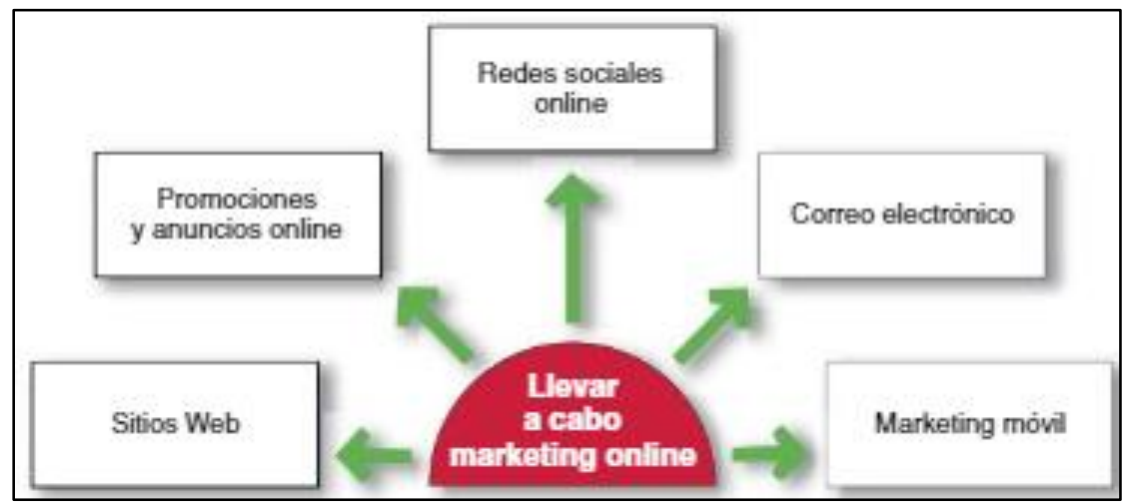

Figura 12: Llevar a cabo marketing online.

Fuente: (Kotler \& Armstrong, Fundamentos de marketing, Edicion 13, 2017)

Sitios web de Marketing

Un sitio web que interactúa con los consumidores para acercarlos a una compra directa u otro resultado de marketing (Kotler \& Armstrong, Fundamentos de marketing, Edicion 13, 2017). pág. 434. 


\section{$\underline{\text { Publicidad online }}$}

Es la publicación que aparece mientras los consumidores navegan por la web, incluyendo publicidad de display, anuncios relacionados a la búsqueda, clasificados online y otras formas (Kotler \& Armstrong, Fundamentos de marketing, Edicion 13, 2017) pág. 435.

\section{$\underline{\text { Redes sociales online }}$}

Son webs independientes y comerciales que proporcionan a los consumidores lugares online para socializar, intercambiar opiniones e información y congregarse (Kotler \& Armstrong, Fundamentos de marketing, Edicion 13, 2017) pág. 439.

\section{Marketing por correo electrónico}

Enviar mensajes de marketing altamente dirigidos, personalizados y que generan relaciones por medio de correo electrónico marketing (Kotler \& Armstrong, Fundamentos de marketing, Edicion 13, 2017) pág. 436.

\section{Marketing Móvil}

Marketing dirigido a los consumidores en movimiento mediante teléfonos inteligentes, teléfonos móviles y tablets (Kotler \& Armstrong, Fundamentos de marketing, Edicion 13, 2017) pág. 443. 


\subsection{Marketing digital en redes sociales}

El factor social tiende a influir en la toma de decisiones intrapersonales. Basado en ese concepto, el marketing en redes sociales hace uso de esta mentalidad humana para sus fines comerciales.

El comportamiento de consumo dependerá de los grupos sociales digitales en donde se mueva el cliente, ya que en redes sociales como Facebook, las fan Pages se transforman en pequeñas comunidades o microentornos donde gente con ideologías similares se juntan compartiendo intereses, alimentando sus creencias y fortaleciendo los hobbies de sus participantes al sentirse parte de un grupo (Chimpén, 2016). Esto en sí fomenta una cultura de consumo basada en el deseo de pertenencia, ya que para pertenecer a uno de estos grupos, es necesario una inversión de tiempo y dinero. Al no invertir estos dos recursos se considera una falta de interés o compromiso, limitando su participación en el grupo y terminando con ser excluido con el tiempo.

Las plataformas más influyentes en fomentar la integración a comunidades sociales digitales, las cuales incentivan el consumo de productos y servicios; son Facebook e Instagram (Kulisz, 2018). Debido a su diseño, estas redes permiten conocer fácilmente a personas que comparten el mismo interés particular del consumidor, generando una especie de feedback el cual tiene tanta influencia como el boca a boca de amigos y familiares.

\subsection{Algunas definiciones relacionadas al marketing digital}

$\underline{\text { SEO }}$

Search Engine Optimization u optimización de búsqueda, se trata del conjunto de técnicas o acciones diseñadas a facilitar a los motores de búsqueda a encontrar palabras clave y así encontrar la información web deseada. 


\section{Posicionamiento Orgánico}

Es la consecuencia de una exitosa campaña de SEO, la cual consigue posicionar el contenido ofrecido en los primeros lugares en los motores de búsqueda al introducir las palabras clave.

\section{Campañas Pay Per Click}

Se trata de pagar por visitas, esto posicionará dependiendo de la suma pagada lugares ventajosos en los motores de búsqueda, sin embargo, habrá un claro mensaje de anuncio resaltando que se trata de publicidad.

Backlink

Son enlaces de un sitio web conseguidos gracias a otro sitio web, estas visitas conseguidas de esta manera son muy útiles a la hora de conseguir un mejor lugar en los motores de búsqueda.

\section{Landing Page}

Se relaciona a la primera interacción que el cliente en potencia tiene con la página dirigida de un anuncio publicitario, normalmente complementado a una estrategia en redes sociales o campañas PPC.

\section{Engagement}

Es la relación cercana que existe entre un cliente y una marca a un nivel personal de significancia, esta interacción se da en las redes sociales y a mayor interacción, mayor será el nivel de engagement. 


\section{Conversión}

Es el fin para el cual se realiza la campaña de marketing por lo general es cuando el cliente realiza una compra.

\section{E-commerce}

Es la comercialización a través de medios digitales, comúnmente asociados a tiendas virtuales.

\section{Tipos de marketing digital}

Al igual que todo tipo de marketing tradicional con el pasar del tiempo fue evolucionando hasta obtener diferentes tipos de marketing digital unos más efectivos que otros dependiendo de la situación o del tipo de cliente.

$\underline{\text { Inbound marketing }}$

Conocido como el método más eficaz de marketing digital, desde el 2006 ha transformado a más clientes potenciales en compradores con el menor tiempo de conversión posible.

Usando contenido propio con los intereses de los clientes consigues atraer, convertir y mantener en el tiempo posibles clientes.

Este contenido al ser hecho a medida, mantiene el interés del cliente naturalmente a través del tiempo incitando a que este vuelva por más.

Su mayor fortaleza recae en que no es un marketing tradicionalmente pagado. Este contenido será público en redes todo el tiempo que se considere relevante. En contraste al marketing digital pagado en diferentes plataformas, como el Adword o anuncios de Facebook tienden a desaparecer una vez se deja de desembolsar el dinero. 


\section{Content marketing}

Este marketing de contenidos se basa en el uso de información con valor agregado y selección especializada de contenidos estratégicos, comúnmente hecho por un content manager. En resumen, es la comercialización de una marca mediante el uso de información entretenida en informativa, la cual busca "mejorar" las vidas de los posibles clientes. Evitando así forzar una idea en los compradores, sino buscando hacerles creer que la idea es suya y por ende sentirse más motivados a ejercer su libertad expresándola en consumismo.

\subsubsection{Productos Fitness}

Productos fitness: la palabra fitness significa un estado de salud general, un conjunto de actividades físicas e ideologías de consumo enfocadas a un estilo de vida saludable. Productos fitness se enfoca en esos productos que satisfacen las ideologías de consumo saludable las cuales ayudan a los consumidores a conseguir sus objetivos estéticos más fácilmente o mantenerse en forma.

Los suplementos deportivos (también se conocen como ayudas ergogénicas) son productos que se usan para mejorar el rendimiento deportivo que podrían incluir vitaminas, minerales, aminoácidos, hierbas o productos botánicos (plantas) o una concentración, extracto o combinación de estos. Se encuentran generalmente en venta libre, sin receta médica (KidsHealth redacción, 2015) publicado en "Suplementos deportivos".

Basado en la cultura de consumo latinoamericano, se sabe que en la actualidad el $80 \%$ de la población conocida como millenials, le preocupa en gran medida su salud y a pesar que un $32 \%$ de esta población tiene desagrado por el sabor de este tipo de productos, consideran que es importante su uso para combatir la obesidad (Rico, 2017). Investigaciones como esta, nos dan entender la importancia que se le da a estos tipos de productos, superando así el concepto del placer del consumo, ya que los objetivos son a largo plazo y los beneficios no son instantáneos (algo que contradice mucho a la mentalidad que se tiene de las nuevas generaciones, las cuales son catalogadas por la búsqueda de satisfacción instantánea). 
Se debe recalcar que los productos o suplementos fitness no son comparables con las hormonas sintéticas conocidas como anabólicos, los cuales "realizan alteraciones hormonales al bombardear el cuerpo con cantidades elebadas de hormonas masculinas para incentibar el crecimiento muscular desproporcionado y antinatural", (Kochi, Pretell, \& Ynouye, 2017) generando muchos efectos secundarios del tipo físico (eliminación de la producción natural de testosterona) y psicológico (tendencias a la agresividad). Según the (U.S. Department of Health \& Human Services, 2019) en su publicasión "Dietary Supplements for Exercise and Athletic Performance" los productos fitness (suplementos de dieta), son productos diseñados para mejorar desempeño físico o complementar una alimentación saludable, siendo ésta una parte integral de una vida saludable. Estos productos se pueden encontrar en diferentes presentaciones como: capsulas, líquidos, polvos, barras, etc. Estos suplementos varían en combinaciones de ingredientes y cantidades, siendo los ingredientes más comunes: cafeína, proteína, creatina, etc. Se estima que en 2016 las ventas fueron de 5.67 billones de dólares o un $13.8 \%$ de todas las ventas de productos relacionados con la nutrición en ese año en los Estados Unidos.

\subsection{Objetivos e hipótesis:}

\subsubsection{Objetivos}

\subsubsection{Objetivo general:}

Determinar si el marketing digital influye en la decisión de compra de productos fitness en usuarios de gimnasios de Lima moderna.

\subsubsection{Objetivos específicos:}

- Determinar si la dimensión de la atracción del marketing digital influye en la decisión de compra de productos fitness en usuarios de gimnasios de Lima moderna.

- Determinar si la dimensión de la difusión del marketing digital influye en la decisión de compra de productos fitness en usuarios de gimnasios de Lima moderna. 
- Determinar si la dimensión de la retención del marketing digital influye en la decisión de compra de productos fitness en usuarios de gimnasios de Lima moderna.

\subsubsection{Hipótesis}

\subsubsection{Hipótesis general:}

El marketing digital influye en la decisión de compra de productos fitness en usuarios de gimnasios de Lima moderna.

\subsubsection{Hipótesis específicas:}

- La dimensión de la atracción del marketing digital influye en la decisión de compra de productos fitness en usuarios de gimnasios de Lima moderna.

- La dimensión de la difusión del marketing digital influye en la decisión de compra de productos fitness en usuarios de gimnasios de Lima moderna.

- La dimensión de la retención del marketing digital influye en la decisión de compra de productos fitness en usuarios de gimnasios de Lima moderna.

\section{Método}

\subsection{Tipo de investigación:}

La investigación partió de un estudio cualitativo, "La perspectiva cualitativa posee una metodología inductiva en la cual no busca comprobar ideas preconcebidas, sino que explora las ideas aportadas por los participantes en la práctica" (Ramírez, Leopoldo, Iriarte, \& Arriaga, 2017), conformado por entrevistas de profundidad a expertos y un focus group, con el fin de hallar puntos claves para la elaboración del estudio cuantitativo, en donde se buscó probar las preferencias de los consumidores, avalándolas a bases de datos numéricos y usando métodos estadísticos. Se empleó el método hipotético deductivo, debido a que se observa un fenómeno que se trata de explicar con una hipótesis y consecuentemente permite verificarla convalidándola con la experiencia observada, de tipo básica. 


\subsection{Diseño de investigación:}

\subsubsection{Diseño de investigación cualitativa}

\subsubsection{Entrevistas a profundidad}

Para el estudio cualitativo se realizaron 3 entrevistas de profundidad a expertos que tengan más de un año de experiencia en la industria fitness, así mismo que utilicen las redes sociales como medio para ofertar estos productos y que comercialicen a más de un distrito de Lima moderna.

\subsubsection{Focus Group}

De la misma manera se realizó un Focus Group de 6 personas conformadas por un panel de usuarios de productos fitness con un perfil deseado, dentro de ello, que residan en Lima moderna, que utilicen diariamente las redes sociales y que a su vez consuman productos fitness.

\subsubsection{Diseño de investigación cuantitativa}

En cuanto al estudio cuantitativo, éste ha sido del tipo correlacional no experimental y de corte transversal:

- Se aplicó un diseño de investigación de tipo no experimental debido a que no se manipula los datos y solo se procede a su recolección. Este tipo de investigación no sufre de los limitantes del tiempo, dinero y organización de un experimento, los que si son sufridos por las investigaciones experimentales (Malhotra N. , 2020) página 230.

- Adicionalmente se desarrolló un estudio correlacional con la finalidad de determinar si la variable dependiente tiene relación con la variable independiente, es una de las estadísticas de más uso ya que resume que tan fuerte es la asociación entre dos variables del tipo métricas (Malhotra N. , 2020) página 513. 
- Así mismo, se empleó un método de Corte transversal, donde la herramienta utilizada fue una encuesta, la cual se aplica en un solo tiempo para el análisis de las variables y no se procede a hacer un seguimiento de la muestra (Malhotra N. , 2020) página 71.

\subsection{Variables:}

La investigación es de nivel correccional, la cual tiene la finalidad de conocer la relación entre la variable independiente y la dependiente.

- Dependiente: Decisión de compra siendo el efecto por el cual las personas optan o no por adquirir productos a través de la influencia del marketing digital.

- Independiente: Marketing Digital debido a que es la variable de la que buscamos entender si influye a la hora de realizar la compra-venta del producto designado.

Tabla 7:

Descripción y operacionalización de las variables de estudio.

\begin{tabular}{|c|c|c|}
\hline Variable & Descripción conceptual & Operacionalización de la variable \\
\hline Nivel de atracción & $\begin{array}{l}\text { Es una variable de tipo ordinal, en } \\
\text { donde su medida descriptiva es de } \\
\text { percentil mediana (Malhotra N., 2020) } \\
\text { página 244; por consiguiente, es una } \\
\text { variable de tipo discreta. Ésta } \\
\text { representa el nivel de aceptación del } \\
\text { participante y es parte de la variable } \\
\text { independiente de marketing digital. }\end{array}$ & $\begin{array}{l}\text { Los datos de esta variable son obtenidos } \\
\text { a través de la encuesta, específicamente } \\
\text { abarca las preguntas del número } 1 \text { al } 6 \text {. } \\
\text { Registrando así la aceptación de los } \\
\text { participantes hacia esta variable usando } \\
\text { una escala que parte de la afirmación "no } \\
\text { importante", la cual numéricamente vale } \\
1 \text { hasta "muy importante", cuyo valor } \\
\text { numérico es } 5 \text {. }\end{array}$ \\
\hline Nivel de difusión & $\begin{array}{l}\text { Es una variable de tipo ordinal, en } \\
\text { donde su medida descriptiva es de } \\
\text { percentil mediana (Malhotra N., 2020) } \\
\text { página 244; por consiguiente, es una } \\
\text { variable de tipo discreta. Ésta } \\
\text { representa el nivel de aceptación del }\end{array}$ & $\begin{array}{l}\text { Los datos de esta variable son obtenidos } \\
\text { a través de la encuesta, específicamente } \\
\text { abarca las preguntas del número } 7 \text { al 15; } \\
\text { registrando así la aceptación de los } \\
\text { participantes hacia esta variable usando } \\
\text { una escala que parte de la afirmación "no } \\
\text { importante", que numéricamente vale } 1\end{array}$ \\
\hline
\end{tabular}




\begin{tabular}{|c|c|c|}
\hline & $\begin{array}{l}\text { participante y es parte de la variable } \\
\text { independiente de marketing digital. }\end{array}$ & $\begin{array}{l}\text { hasta "muy importante", que } \\
\text { numéricamente posee el valor de } 5 .\end{array}$ \\
\hline Nivel de retención & $\begin{array}{l}\text { Es una variable de tipo ordinal, en } \\
\text { donde su medida descriptiva es de } \\
\text { percentil mediana (Malhotra N. , 2020) } \\
\text { página 244; por consiguiente, es una } \\
\text { variable de tipo discreta. Ésta } \\
\text { representa el nivel de aceptación del } \\
\text { participante y es parte de la variable } \\
\text { independiente de marketing digital. }\end{array}$ & $\begin{array}{l}\text { Los datos de esta variable son obtenidos } \\
\text { a través de la encuesta, específicamente } \\
\text { abarca las preguntas del número } 16 \text { al } \\
\text { 22; registrando así la aceptación de los } \\
\text { participantes hacia esta variable usando } \\
\text { una escala que parte de la afirmación "no } \\
\text { importante", que numéricamente vale } 1 \\
\text { hasta "muy importante", que } \\
\text { numéricamente posee el valor de } 5 \text {. }\end{array}$ \\
\hline Frecuencia de compra & $\begin{array}{l}\text { Es una variable de tipo ordinal, en } \\
\text { donde su medida descriptiva es de } \\
\text { percentil mediana (Malhotra N., 2020) } \\
\text { página 244; por consiguiente, es una } \\
\text { variable de tipo discreta. Ésta } \\
\text { representa el nivel de aceptación del } \\
\text { participante y es parte de la variable } \\
\text { dependiente de decisión de compra. }\end{array}$ & $\begin{array}{l}\text { Los datos de esta variable son obtenidos } \\
\text { a través de la encuesta, específicamente } \\
\text { abarca las preguntas del número } 23 \text { al } \\
27 \text {; registrando así la aceptación de los } \\
\text { participantes hacia esta variable usando } \\
\text { una escala que parte de la afirmación "no } \\
\text { me identifico", que numéricamente vale } \\
1 \text { hasta "me identifico en gran medida", } \\
\text { que numéricamente posee el valor de } 5 .\end{array}$ \\
\hline Motivación de compra & $\begin{array}{l}\text { Es una variable de tipo ordinal, en } \\
\text { donde su medida descriptiva es de } \\
\text { percentil mediana (Malhotra N., 2020) } \\
\text { página 244; por consiguiente, es una } \\
\text { variable de tipo discreta. Ésta } \\
\text { representa el nivel de aceptación del } \\
\text { participante y es parte de la variable } \\
\text { dependiente de decisión de compra. }\end{array}$ & $\begin{array}{l}\text { Los datos de esta variable son obtenidos } \\
\text { a través de la encuesta, específicamente } \\
\text { abarca las preguntas del número } 28 \text { al } \\
\text { 33; registrando así la aceptación de los } \\
\text { participantes hacia esta variable usando } \\
\text { una escala que parte de la afirmación "no } \\
\text { me identifico", que numéricamente vale } \\
1 \text { hasta "me identifico en gran medida", } \\
\text { la cual numéricamente vale } 5 \text {. }\end{array}$ \\
\hline
\end{tabular}

Fuente: Elaboración propia 


\subsection{Proceso de muestreo:}

\subsubsection{Universo:}

El universo está conformado por hombres y mujeres millennials que residen en Lima moderna, quienes tienen edades entre 19 y 39 años, según los datos obtenidos del último censo (CPI, 2017). Nuestro universo se determinó en base a 3 aspectos: los millennials que son la población económicamente activa más preocupada por su salud en Latinoamérica (Rico, 2017) , que además asisten a gimnasios en Lima, según el porcentaje dado por (Front Consulting, 2016) y que consumen productos fitness, porcentaje obtenido del trabajo de investigación (Cabrera \& Pisfil, 2016). De esta manera, estimaremos la cantidad de personas que asisten a gimnasios en lima moderna.

Todo esto con el fin de tener una muestra que se adapte a las características deseadas, obtenidas de las respuestas recopiladas del estudio cualitativo. La muestra fue calculada en el programa Microsoft Excel (ver tabla 7).

\subsubsection{Muestra:}

\section{1) Población meta:}

Elementos: Hombres o mujeres de 19 a 39 años, que asisten al gimnasio y que compren productos fitness

Unidades de muestreo: Usuarios de gimnasios que consuman productos fitness Extensión: Lima moderna

Tiempo: 2019.

2) Marco de muestreo: Base de datos Facebook Business Manager

3) Técnica de muestreo: Muestreo aleatorio simple

4) Tamaño de la muestra: 362 
Tabla 8:

Tamaño de muestra.

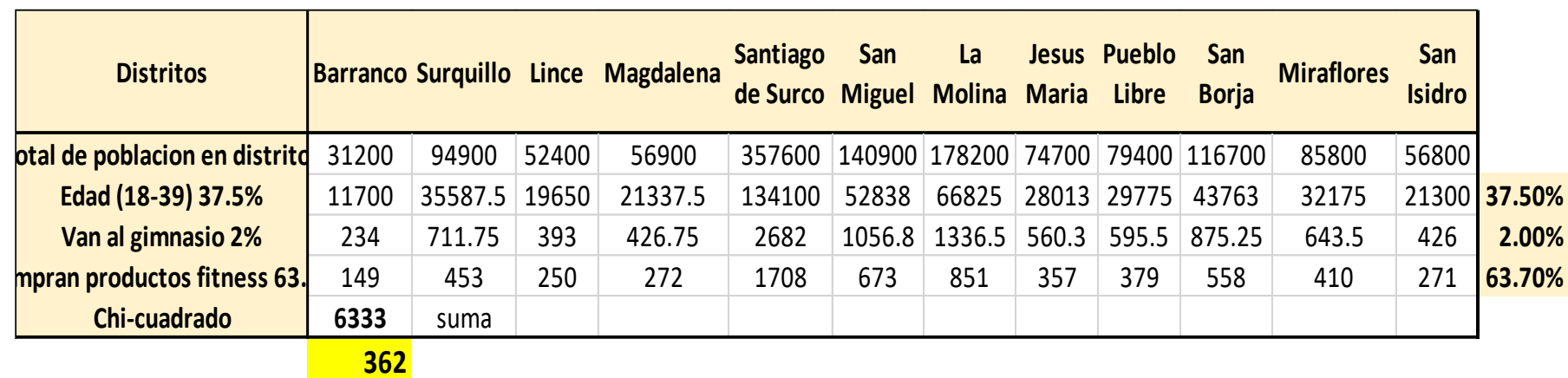

Fuente: Elaboración propia, (CPI, 2017) Tamaño de muestra, (Front Consulting, 2016) Población limeña que va al gimnasio y del trabajo de (Cabrera \& Pisfil, 2016) porcentaje de limeños que compraría productos fitness.

5) Realización: Generar una encuesta en la plataforma Google Forms y enviar al público objetivo por medio de las redes sociales Facebook e Instagram.

El muestreo es probabilístico del tipo aleatorio simple de corte transversal, ya que cada elemento en la población tiene la probabilidad de selección conocida y equitativa, cada elemento se selecciona en forma independiente a otro elemento (Malhotra N. , 2020) pag 325. Se obtuvo una muestra de 6333 personas (ver tabla 7), las cuales fueron obtenidos multiplicando la población por los porcentajes de las características mencionadas y se procedió a calcular la muestra usando el método de cálculo de la población, conocido como la fórmula estadística de SHAO.

$$
n=\frac{N \times Z_{a}{ }^{2} \times p \times q}{d^{2} \times(N-1)+Z_{a}{ }^{2} \times p \times q}
$$

Leyenda:

$\mathrm{n}=$ Tamaño de la muestra

$\mathrm{N}=$ Tamaño de la población

$Z=$ Nivel de confianza

$\mathrm{p}=$ Probabilidad de éxito o proporción esperada

$q=$ Probabilidad de fracaso

d = Precisión (Error máximo admisible en términos de proporción). 
En donde:

$\mathrm{n}=$ Tamaño de la muestra

$\mathrm{N}=6333$

$Z=1.96(95 \%$ nivel de confianza)

$p=50 \%$

$q=50 \%$

d $=5 \%$ (Error máximo admisible en términos de proporción).

Lo que dio como resultado en $n=362$ personas. La muestra fue extraída a finales de 2019 y a inicios del 2020, entre diciembre y enero de los años mencionados. Para la recopilación de datos se usó la plataforma de Google Forms el cual permitió diseñar y digitalizar la encuesta, siendo un estudio de marketing digital, ésta se distribuyó usando las redes sociales conocidas como Facebook e Instagram, las que por su preferencia por parte de la muestra objetivo (ver figura 7 y figura 8) permitieron llegar a nuestro público deseado usando pocos recursos con la finalidad de hallar la percepción de los clientes frente a los productos fitness ofertados por este medio.

\subsection{Instrumentos de investigación}

\subsubsection{Entrevista a Profundidad:}

Las entrevistas a profundidad se elaboraron de manera estructurada debido a que las preguntas eran las mismas para todos los entrevistados, además estas siguen un mismo orden especifico, enfocándose en encontrar los puntos de vista más resaltantes que poseen los expertos sobre el mercado fitness y sus experiencias con los consumidores que participen en éste. (ver anexo E).

\subsubsection{Focus Group:}

Basado en los resultados de las entrevistas en profundidad, se procedió a elaborar una guía de pautas para un focus group conformada por una muestra representativa del consumidor promedio de productos fitness según las especificaciones de los expertos del mercado. (ver anexo C). 


\subsubsection{Encuesta:}

Debido a la naturaleza de la investigación, se realizó una encuesta exclusivamente en formato digital, llegando así al público objetivo; basado en los resultados cualitativos se determinó los aspectos más relevantes a estudiar sobre marketing digital y su relación con la decisión de compra de productos fitness.

- Google forms: Es una aplicación perteneciente a los servicios de Google drive que permite realizar cuestionarios de diversos estilos para poder hacer estudios a través de plataformas digitales, ofreciendo herramientas básicas y gratuitas para todo estudiante o profesional. Este instrumento fue utilizado para digitalizar la encuesta y tabular de manera simple las respuestas obtenidas.

- Facebook ad manager: Es una herramienta especializada para profesionales o conocedores de marketing digital, la cual permite dirigir publicidad, enlaces, videos, etc., por medio de las redes sociales que la compañía Facebook, Inc. Posee (Facebook e Instagram), a un público muy específico de manera simultánea y por un mismo precio en todas sus redes sociales. Este instrumento fue utilizado para direccionar nuestras encuestas a nuestro público objetivo, realizando bajas inversiones de dinero al poseer una gran y valiosa base de datos.

- Microsoft Exel: Programa que pertenece al paquete de Microsoft office. En este programa se pueden realizar desde hojas de cálculo simples hasta complejas operaciones interconectadas, que permiten resolver graficar y administrar datos de tipo numérico, así como de letras. Esta herramienta nos permitió calcular el tamaño de la población y administrar nuestros datos obtenidos de las encuestas, para luego ser ingresados en otro programa.

- IBM SPSS: Programa popularmente conocido para estudios de mercado, sus herramientas permiten a estudiantes y profesionales realizar complejos estudios de mercado, tabulando así grandes bases de datos. Esta herramienta nos permitió responder a las preguntas estadísticas de este estudio, permitiendo así llegar a las conclusiones y recomendaciones del presente trabajo. 
Tabla 9:

Las dimensiones teóricas de afirmaciones del instrumento de investigación.

\begin{tabular}{|c|c|}
\hline Dimensión Teórica & Objetivo Especifico \\
\hline $\begin{array}{l}\text { Etapa } 1 \text { del comportamiento de } \\
\text { compra "Necesidad de } \\
\text { identificación": (Teruel, 2019), la } \\
\text { identificación es un proceso } \\
\text { natural que parece como } \\
\text { respuesta a un estímulo, la cual al } \\
\text { ser evaluada permite planificar de } \\
\text { manera correcta una campaña } \\
\text { mediática para presentar un } \\
\text { producto frente a posibles } \\
\text { compradores }\end{array}$ & $\begin{array}{l}\text { Obj.1 Determinar si la dimensión } \\
\text { de la atracción del marketing } \\
\text { digital influye en la decisión de } \\
\text { compra de productos fitness en } \\
\text { usuarios de gimnasios de Lima } \\
\text { moderna. }\end{array}$ \\
\hline
\end{tabular}

Afirmaciones del cuestionario de la investigación

La marca a la hora de adquirir

productos fitness (Obj.1)

El precio a la hora de adquirir productos fitness (Obj.1)

El valor nutricional a la hora de adquirir productos fitness (Obj.1)

Una recomendación previa a la hora de adquirir productos fitness. (Obj.1)

Los comentarios de expertos a la hora de adquirir productos fitness (Obj.1)

La innovación de un producto a la hora de adquirir productos fitness.

(Obj.1)

La publicidad por medios digitales a la hora de adquirir productos fitness. (Obj.2)

Etapa 2 del comportamiento de compra "Reunión de información": (Teruel, 2019), el deseo de un cliente de satisfacer una necesidad en la era digital por lo general lo lleva a la búsqueda de información en los medios digitales; debido a ello la visibilidad y la cantidad de información que se pueda obtener en línea sobre productos y servicios es un medio disuasorio para que los clientes elijan asistir a Obj.2 Determinar si la dimensión Los descuentos en línea a la hora de adquirir productos fitness. (Obj.2)

Recepción de información en línea para realizar compras grandes a la de la difusión del marketing hora de adquirir productos fitness.

(Obj.2)

digital influye en la decisión de

El poder hacer compras por compra de productos fitness en tiendas digitales a la hora de usuarios de gimnasios de Lima moderna.

adquirir productos fitness evitando salir de casa. (Obj.2)

Que las páginas web de los vendedores aparezcan en los anuncios destacados del buscador web a la hora de adquirir productos fitness. (Obj.2)

Recibir correos de vendedores con novedades y ofertas a la hora de adquirir productos fitness. (Obj.2) 


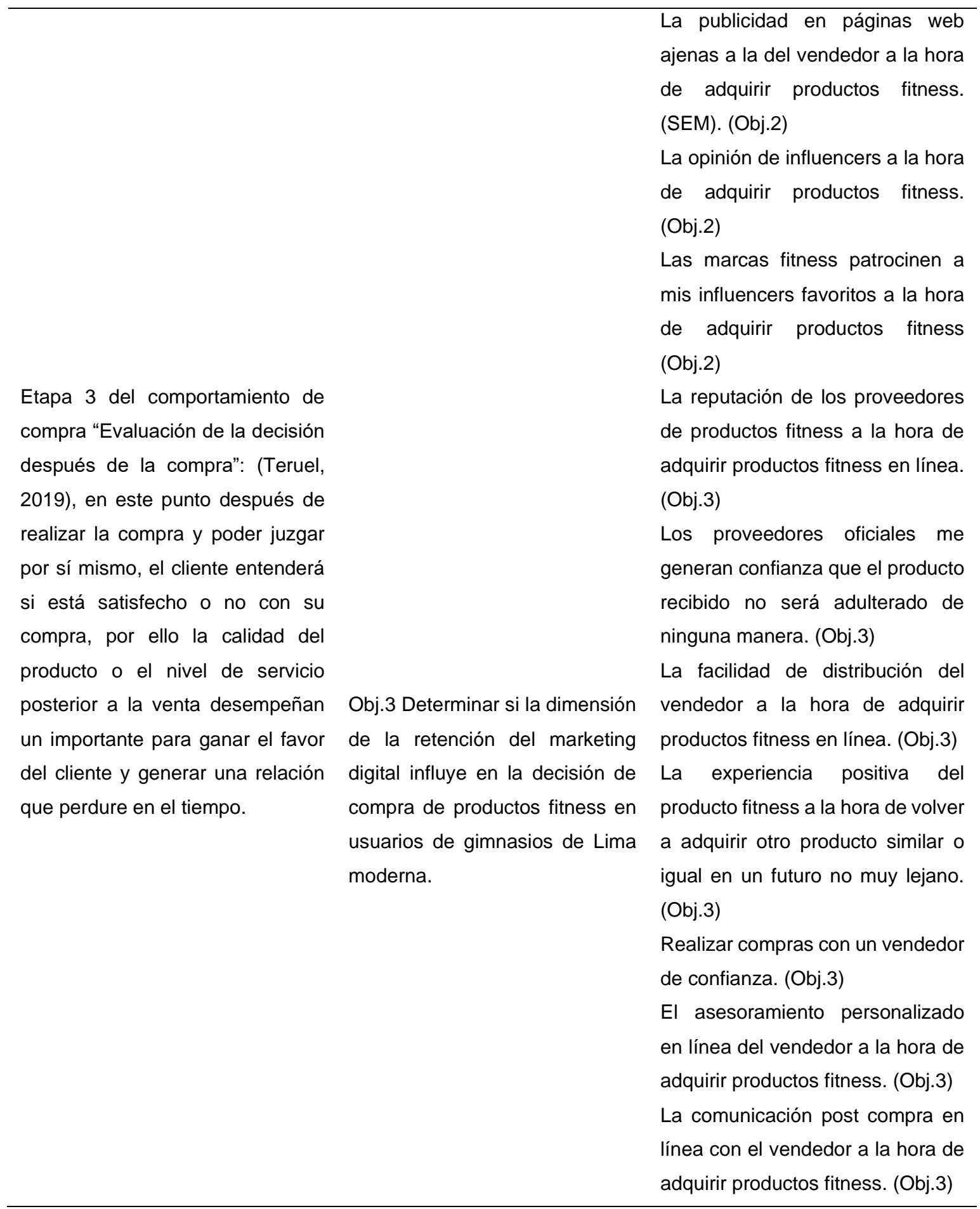

Fuente: Elaboración propia 


\subsection{Procedimiento de recolección de datos}

\subsubsection{Criterios de inclusión y exclusión}

\subsubsection{Criterios de inclusión}

\subsection{Muestra cualitativa:}

\section{Entrevistas de profundidad:}

- Personas con más de un año de experiencia en productos fitness

- Personas que ofertan por medios digitales

- Personas que comercian en más de un distrito (ofertan o venden)

\section{Focus Group:}

- Hombres y mujeres cuyas edades ronden entre los 18 y 39

- Utilizan redes sociales diariamente.

- Consumen productos fitness por lo menos tres veces al mes

- Viven en Lima moderna: San Borja, Surquillo, La Molina, Santiago de Surco, Pueblo Libre, San Miguel, Lince, Miraflores, Jesús María, San Isidro y Magdalena del Mar y Barranco.

\subsection{Muestra cuantitativa:}

- Hombres y mujeres cuyas edades sean de 18 a 39.

- Utilizan redes sociales diariamente.

- Asisten al gimnasio por lo menos tres veces a la semana.

- Consumen productos fitness por lo menos tres veces al mes.

- Viven en Lima moderna: San Borja, Surquillo, La Molina, Santiago de Surco, Pueblo Libre, San Miguel, Lince, Miraflores, Jesús María, San Isidro y Magdalena del Mar y Barranco. 


\subsubsection{Criterios de exclusión}

\subsection{Muestra cualitativa:}

\section{Entrevistas a profundidad:}

- Poseen menos de un año de experiencia en productos fitness.

- No ofertan por medios digitales.

- Comercian en solo un distrito.

\section{Focus Group:}

- Hombres y mujeres cuyas edades no ronden entre los 18 y 39

- No utilizan redes sociales diariamente.

- No consumen productos fitness por lo menos tres veces al mes

- Viven en distritos que no pertenecen a Lima moderna.

\subsection{Muestra cuantitativa:}

- Hombres y mujeres cuyas edades no sean de 18 a 39.

- No utilizan redes sociales diariamente.

- No asistan al gimnasio por lo menos tres veces a la semana.

- No consumen productos fitness por lo menos tres veces al mes.

- Viven en distritos que no pertenecen a Lima moderna.

\subsection{Procedimiento de recolección de información cualitativa}

El estudio cualitativo inició con la entrevista a los expertos en venta y uso de productos fitness quienes contaban con amplia experiencia profesional en el campo. El contacto se dió a través de las redes sociales como Facebook e Instagram, seleccionando aquellos expertos que tenían más de un año de experiencia vendiendo y comunicando a través de estas plataformas mediante comentarios positivos, preferencias y "me gusta" por parte de los clientes, y la importancia de comercializar a través de los distintos distritos de Lima moderna. Por consiguiente, se procedió a seleccionar a tres expertos, en donde se entabló una comunicación previa para la coordinación de las entrevistas. Seguidamente estos participantes fueron citados en diferentes locaciones, basándose en sus horarios y disponibilidad. Previa 
aceptación de los entrevistados, finalmente se procedió a grabar dos entrevistas en video y uno sólo en audio, debido a las condiciones del participante. Así mismo se usó una guía de pautas para direccionar la entrevista, sin embargo, dependiendo de las respuestas se permitió cambios en las preguntas. (ver anexo E).

La segunda parte del estudio cualitativo fue un Focus group, y para ello, usando los datos recopilados de la entrevista, se creó un perfil del consumidor y se procedió a analizar a los participantes que cumplían con estas características a través de contactos de asistentes de gimnasio perteneciente a los distritos de Lima moderna. Luego de la selección, se procedió a la invitación y coordinación de los seis participantes para asistir al lugar pactado para la reunión del focus group. El estudio se realizó en la vivienda de uno de los tesistas, se preparó con equipo de grabación y se ofreció bocaditos y bebidas de tipo fitness, para mantener la ilación de la investigación. Finalmente se usó una guía de pautas para así direccionar la conversación y llevarla a presentar datos que ayudarían a la investigación (ver anexo C). El video fue editado para eliminar las pausas realizadas por los participantes que solicitaban el uso de los servicios higiénicos. Al final de esta investigación, se procedió a redactarse la encuesta del estudio cuantitativo.

\subsubsection{Resumen de información obtenida del estudio cualitativo}

- Entrevistas de profundidad:

La importancia de la fidelización de los clientes a través del asesoramiento personalizado, así como de transparencia en la información brindada sobre recomendaciones de productos nuevos y la resolución de problemas a la brevedad, fueron los factores que sobresalieron de estas entrevistas.

- Focus group:

Los participantes resaltaron la importancia de los canales virtuales para el comercio de productos fitness y sus dudas al realizar compras por estas plataformas. Se encontró expectativa sobre las posibilidades futuras del comercio en línea, sin embargo, la mayoría considera que faltan resolver muchos problemas relacionados a este tipo de comercio. 


\subsection{Procedimiento de recolección de información cuantitativo}

Para la recolección de datos del estudio cuantitativo, se procedió a enviar la encuesta, previa aprobación de la asesora de tesis, así como la aprobación de un experto en el tema. Debido a la naturaleza de la investigación, ésta se realizó exclusivamente de manera digital, por ello para distribuir la encuesta se utilizó la plataforma de Facebook ad manager, la cual permitió dirigirla a través de las plataformas de Facebook e Instagram de acuerdo a las características del público objetivo deseado, conformada por un cuestionario de 33 preguntas (ver anexo D). el cual comenzó a finales del 2019 siendo el mes de diciembre y terminando el mes de enero del 2020, permitiendo recolectar los datos en un tiempo de solo 2 meses.

Por consiguiente, los encuestados deben elegir respuestas del tipo textual, en este caso su apreciación de las variables a través de respuestas en escala Likert; sin embargo, estas son transformadas a valores numéricos de carácter ordinal. Por ello la escala de Likert presenta al participante, ítems que simbolizan propiedades a medir, estas respuestas reciben un valor numérico el cual permite hallar una puntuación general, la que posiciona de manera ordinal el grado de representación de la variable a medir haciéndola así un instrumento de medición cuantitativo" (Bedoya, 2017).

\subsubsection{Análisis de Fiabilidad}

- El análisis cuantitativo sirvió para obtener respuestas avaladas por conceptos estadísticos, permitiendo tener una percepción más profunda y certera de los resultados arrojados por esta investigación.

- Se incluyó además un análisis de fiabilidad, más conocido como el Alfa de Cronbach para validar el instrumento de la encuesta y sus 33 afirmaciones. Se debe considerar que para obtener un valor significativo el alfa debe ser superior a 0.7 , lo cual automáticamente garantiza la fiabilidad del instrumento. El siguiente cuadro fue elaborado a través del programa SPSS (ver tabla 10). 
Tabla 10:

Fiabilidad del instrumento.

\begin{tabular}{lc}
\hline \multicolumn{2}{l}{ Estadísticas de fiabilidad } \\
\hline Alfa de & N de elementos \\
Cronbach & 33 \\
.726 & 33 \\
\hline
\end{tabular}

Fuente: elaboración propia

\subsection{Plan de análisis de datos cuantitativos}

El análisis de los datos obtenidos de la investigación cuantitativa (encuestas), se realizó por medio del uso del programa SPSS, debido a las facilidades que presenta al poder analizar y graficar simultáneamente los resultados de la investigación.

\section{Resultados}

\subsection{Análisis de resultados}

El análisis presenta los datos cualitativos adquiridos del focus group realizados a la muestra seleccionada, así mismo tres entrevistas a profundidad a expertos con experiencia en el mercado y finalmente, se presenta el estudio cuantitativo a través de un cuestionario en escala tipo Likert.

\subsubsection{Análisis de resultados del estudio cualitativo:}

En esta sección se procede a mostrar los análisis respectivos del estudio cualitativo:

\subsubsection{Análisis de las entrevistas a expertos}

Se hicieron 3 entrevistas con el fin de encontrar características en común, observadas por expertos sobre los clientes que consumen este tipo de productos, para poder así establecer los puntos más relevantes al preguntar a los consumidores. 


\subsection{Entrevista a Juan Manuel Angulo Espinoza}

Entrenador de Smartfit, con más de 4 años de experiencia en ventas por internet y fundador Active Fit funtional kids (programa de entrenamiento funcional para niños), ventas en más de un distrito y amplia experiencia en mantener comunicación y asesoramiento personalizado con sus clientes, en especial clientes mayores de 35 años, los cuales tienden a tener muchas ideas erradas sobre el consumo de productos fitness.

- Realiza ventas tanto personalmente como por internet.

- Mantiene su inventario según recomendaciones de los importadores mayoristas.

- Utiliza principalmente Facebook para realizar campañas de ventas y aprovechando su condición como entrenador, promueve su fanpage para mantener a sus clientes cercanos a las novedades del mercado.

- Debido a la cantidad de oferta y demanda, los clientes buscan estar informados y los vendedores le dan toda la información posible para atraer a los clientes a probar nuevos productos, marcas y acompañarlos con un régimen personalizado.

- Sus márgenes de ganancia son potenciados gracias al servicio extra que brindan con la venta, pero al mismo tiempo no le dedica más que el $20 \%$ de su esfuerzo laboral, debido a que las redes sociales hacen el trabajo por él.

- Las nuevas generaciones están más informadas y por ello una estrategia de sensibilización, no es requerida para vender productos costosos a novatos.

- Si el producto viene acompañado con un servicio, se considera que la retención de un cliente será mucho mayor debido a la constante comunicación y retroalimentación en cuanto a su meta y progreso.

Su entrevista sirvió para comprender que existe una importancia entre la comunicación de los clientes con el vendedor, en especial con la retroalimentación; enfocados en conseguir lograr sus metas y objetivos, esto con el fin de crear una relación duradera y lucrativa.

\subsection{Entrevista a Marcos Campos Torres}

Profesor de educación física, con más de 5 años por internet y supervisor de operaciones de la cadena Gold Gym, comercializa sus productos en varios distritos, teniendo las mayores 
ventas en el norte de la capital, así como poseedor de su propia tienda de productos fitness en la Molina. Su asesoramiento personalizado enfocado en el alcance de resultados como parte de su servicio, es debido a su preparación profesional, atrayendo así a jóvenes, los cuales buscan un entrenador privado a la hora de recibir asesoramiento fitness.

- Ingresó a la venta de productos fitness debido a la falta de información de la época, así como por interés propio, y que el deportista encuentre el producto que necesite de él, que le quiere vender.

- A pesar de pertenecer a la generación boomer, entiende la importancia y las facilidades que las redes sociales presentan a la hora de ofertar sus productos.

- El constante intercambio de información con el comprador, le permite ganarse su confianza e incrementar sus nuevos clientes entre un $20 \%$ y $30 \%$ al mes.

- El cono norte representa para este vendedor, uno de los mercados más grandes, debido a que las personas están más interesadas en invertir en el crecimiento personal.

- El entrevistado combina una tienda física con ventas en línea, debido a que eso le permite abarcar un mercado mucho más grande sin tener que abrir una tienda por distrito.

- El entrevistado considera que para ganarse la credibilidad con el cliente, debe crear una relación de confianza mutua basada en el entendimiento real de las metas y objetivos de su cliente, y así respetando estas metas y considerando el tiempo en el mundo fitness, ofrecer productos con los cuales se pueda adoptar un estilo de vida como una práctica permanente.

La entrevista sirvió para considerar los beneficios del comercio digital, los cuales ayudan a eliminar las barreras asociadas con la tradicional tienda física, ya que usando los canales de distribución recientemente creados como globo, permiten hacer entregas a todo Lima, incluso a aquellos que no poseen movilidad propia, con tan solo el pago de un sobrecargo de envío.

\subsection{Entrevista a Gabriel Lozano}

Personal trainer certificado por federación peruana en el año 2008 y con más de 3 años de experiencia vendiendo por internet, al igual que los anteriores, no tiene un distrito específico y realiza ventas en toda Lima incluyendo envíos al interior del país por un cargo extra; ofrece 
asesorías e incluso video tutoriales de consumo o reviews, aunque no siempre hechos por él mismo. Su enfoque a transformar a sus alumnos de gimnasio en clientes y crear un boca a boca, es una estrategia con la que comenzó y que aún hoy en día le rinde resultados.

- Uno de sus ingresos más importantes es la venta de suplementos y diseñar dietas a deportistas.

- Ingresó a este mercado para obtener un ingreso más, darle calidad de vida a sus alumnos en el gimnasio y poder optimizar sus entrenamientos.

- Hace ventas directas para sus alumnos en los gimnasios y utiliza las redes sociales como método para atraer nuevos clientes y ofrecerles productos y servicios.

- Sabe del potencial en usar los medios digitales para poder incrementar sus ventas, ya que el ingreso que obtuvo en poco tiempo fue bueno, publicitando en estos medios.

El costo beneficio de publicitar en las plataformas de redes sociales requiere poca especialización y ofrece grandes retribuciones; aun así, usar las herramientas especializadas que existen puede generar mayores beneficios, por eso la utilidad de llevar cursos sobre el tema o trabajar junto a un especialista son buenas inversiones, para lograr una mayor diferenciación con la creciente competencia.

\subsubsection{Análisis de focus group}

Tabla 11:

Participantes focus group

\begin{tabular}{lcc}
\hline Participantes & Edad & Distritos \\
\hline Niccol Arias & 26 años & La Molina \\
Greysi alhuay & 18 años & La Molina \\
Kathleen Villaverde & 27 años & Surco \\
Silvia Ramirez & 31 años & Barranco \\
Miguel Martel & 26 años & Magdalena \\
Daniel Taipe & 26 años & San Miguel \\
\hline
\end{tabular}

Fuente: Elaboración propia 


\section{Rutina y hábitos de consumo}

- La mayoría de los participantes son personas que trabajan en empresas con horario de oficina de 9 am a 6 pm, algunos de ellos independientes; no obstante, todos ellos son activos o entusiastas del deporte y buscan mejorar sus resultados a través del uso de productos fitness.

- Sobre su alimentación es balanceada y tratan de evitar comidas "fast food".

- Consideran que el consumo de este tipo de productos, no es una etapa temporal de su vida y estiman que se transformará en parte natural de sus hábitos de vida.

- Otro factor importante para ellos son los roles que la sociedad impone en cuanto a comportamiento social, como patrones de vestimenta y nutrición como factor de motivación para seguir uno de estos hábitos de consumo saludable.

\section{Uso y percepción de la comunicación digital}

- Todos ellos usan sus redes sociales como parte esencial de su rutina diaria, así mismo tienen experiencia comprando productos y solicitando servicios por medio de sus teléfonos móviles o computadoras; aunque no siempre tienen una buena experiencia, aceptan que es parte de la vida cotidiana, que el comercio sea vía digital.

- En cuanto a la influencia del marketing digital, es la natural evolución del marketing hacia la nueva plataforma comercial; incluso algunos de ellos comercializan por este medio, productos y otros servicios aprovechando las ventajas económicas que estas plataformas ofrecen, ya que no hay necesidad de pagar o declarar impuestos al tener una tienda virtual.

- Los participantes consideran que el internet y las redes sociales facilitan las compras por impulso, ya que se presentan como publicidad especialmente dirigida al consumidor, previa evaluación de su perfil digital. 


\section{Factores de decisión de compra}

- Los participantes consideran que la información es vital antes de tomar la decisión de consumir cualquier producto, ya que uno debe hacer compras informadas en esta era de la comunicación, en donde toda la información está disponible al alcance de todos.

- Además, los participantes consideran que aún después de haber tomado la decisión de comprar o adquirir un producto, es necesario hacer una comparación de precios 0 incluso buscar una mejor versión del producto antes de realizar la compra.

- Ellos consideran que la constante exposición a la información sobre este tipo de productos, los incentiva averiguar un poco más y posiblemente comprarlos ya que su interés despierta al ver tanta exposición en redes.

- A su parecer la conveniencia de recibir productos a la comodidad de su hogar, amerita un pago extra, ya que consideran que en tienda podrían no encontrar lo que buscan o que el ahorro obtenido no es lo suficientemente importante, en comparación del tiempo que se gana al obtener un producto, independiente a la lejanía de ubicación del proveedor físico.

- A su entender, al inicio uno debe seguir las recomendaciones de aquellas personas experimentadas en especial cuando se trata de marca y precio, pero ya con el tiempo la familiarización les permitiría conseguir un razonamiento más objetivo sobre estas variables.

- A pesar de no ser expertos en informática, consideran que se debe buscar todas las opciones de seguridad disponibles que garanticen su información financiera, para que ésta no sea hurtada.

- A su percepción, el tener la opción de comprar en línea aún les genera desconfianza y consideran que las herramientas para una compra completamente segura no existen, o sí existen, no son de conocimiento público. 


\section{$\underline{\text { Conclusiones }}$}

- Se considera que este medio tiene mucho valor para este tipo de productos, en especial si se logra ofrecer productos por disciplinas deportivas y de manera personalizada, explican sus beneficios para los deportistas entusiastas.

- Este mercado tiene el potencial de convertirse en el medio de venta de muchos productos. Lo importante es que se adapte a las percepciones y demandas culturales del cliente peruano.

- Las herramientas de seguridad para proteger la información sensible de los usuarios, debe ser explicada de manera más simplificada para así mejorar la confianza en los usuarios, que aún tienen algunos miedos a la hora de comercializar en línea.

- Las pasarelas de pago necesitan mayor exposición ya que éstas pueden proteger ya sea al comprador o vendedor de una posible estafa; sin embargo, incluso personas que no tengan miedo de realizar transferencias bancarias móviles pueden sentirse intimidadas por éstas o no entender su importancia y considerar que solo aumentan los gastos de compra/venta.

\subsubsection{Conclusión de estudio cualitativo}

Este estudio confirmó teorías planteadas sobre el mercado fitness. Además de aportar puntos no considerados previamente, como el uso de asesorías personalizadas que son un gran factor de retención de clientes, estos puntos ayudaron a crear preguntas relevantes, como aquellas que cubren todos los aspectos más importantes sobre el marketing digital y la venta de productos fitness, así como entender los sentimientos del comprador relacionados a esta práctica, punto que no puede conocerse hasta que no se experimente en la práctica y que gracias a las experiencias de los expertos y a lo compartido en el focus group, se pudo entender más fácilmente. 


\subsubsection{Análisis de resultados de estudio cuantitativo:}

La encuesta fue realizada a 368 personas mediante el uso de la plataforma Google forms y fue difundida por medio de una campaña de Facebook Bussines Manager.

\subsubsection{Dimensión de atracción}

Es una técnica de marketing enfocada en la atracción de clientes potenciales mediante el uso de información que este perfil específico de cliente considera relevante, ya sea mediante artículos, animaciones, videos, etc. El objetivo es captar la atención y el interés del cliente potencial.

Por ello las preguntas del 1 al 6 buscan determinar si la dimensión atracción del marketing digital influye en la decisión de compra de productos fitness en usuarios de gimnasios de Lima moderna. 
En la figura 13 , el $56 \%$ de personas considera importante la marca a la hora de adquirir productos fitness; y el 30\% lo considera muy importante. Esto demuestra que la marca es un factor relevante a la hora de comprar productos fitness, al ser una muestra de garantía el tener un nombre reconocible al cual asociar una característica como calidad o garantía.

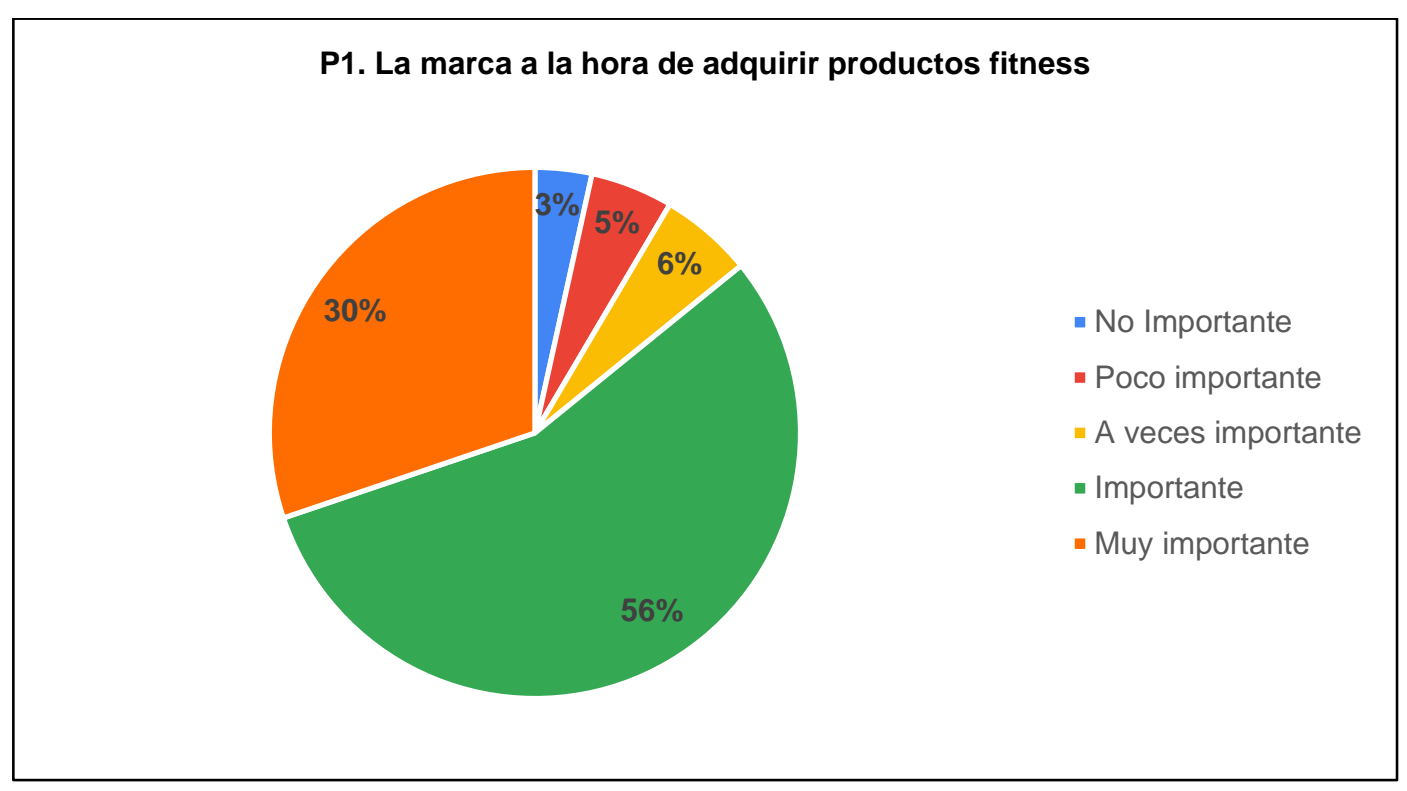

Figura 13: Análisis de la pregunta 1 del instrumento cuantitativo.

Fuente: Resultados de investigación elaboración propia 
En la figura 14, el $44 \%$ de consumidores de productos fitness consideran importante el precio a la hora de adquirirlos; el $33 \%$ lo considera muy importante. Y por otro lado el $15 \%$ es indiferente, lo cual significaría que si el precio es alto no impacta en gran medida en su decisión de compra a diferencia de otro tipo de mercado, al no ser un producto de primera necesidad, y estar ligado más a una población que lo considera relevante por motivos interpersonales.

\section{P2. El precio a la hora de adquirir productos fitness}

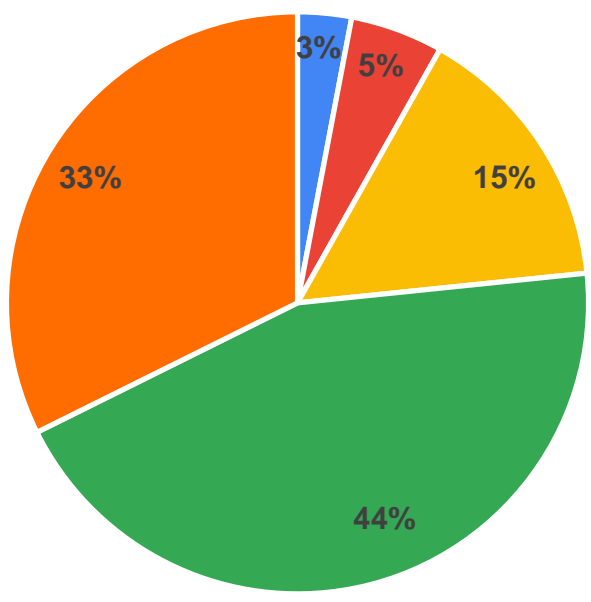

- No Importante

- Poco importante

- A veces importante

- Importante

- Muy importante

Figura 14: Análisis de la pregunta 2 del instrumento cuantitativo.

Fuente: Resultados de investigación elaboración propia 
En la figura 15 se indica que el $55 \%$ de personas consideran importante el valor nutricional a la hora de adquirir productos fitness y el $38 \%$ muy importante. Estos resultados explican que la gran mayoría concuerda que el valor nutricional es un factor bastante relevante a considerar en este tipo de productos, ya que los beneficios nutricionales esperados están ligados a sus ingredientes, los cuales son seleccionados por tendencias de apreciación en cuanto a sus efectos beneficiosos.

\section{P3. El valor nutricional a la hora de adquirir productos fitness}

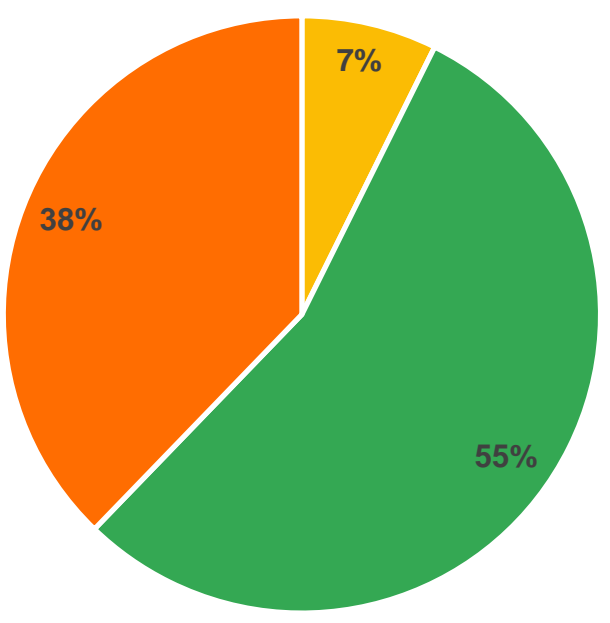

- No Importante

- Poco importante

- A veces importante

- Importante

- Muy importante

Figura 15: Análisis de la pregunta 3 del instrumento cuantitativo.

Fuente: Resultados de investigación elaboración propia 
En la figura 16 el 55\% de los consumidores consideran importante una recomendación previa a la hora de adquirir productos fitness; y $21 \%$ lo consideran muy importante, en cambio solo el $18 \%$ consideran que a veces puede ser importante una recomendación. Estos indicadores demuestran que el usuario tiende a aceptar recomendaciones de personas que consideran confiables para poder aventurarse a probar estos productos, en especial si solo son entusiastas aquellos que apenas ingresaron en el mundo del fitness y desean acelerar sus resultados, observación que se pudo rescatar del focus group en donde mencionaban que no consideraban a estos productos milagrosos, sino que son un empuje para alcanzar las metas deseadas en un menor tiempo.

P4. Una recomendación previa a la hora de adquirir productos fitness

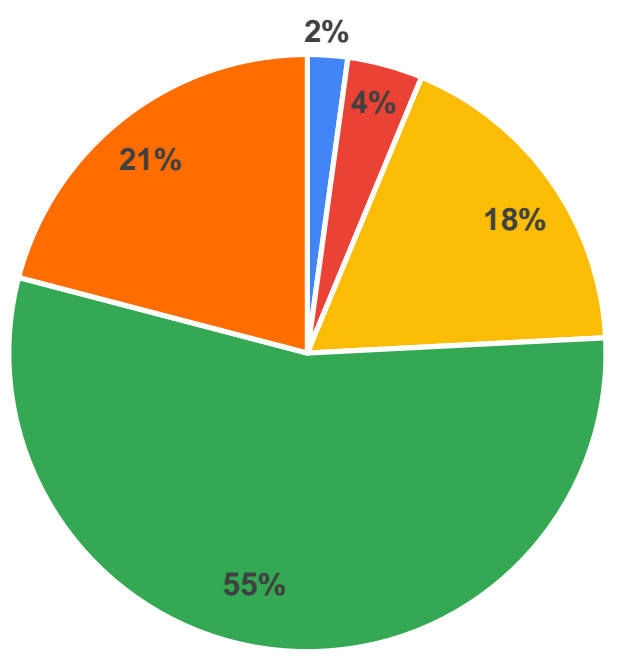

- No Importante

- Poco importante

- A veces importante

- Importante

- Muy importante

Figura 16: Análisis de la pregunta 4 del instrumento cuantitativo.

Fuente: Resultados de investigación elaboración propia 
En la figura 17, el 54\% de consumidores de productos fitness suelen escuchar o leer comentarios de expertos a la hora de adquirir productos fitness, de la misma manera el $29 \%$ lo considera muy importante, en contraste al $14 \%$ les resulta indiferente. Los resultados permiten afirmar que sí existe cierta expectativa de la comunidad fitness sobre aquellos que considera líderes de opinión, en especial debido a que es parte natural del ser humano buscar un tipo de prueba que demuestre la efectividad de un producto o servicio, ya que el objetivo es conseguir resultados, algo mencionado por los expertos en las entrevistas de profundidad, al resaltar que el atleta debe ser correctamente asesorado porque muchas veces sigue patrones de moda y termina frustrado por no conseguir los objetivos propuestos, en muchos casos por seguir a líderes de opinión, los cuales no comparten toda la información sobre su transición de cambio o de uso de un producto en específico.

P5. Los comentarios de expertos a la hora de adquirir productos fitness

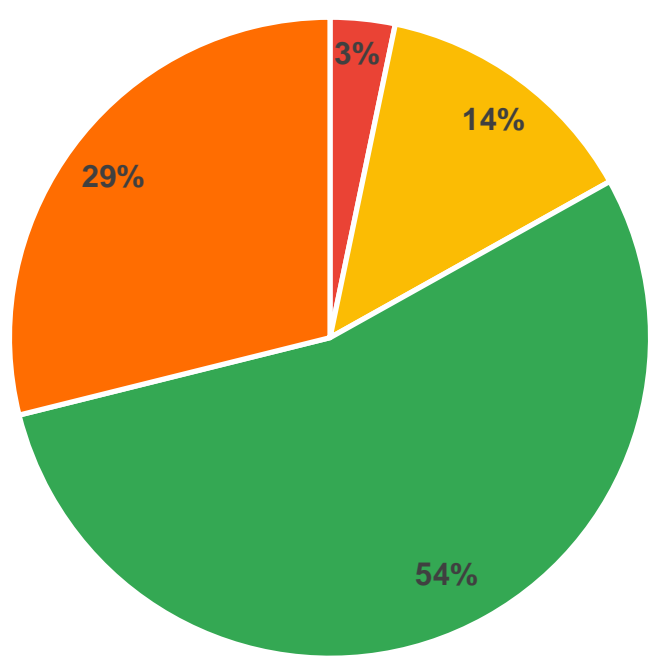

- No Importante

- Poco importante

- A veces importante

- Importante

- Muy importante

Figura 17: Análisis de la pregunta 5 del instrumento cuantitativo.

Fuente: Resultados de investigación elaboración propia 
La figura 18 señala que el $55 \%$ de las personas afirman que es importante la innovación de un producto a la hora de adquirir productos fitness, de igual manera un $25 \%$ lo considera muy importante. Al contrario, solo el $16 \%$ de personas le es indiferentes. Según estos resultados se puede observar que la innovación es de interés para los consumidores, lo cual es importante para mantener la industria activa, debido que al no existir novedades, el mercado se estancaría y no permitiría su crecimiento económico; por ese motivo se promueven todo tipo de productos, aquellos que no tienden a ser más efectivos que los anteriores, sin embargo al ser avalados por la novedad y la emoción del momento pueden conseguir una fama temporal y generar una demanda para fabricar líneas enteras de productos basados en un solo ingrediente novedoso.

P6. La innovación de un producto a la hora de adquirir productos fitness

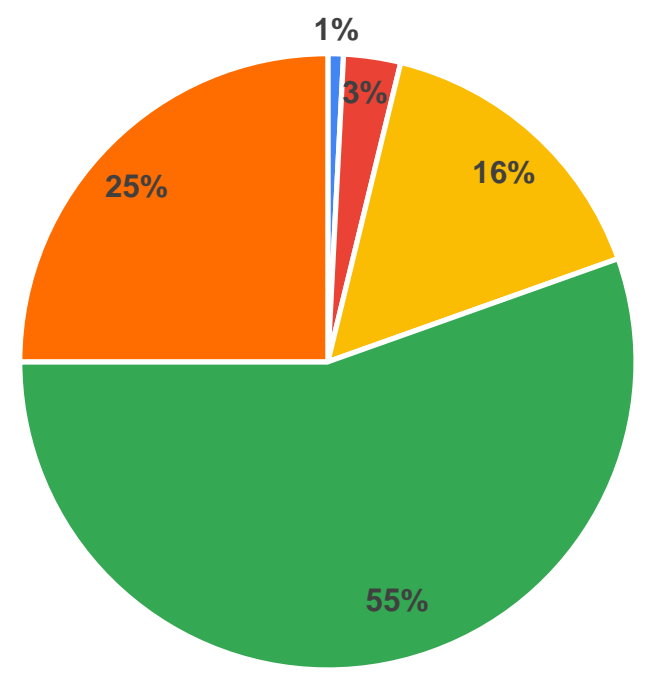

- No Importante

- Poco importante

- A veces importante

- Importante

- Muy importante

Figura 18: Análisis de la pregunta 6 del instrumento cuantitativo.

Fuente: Resultados de investigación elaboración propia 
Para resumir el análisis del objetivo específico 1 hemos diseñado la tabla 11

Tabla 12:

Análisis de resultados del primer objetivo específico.

\begin{tabular}{|c|c|c|}
\hline Problema específico 1 & Hipótesis especifica 1 & Conclusión \\
\hline $\begin{array}{l}\text { ¿La dimensión de la } \\
\text { atracción del marketing } \\
\text { digital influye en la decisión } \\
\text { de compra de productos } \\
\text { fitness en usuarios de } \\
\text { gimnasios de Lima } \\
\text { moderna? }\end{array}$ & $\begin{array}{l}\text { La dimensión de la atracción } \\
\text { del marketing digital influye } \\
\text { en la decisión de compra de } \\
\text { productos fitness en usuarios } \\
\text { de gimnasios de Lima } \\
\text { moderna. }\end{array}$ & $\begin{array}{l}\text { Factores como la marca, el valor } \\
\text { nutricional y el precio son importantes } \\
\text { para los consumidores novatos y } \\
\text { veteranos, a pesar de esto las personas } \\
\text { están abiertas a aceptar } \\
\text { recomendaciones de conocidos y no tan } \\
\text { conocidos a la hora de adquirir productos } \\
\text { fitness, teniendo también un espacio para } \\
\text { aceptar la innovación en esta industria. } \\
\text { Comprobando así apreciaciones del focus } \\
\text { group y de los expertos, los cuales } \\
\text { mencionaron que las personas tenían a } \\
\text { captar la información en línea e } \\
\text { interesarse en adquirir más información } \\
\text { buscando como consecuencia adquirir el } \\
\text { producto a un mejor precio o una versión } \\
\text { con mejores características. }\end{array}$ \\
\hline
\end{tabular}

Fuente: elaboración propia

\subsubsection{Dimensión de Difusión}

Este proceso está enfocado en conseguir la aceptación de un nuevo producto por parte de un mercado específico, su nivel de éxito está relacionado con la velocidad y facilidad en la que una idea se propaga y es aceptada de un comprador a otro gracias en gran medida al mensaje boca a boca.

A continuación, se procedió a analizar los resultados de las preguntas del 7 al 15, que pertenecen a la variable marketing digital dimensión de difusión, siendo éste el objetivo específico 2 que nos ayudaran a determinar si existe influencia de la difusión del marketing digital en la decisión de compra de productos fitness, en usuarios de gimnasios de Lima moderna. 
La figura 19 muestra que el $63 \%$ de consumidores de productos fitness, consideran importante la publicidad de medios digitales a la hora de adquirirlos; de igual manera el $21 \%$ considera muy importante. Por otro lado, el $12 \%$ lo ven indiferente. Estos resultados demuestran que los medios digitales son relevantes a la hora de adquirir productos fitness, específicamente cuando se trata de presentar novedades, nuevas presentaciones y productos especializados, los cuales requieren una plataforma interactiva en donde se puedan presentar ideas más complejas sin incrementar los costos de publicidad.

\section{P7. La publicidad por medios digitales a la hora de adquirir productos fitness}

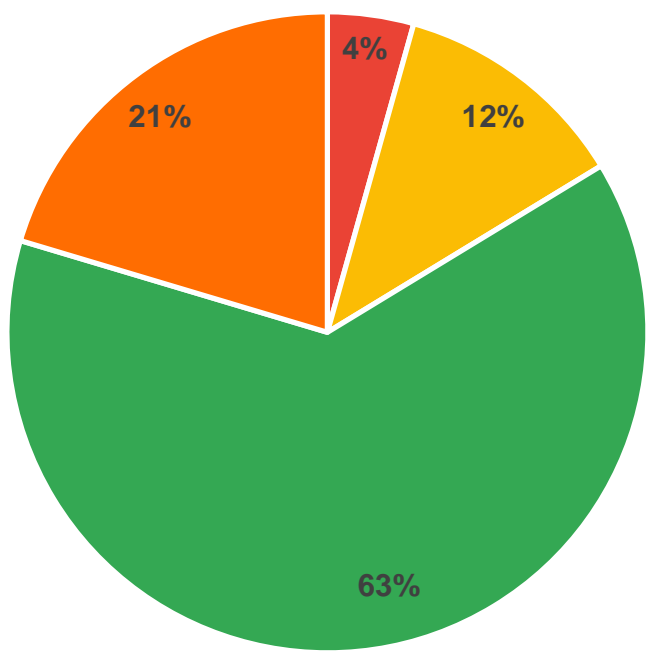

- No Importante

- Poco importante

- A veces importante

- Importante

- Muy importante

Figura 19: Análisis de la pregunta 7 del instrumento cuantitativo.

Fuente: Resultados de investigación elaboración propia 
La figura 20 demuestra que el $48 \%$ de personas consideran importante los descuentos en línea a la hora de adquirir productos fitness y también en gran medida un $35 \%$ muy importante. Estos resultados indican que los descuentos al igual que en cualquier otro tipo de producto, incentivan la compra de productos fitness, sirviendo especialmente como una oportunidad, para que el cliente pruebe un producto que le llame la atención y que al mismo tiempo su precio de entrada, interviene para realizar esta prueba.

\section{P8. Los descuentos en línea a la hora de adquirir productos fitness}

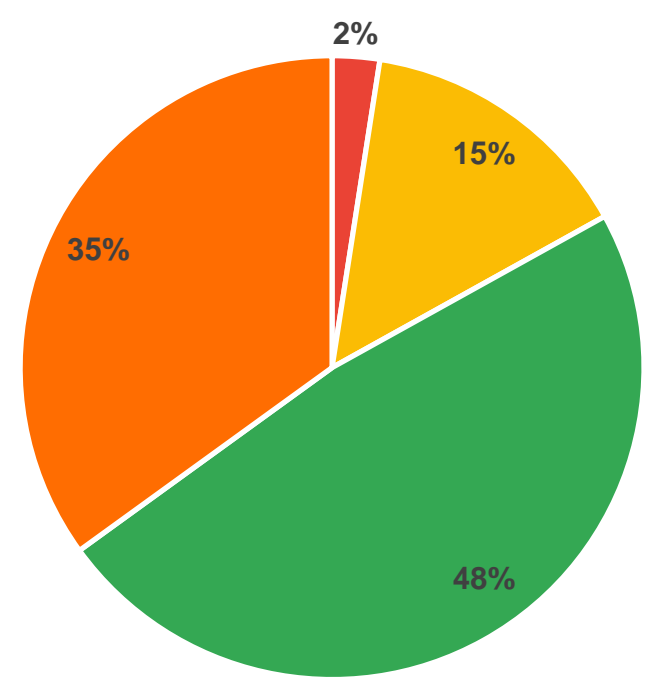

- No Importante

- Poco importante

- A veces importante

- Importante

- Muy importante

Figura 20: Análisis de la pregunta 8 del instrumento cuantitativo.

Fuente: Resultados de investigación elaboración propia 
La figura 21 muestra que el $56 \%$ de personas valoran como importante la recepción de información en línea para realizar compras grandes a la hora de adquirir productos fitness y el 19\% lo considera indiferente. Estos indicadores demuestran que la recepción de data por internet, juega un roll importante en la mentalidad del consumidor, esto debido a que al día de hoy el peruano promedio pasa 80 minutos al día conectado a internet por medio de su teléfono inteligente, y en el caso de la generación millennial, unos 90 minutos según (IMS (Internet Media Services), 2017), lo cual permite al usuario peruano estar expuesto a información en la red y así ser influenciado para cualquier producto, cuya información se encuentre en línea.

\section{P9. Recepción de información en línea para realizar compras grandes a la hora de adquirir productos fitness}

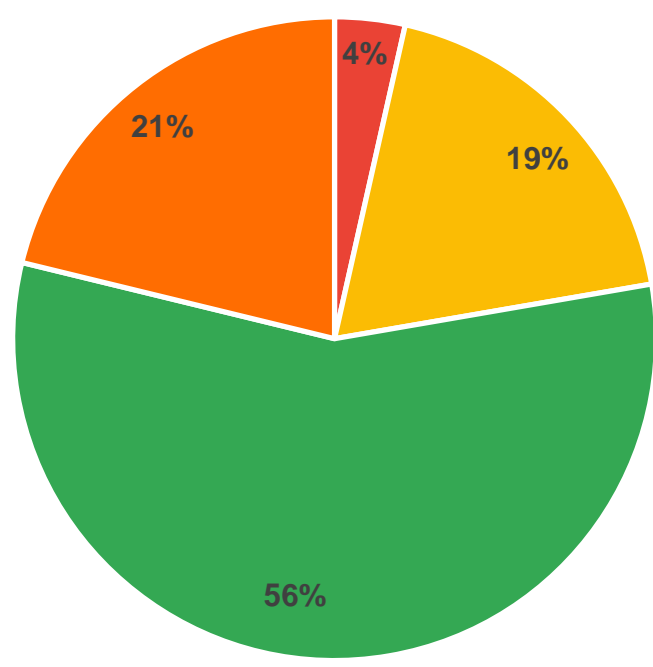

- No Importante

- Poco importante

- A veces importante

- Importante

- Muy importante

Figura 21: Análisis de la pregunta 9 del instrumento cuantitativo.

Fuente: Resultados de investigación elaboración propia 
Se manifiesta en la figura 22 que el $60 \%$ de consumidores afirman que es importante el poder hacer compras por tiendas digitales a la hora de adquirir productos fitness, evitando salir de casa, en cambio solo el $23 \%$ se consideran indiferentes. Esto indica que a pesar que la compra digital es cada vez más aceptada, aún existe cierto escepticismo por parte del consumidor, por ese motivo el porcentaje no es tan grande como lo sería en otros países, en donde la automatización de procesos y servicios ofrecidos por empresas gigantes como Amazon permite comprar literalmente todo sin salir de casa y recibirlo el mismo día.

P10. El poder hacer compras por tiendas digitales a la hora de adquirir productos fitness evitando salir de casa

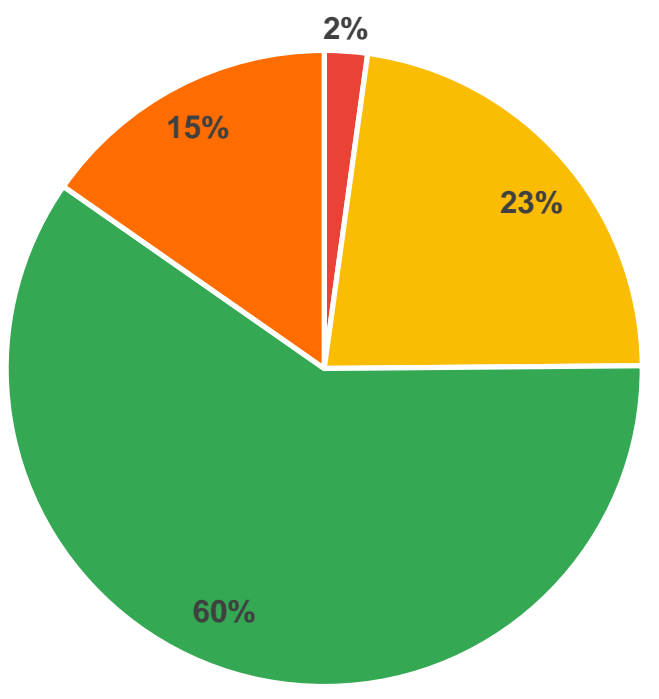

- No Importante

- Poco importante

$\because$ A veces importante

- Importante

- Muy importante

Figura 22: Análisis de la pregunta 10 del instrumento cuantitativo.

Fuente: Resultados de investigación elaboración propia 
La figura 23 señala que el $46 \%$ de personas valoran como importante que las páginas web de los vendedores aparezcan en anuncios destacados del buscador web a la hora de adquirir productos fitness, en cambio el $18 \%$ se considera indiferente. Esto demuestra que un gran porcentaje de consumidores valoran encontrar información en los primeros resultados de búsqueda, los cuales pueden ser influenciados por la respuesta psicológica del usuario que rara vez visita la segunda página de búsqueda; según (Patel, 2017) "el 75\% de usuarios no pasa de la primera página de resultados en Google".

\section{P11. Que las páginas web de los vendedores aparezcan en los anuncios destacados del buscador web a la hora de adquirir productos fitness}

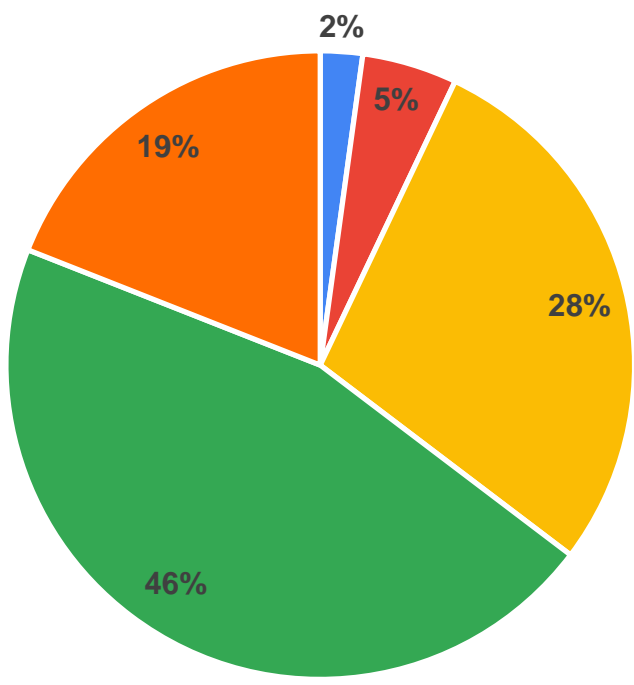

- No Importante

- Poco importante

- A veces importante

- Importante

- Muy importante

Figura 23: Análisis de la pregunta 11 del instrumento cuantitativo.

Fuente: Resultados de investigación elaboración propia 
En la figura 24 los consumidores consideran importante en un $45 \%$ el recibir correos de vendedores con novedades y ofertas a la hora de adquirir producto fitness, en cambio en gran medida el $30 \%$ les es indiferente. Este análisis deja entender que la publicidad por correo electrónico no es el medio más popular entre los encuestados, sin embargo, el margen de indiferencia no llega ni al $45 \%$, lo cual no hace a esta práctica menos efectiva.

\section{P12. Recibir correos de vendedores con novedades y ofertas a la hora de adquirir productos fitness}

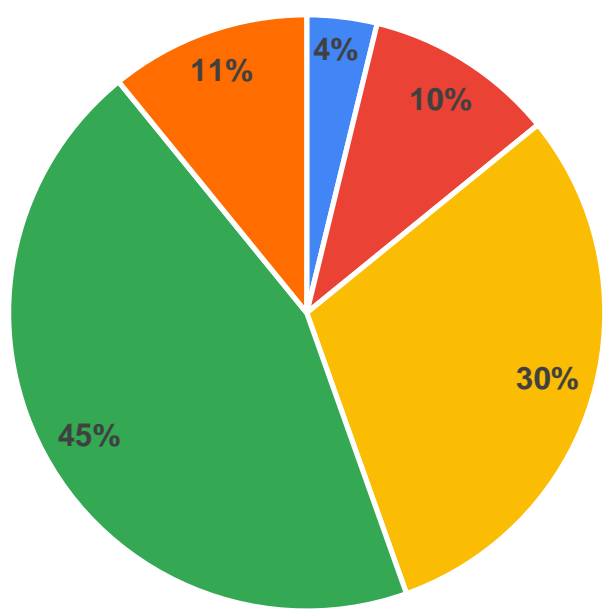

- No Importante

- Poco importante

- A veces importante

- Importante

- Muy importante

Figura 24: Análisis de la pregunta 12 del instrumento cuantitativo.

Fuente: Resultados de investigación elaboración propia 
En la figura 25, el $48 \%$ de personas valoran como importante la publicidad en páginas web ajenas a la del vendedor a la hora de adquirir productos fitness (SEM); en contraste el $21 \%$ es indiferente y solo el $11 \%$ de personas los considera no importante. Esto nos indica que es una técnica aceptable ya que los encuestados marcaron como muy importante e importante en la encuesta, concentrando así más del 50\% de aceptación, motivo por el cual se observa un menor interés en comparación de otras, debido al abuso del anuncio en páginas ajenas que en la actualidad plaga muchos sitios web, como pop apps incomodos y tener que aceptar cookies (Archivos que recolectan información de tu dispositivo con fines de marketing) ya que la gente menos experta no sabe evitar.

P13. La publicidad en páginas web ajenas a la del vendedor a la hora de adquirir productos fitness(SEM)

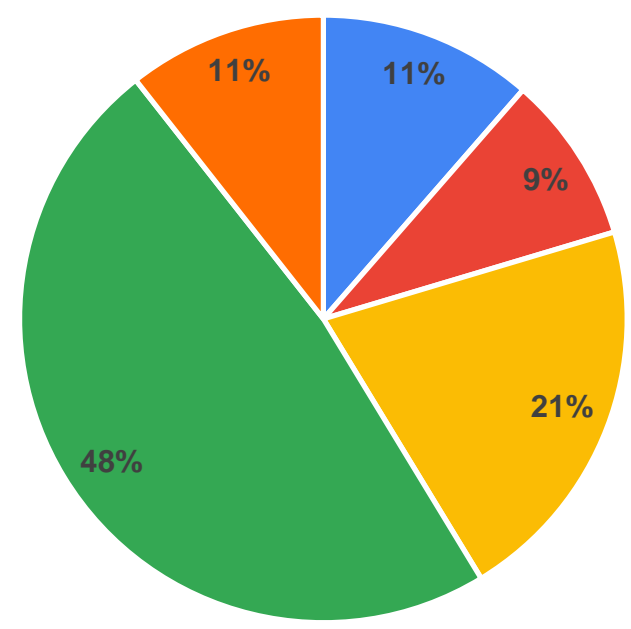

- No Importante

- Poco importante

- A veces importante

- Importante

- Muy importante

Figura 25: Análisis de la pregunta 13 del instrumento cuantitativo.

Fuente: Resultados de investigación elaboración propia 
La figura 26 indica que el $43 \%$ de consumidores de productos fitness consideran importante la opinión de influencers a la hora de adquirir estos tipos de productos, en cambio el $22 \%$ lo consideran no importante. Este análisis muestra que a pesar de la popularidad de los líderes de opinión, estos aún no obtienen la aceptación que tienen en otros países, probablemente debido a la cultura y la generación actual, sin embargo, esto podría cambiar en algunos años ante mayor exposición a los medios digitales y al crecimiento del poder adquisitivo de las siguientes generaciones como la generación $Z$, la cual ya más familiarizada con el manejo de redes sociales podría aceptar más fácilmente la importancia de los influencers.

\section{P14. La opinión de influencers a la hora de adquirir productos fitness}

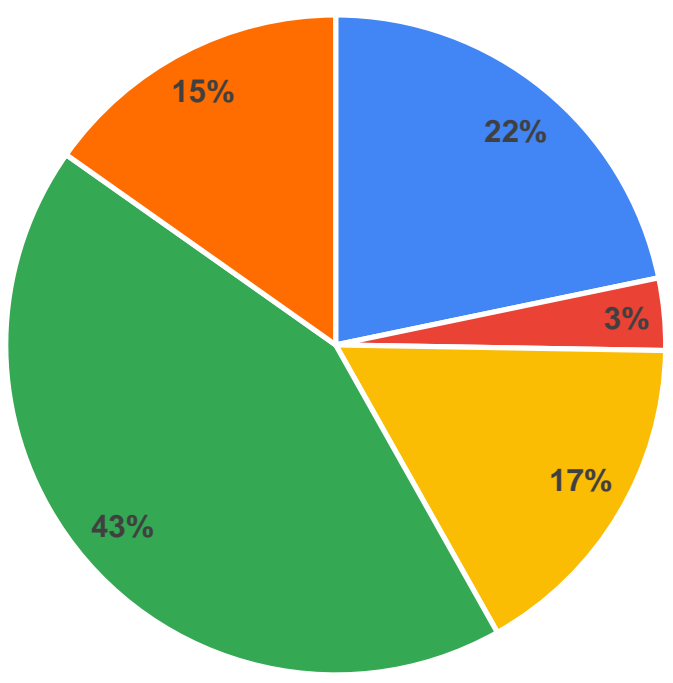

- No Importante

- Poco importante

- A veces importante

- Importante

- Muy importante

Figura 26: Análisis de la pregunta 14 del instrumento cuantitativo.

Fuente: Resultados de investigación elaboración propia 
En la figura 27, el $37 \%$ de personas valoran como importante que las marcas fitness patrocinen a los influencers preferidos a la hora de adquirir productos fitness, por el contrario, el $23 \%$ lo considera no importante y solo el $20 \%$ de personas les es indiferente. Según estos resultados indican que, siguiendo el análisis de la afirmación anterior, sí las personas no tienen un concepto tan relevante sobre los líderes de opinión al momento, aunque sean patrocinados, no traerán más atención que con su contenido normal.

\section{P15. Las marcas fitness patrocinen a mis influencers favoritos a la hora de adquirir productos fitness}

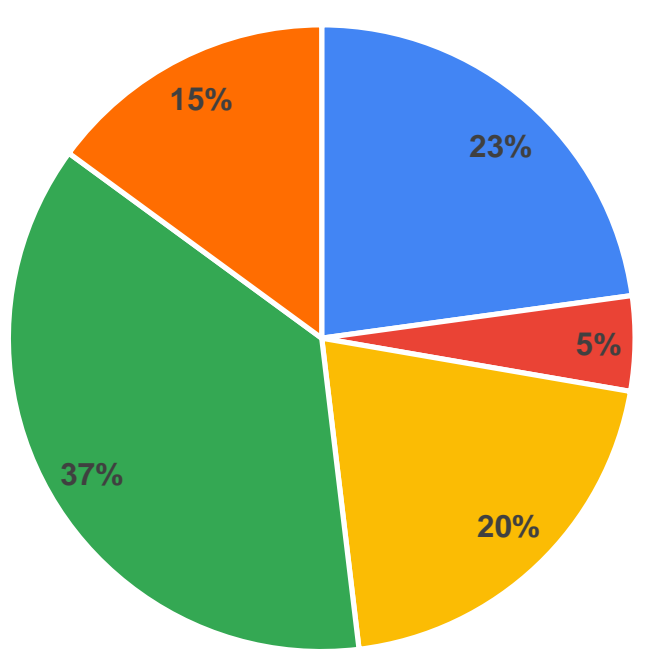

- No Importante

- Poco importante

- A veces importante

- Importante

- Muy importante

Figura 27: Análisis de la pregunta 15 del instrumento cuantitativo.

Fuente: Resultados de investigación elaboración propia 
Para resumir el análisis del objetivo específico 2 hemos diseñado la tabla 12:

Tabla 13:

Análisis de resultados del segundo objetivo específico.

\begin{tabular}{|c|c|c|}
\hline Problema específico 2 & Hipótesis especifica 2 & Conclusión \\
\hline $\begin{array}{l}\text { ¿La dimensión de la } \\
\text { difusión del marketing } \\
\text { digital influye en la decisión } \\
\text { de compra de productos } \\
\text { fitness en usuarios de } \\
\text { gimnasios de Lima } \\
\text { moderna? }\end{array}$ & $\begin{array}{l}\text { La dimensión de la difusión } \\
\text { del marketing digital influye } \\
\text { en la decisión de compra de } \\
\text { productos fitness en usuarios } \\
\text { de gimnasios de Lima } \\
\text { moderna. }\end{array}$ & $\begin{array}{l}\text { La difusión es una práctica de marketing } \\
\text { digital moderna que ofrece muchas } \\
\text { facilidades, sin embargo, no ha sido aún } \\
\text { aceptada por el consumidor peruano, } \\
\text { aunque solo es cuestión de tiempo que se } \\
\text { adapten a estas estrategias de marketing, } \\
\text { las cuales, si son bien percibidas en otros } \\
\text { países, en especial si consideramos que } \\
\text { el uso de influencers en el Perú apenas } \\
\text { está comenzando. } \\
\text { Todo esto confirma lo hablado en el focus } \\
\text { froup, en donde se mencionó que la } \\
\text { adaptación de la tecnología y el consumo } \\
\text { tiene aún sus barreras, en especial la } \\
\text { confianza que se tiene con las } \\
\text { plataformas digitales relativamente } \\
\text { nuevas pero que sin duda alguna } \\
\text { seguirán implementando incentivos y } \\
\text { facilidades que harán que su uso se } \\
\text { normalice cada vez más. }\end{array}$ \\
\hline
\end{tabular}

Fuente: elaboración propia

\subsubsection{Dimensión de Retención}

La retención de clientes es un fin que buscan las empresas enfocadas en mantener una participación del mercado, lo cual está directamente relacionado a las ganancias obtenidas en la empresa ya que un cliente fidelizado es más propenso a consumir productos de manera continua y al mismo tiempo es más abierto a la posibilidad de adquirir versiones más caras y nuevos paquetes que no son aceptados por el comprador promedio. 
A continuación, se procederá a analizar los resultados de las preguntas 16 al 22 que pertenecen a la variable marketing digital dimensión de retención, siendo éste el objetivo específico 3, que ayudará a determinar si existe influencia de la retención del marketing digital en la decisión de compra de productos fitness en usuarios de gimnasios de Lima moderna.

En la figura 28 se observa que el $64 \%$ de personas valoran como importante, la reputación de los proveedores a la hora de adquirir productos fitness en línea, de la misma manera el $25 \%$ lo considera muy importante. Los resultados permiten afirmar que los sistemas de calificación de las diferentes plataformas de venta, sirven para asegurar una mejor experiencia de compra y venta en especial cuando se trata de comercializar con desconocidos.

P16. La reputación de los proveedores de productos fitness a la hora de adquirir productos fitness en línea

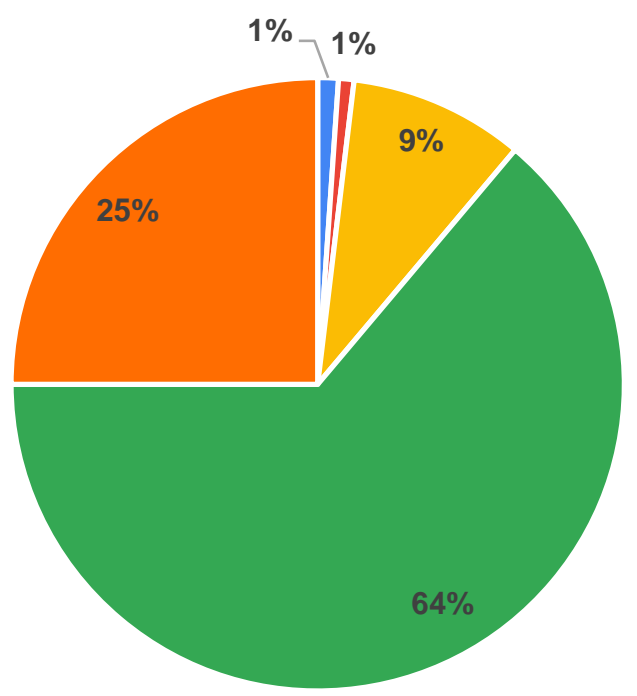

- No Importante

- Poco importante

- A veces importante

- Importante

- Muy importante

Figura 28: Análisis de la pregunta 16 del instrumento cuantitativo.

Fuente: Resultados de investigación elaboración propia 
La figura 29 indica que el $50 \%$ de consumidores de productos fitness, consideran importante que los proveedores sean oficiales, ya que les generarán confianza que el producto recibido no será adulterado de ninguna manera, también en gran medida el 34\% lo considera muy importante. Según estos resultados se concluye que las personas consideran que los proveedores oficiales pueden ofrecer la garantía que sus productos no serán adulterados de alguna manera, lo cual considerando que como se trata de productos de consumo, podrían generar serios problemas a la salud en caso se trate de falsificaciones.

P17. Los proveedores oficiales me generan confianza que el producto recibido no será adulterado de ninguna manera

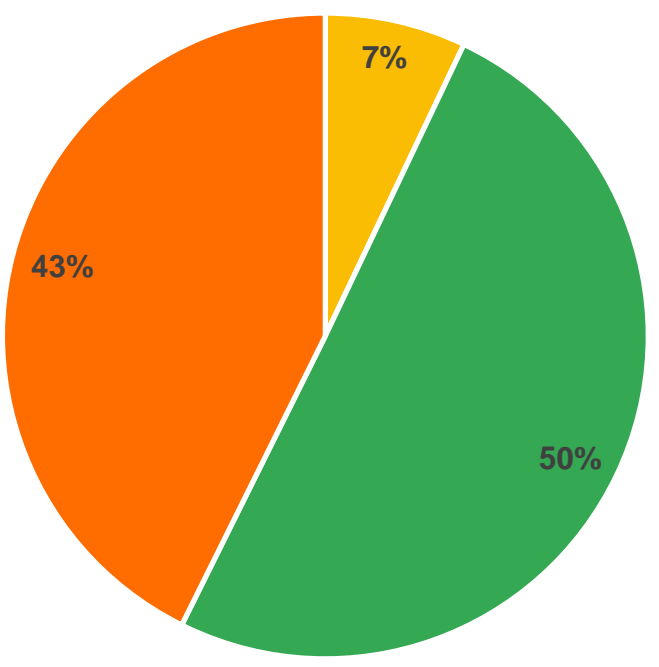

- No Importante

- Poco importante

- A veces importante

- Importante

- Muy importante

Figura 29: Análisis de la pregunta 17 del instrumento cuantitativo.

Fuente: Resultados de investigación elaboración propia 
Se manifiesta en la figura 30 , que el $53 \%$ de personas consideran importante la facilidad de distribución del vendedor a la hora de adquirir productos fitness en línea, y el 32\% muy importante. Estos datos indican que las personas buscan que sus productos comprados en línea lleguen rápidamente a sus hogares para poder disfrutarlos, ya que es costumbre que al ir a una tienda y adquirir el producto, éste se comience a usarlo, algo que no se puede realizar con una tienda virtual, excepto en países como EEUU donde gigantes de la industria como Amazon ofrecen entrega el mismo día de compra.

\section{P18. La facilidad de distribución del vendedor a la hora de adquirir productos fitness en línea}

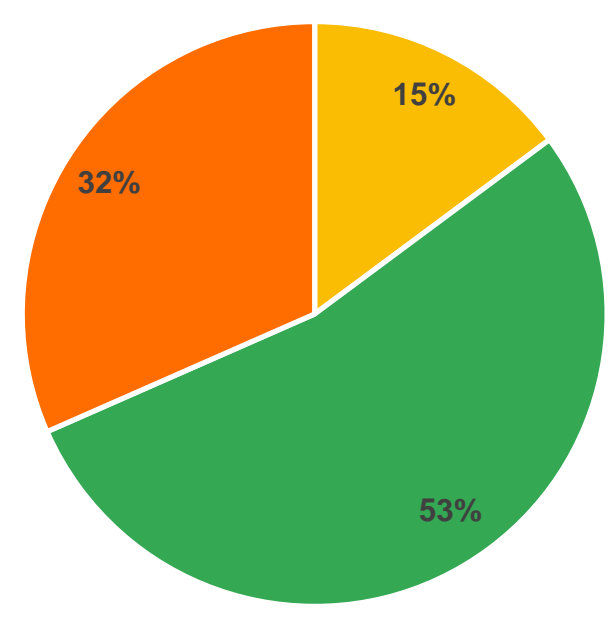

- No Importante

- Poco importante

- A veces importante

- Importante

- Muy importante

Figura 30: Análisis de la pregunta 18 del instrumento cuantitativo.

Fuente: Resultados de investigación elaboración propia 
Se aprecia en la figura 31 que las personas consideran importante en un $58 \%$ la experiencia positiva del producto fitness a la hora de volver a adquirir otro producto similar 0 igual en un futuro no muy lejano, de igual manera lo valoran como muy importante en un $33 \%$. Este análisis revela que una experiencia positiva mantendrá a los consumidores más inclinados a repetirla.

P19. La experiencia positiva del producto fitness a la hora de volver a adquirir otro producto similar o igual en un futuro no muy lejano

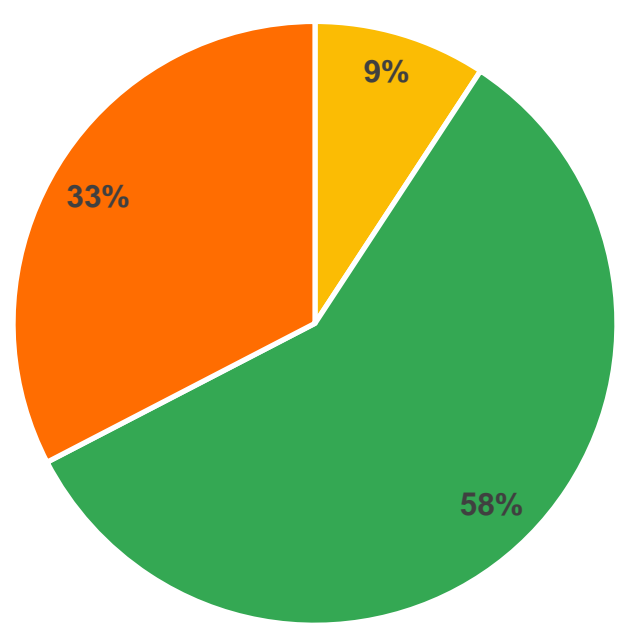

- No Importante

- Poco importante

$\llbracket$ A veces importante

- Importante

- Muy importante

Figura 31: Análisis de la pregunta 19 del instrumento cuantitativo.

Fuente: Resultados de investigación elaboración propia 
En la figura 32 indica que el $48 \%$ de consumidores de productos fitness consideran muy importante realizar compras con un vendedor de confianza, así mismo un $43 \%$ lo considera importante. Esto afirma que, una vez generado un vínculo de confianza con un vendedor, la gran mayoría prefiere volver hacer negocio con la misma persona que aventurarse a buscar un nuevo proveedor y arriesgarse a tener una mala experiencia.

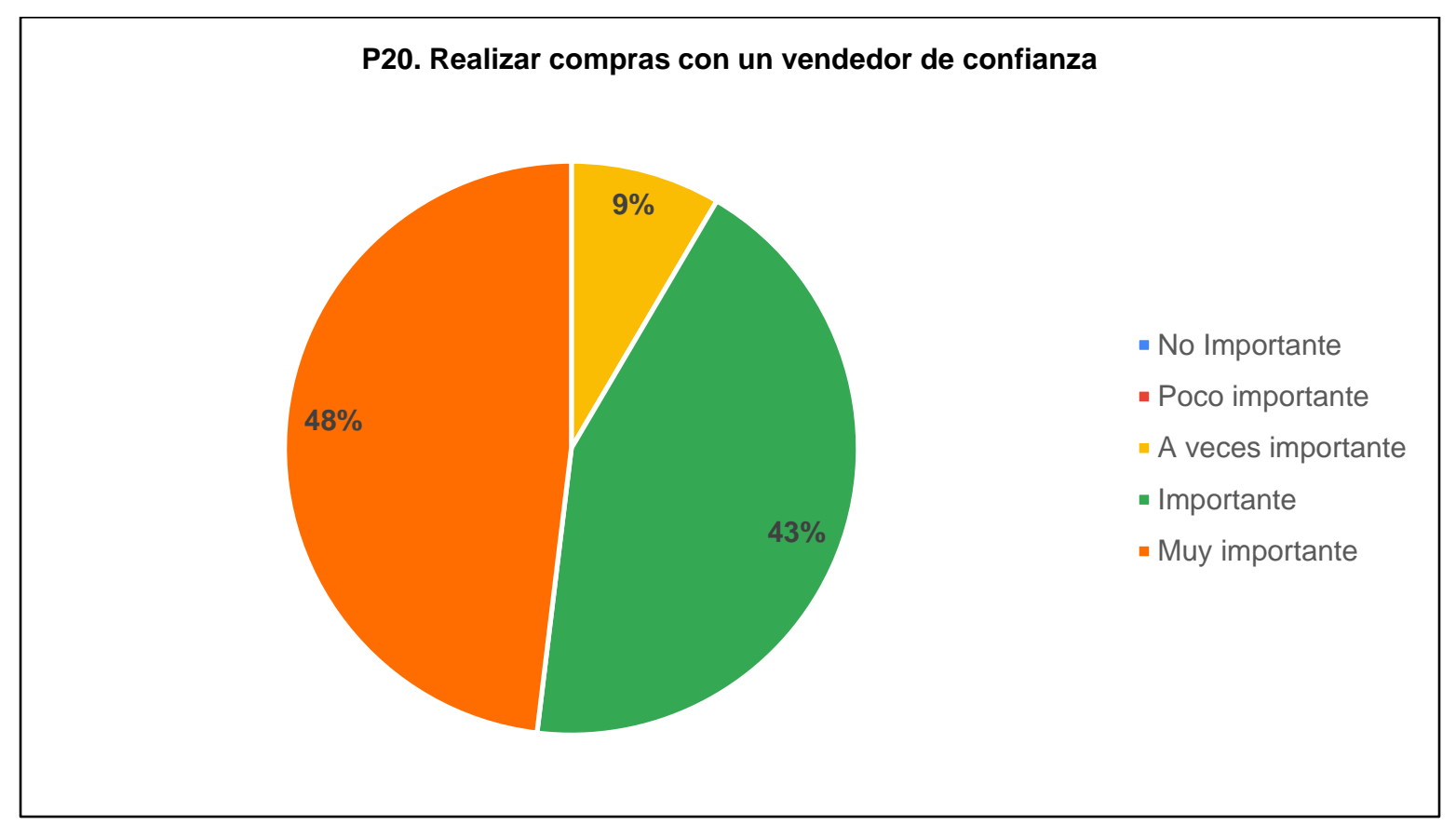

Figura 32: Análisis de la pregunta 20 del instrumento cuantitativo.

Fuente: Resultados de investigación elaboración propia 
En la figura 33 el $46 \%$ de personas consideran importante el asesoramiento personalizado en línea del vendedor a la hora de adquirir productos fitness; el 24\% lo considera muy importante y por el contrario el $18 \%$ es indiferente. Esto demuestra que, a diferencia del resto de afirmaciones del cuestionario, aquí se tiene un $10 \%$ que no considera importante mantenerse comunicado en línea con el vendedor, ya que hay personas que prefieren ir por un producto ya definido y no recibir otras sugerencias que podrían ir en contra de sus presupuestos o ideología de consumo.

\section{P21. El asesoramiento personalizado en línea del vendedor a la hora de adquirir productos fitness}

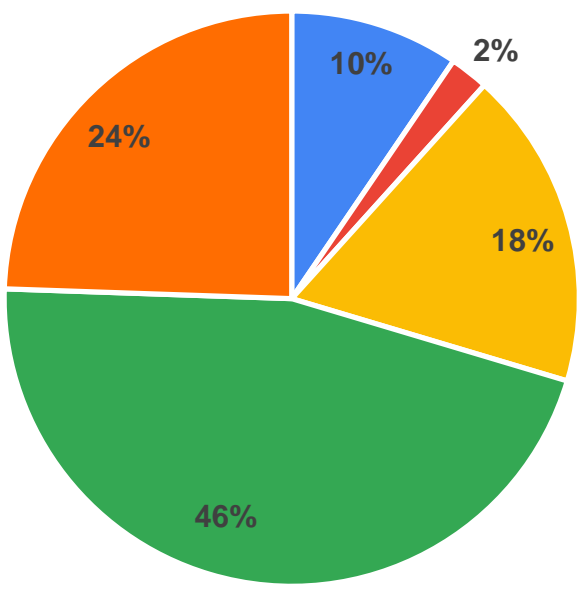

- No Importante

- Poco importante

- A veces importante

- Importante

- Muy importante

Figura 33: Análisis de la pregunta 21 del instrumento cuantitativo.

Fuente: Resultados de investigación elaboración propia 
La figura 34 indica que el $53 \%$ de consumidores de productos fitness consideran importante la comunicación post compra en línea con el vendedor, así mismo un $24 \%$ lo considera muy importante y solo el $10 \%$ les es indiferente. Este análisis demuestra que un gran porcentaje de personas están interesadas en tener una retroalimentación con el vendedor para saber si están consumiendo correctamente sus productos o como potenciar sus resultados una vez realizada la compra.

\section{P22. La comunicación post compra en línea con el vendedor a la hora de adquirir productos fitness}

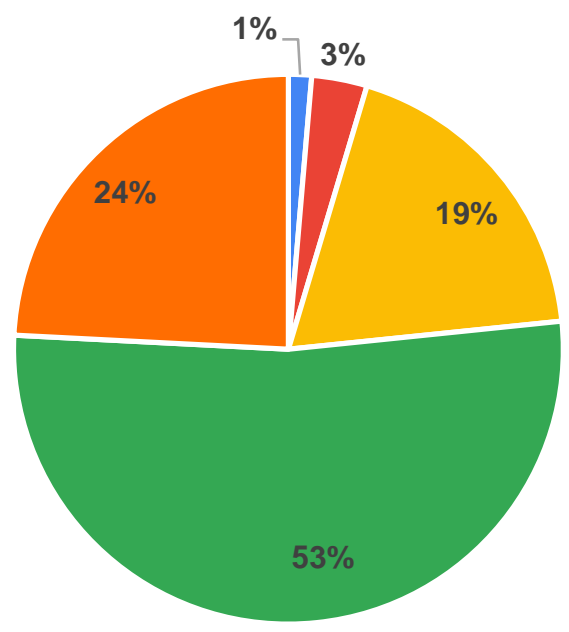

- No Importante

- Poco importante

- A veces importante

- Importante

- Muy importante

Figura 34: Análisis de la pregunta 22 del instrumento cuantitativo.

Fuente: Resultados de investigación elaboración propia 
Para resumir el análisis del objetivo específico 3, hemos diseñado la tabla 13:

Tabla 14:

Análisis de resultados del tercer objetivo específico.

\begin{tabular}{|c|c|c|}
\hline Problema específico 3 & Hipótesis especifica 3 & Iusión \\
\hline $\begin{array}{l}\text { ¿La dimensión de la } \\
\text { retención del marketing } \\
\text { digital influye en la decisión } \\
\text { de compra de productos } \\
\text { fitness en usuarios de } \\
\text { gimnasios de Lima } \\
\text { moderna? }\end{array}$ & $\begin{array}{l}\text { La dimensión de la retención } \\
\text { del marketing digital influye } \\
\text { en la decisión de compra de } \\
\text { productos fitness en usuarios } \\
\text { de gimnasios de Lima } \\
\text { moderna. }\end{array}$ & $\begin{array}{l}\text { Las personas son más propensas a } \\
\text { permanecer en el mundo fitness una vez } \\
\text { iniciadas, ya sea por factores como la } \\
\text { facilidad de comunicación, la confianza y } \\
\text { la retroalimentación que ofrecen algunos } \\
\text { proveedores, lo cual les permite alcanzar } \\
\text { sus objetivos y metas trazadas más } \\
\text { rápidamente. } \\
\text { Esto fue mencionado en las entrevistas a } \\
\text { expertos, en donde consideraban que la } \\
\text { retención de clientes es posible al } \\
\text { diferenciarse de la competencia a través } \\
\text { de la oferta de servicios personalizados } \\
\text { de asesoramiento. }\end{array}$ \\
\hline
\end{tabular}

Fuente: elaboración propia

A continuación, se procede analizar las afirmaciones realizadas a la variable dependiente de decisión de compra, las cual es un proceso que tiene como resultado la toma de decisión final relacionada a la adquisición de un producto o servicio. 


\subsubsection{Frecuencia de compra}

Esta es la cantidad de productos adquiridos durante los días transcurridos entre una compra y otra, la cual arroja un promedio que se utiliza para determinar la frecuencia de compra como un valor medible.

En la figura 35 , el $49 \%$ de personas se identifican con respecto al consumo de productos fitness más de una vez a la semana, y el $39 \%$ se identifican en gran medida. Estos resultados afirman que el consumo mínimo de estos productos fitness supera a más de una ocasión por semana, transformándose en un hábito indispensable para el consumidor fitness.

P23. Consumo productos fitness más de una vez a la semana

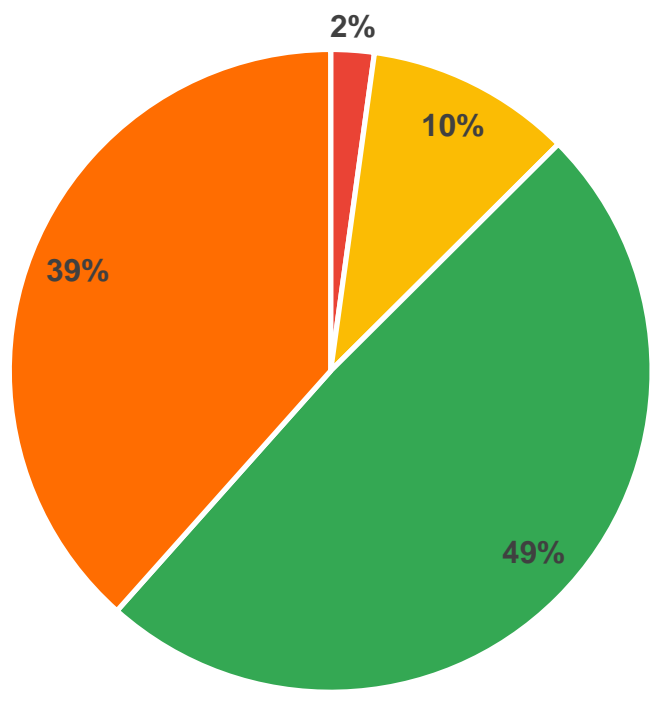

- No me identifico

- Me identifico Poco

$\because$ A veces me identifico

- Me identifico

- Me identifico en gran medida

Figura 35: Análisis de la pregunta 23 del instrumento cuantitativo.

Fuente: Resultados de investigación elaboración propia 
En la figura 36, el $40 \%$ identifican en gran medida que compran productos fitness más de una vez cada tres meses o al menos una vez cada tres meses; y el $36 \%$ solamente se sienten identificados, en cambio el $20 \%$ se consideran indiferentes. Estos indicadores demuestran que la compra mínima de estos productos, para los distintos objetivos personales de los consumidores, supera a una ocasión cada 3 meses, lo cual es consecuente con la pregunta anterior, debido a que un producto fitness puede durar más de 3 meses; sin embargo, consumirlo seguido requiere un reabastecimiento más continuo.

P24. Compro productos fitness más de una vez cada tres meses o al menos una vez cada tres meses

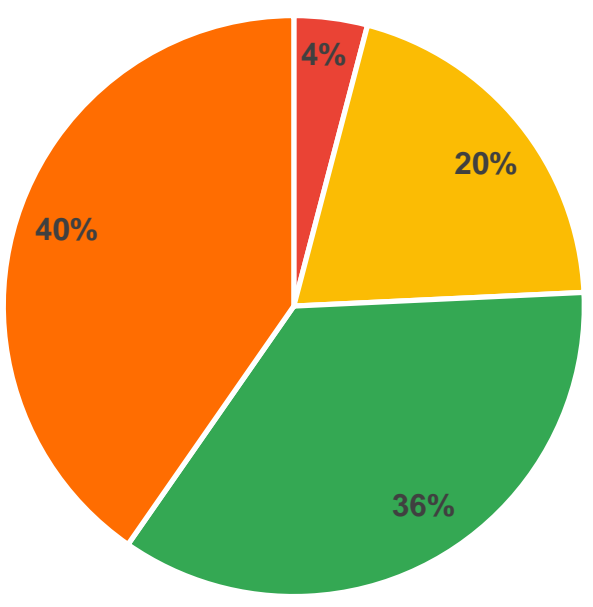

- No me identifico

- Me identifico Poco

- A veces me identifico

- Me identifico

- Me identifico en gran medida

Figura 36: Análisis de la pregunta 24 del instrumento cuantitativo.

Fuente: Resultados de investigación elaboración propia 
En la figura 37 se indica que el $42 \%$ de las personas se identifican en comprar varios productos en conjunto, para evitar el desabastecimiento de sus productos fitness; así mismo el $34 \%$ de personas se identifican en gran medida, y finalmente solo el $18 \%$ le es indiferente. Según los resultados se analiza que la compra masiva es un elemento importante para los consumidores ya que evita el desabasteciendo.

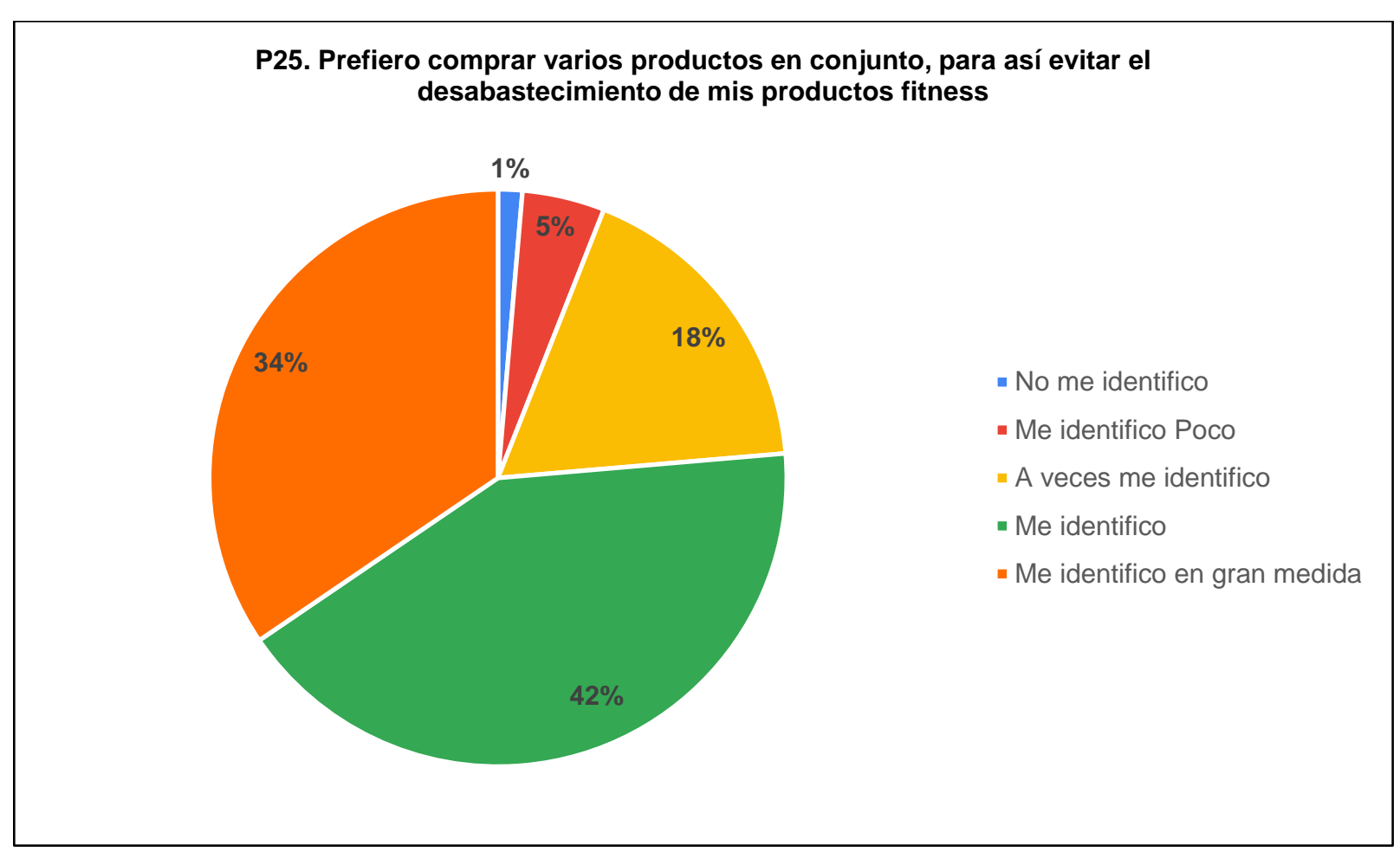

Figura 37: Análisis de la pregunta 25 del instrumento cuantitativo.

Fuente: Resultados de investigación elaboración propia 
En la figura 38 se aprecia que el $58 \%$ de los encuestados se identifican con el asesoramiento personalizado, lo cual les incentiva a adquirir con mayor frecuencia productos fitness, por otro lado, el $15 \%$ lo considera indiferente. Esto revela que, al incluir un servicio extra por parte de los vendedores, incentiva a los consumidores a poder volver a repetir la compra.

P26. El asesoramiento personalizado me incentiva a adquirir con mayor frecuencia productos fitness

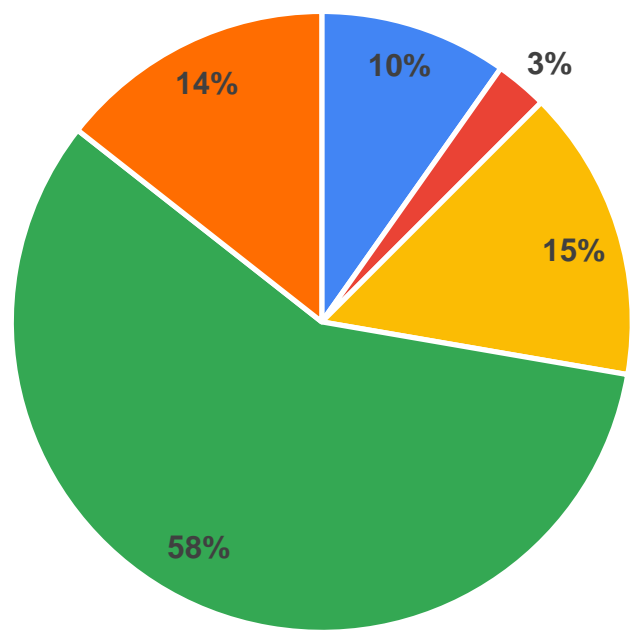

- No me identifico

- Me identifico Poco

- A veces me identifico

- Me identifico

- Me identifico en gran medida

Figura 38: Análisis de la pregunta 26 del instrumento cuantitativo.

Fuente: Resultados de investigación elaboración propia 
La figura 39 indica que el $49 \%$ de personas se identifican en intentar llevar un estilo de vida fitness, por ello consideran importante consumir productos fitness y el $41 \%$ se identifican en gran medida. Según estos resultados se concluye que los consumidores al llevar un estilo de vida diferente, optan a adquirir estos productos fitness suficiente para lograr sus objetivos personales en el día a día como un esfuerzo continuo.

P27. Estoy intentando llevar un estilo de vida fitness por ello considero importante, consumir productos fitness en mi día a día

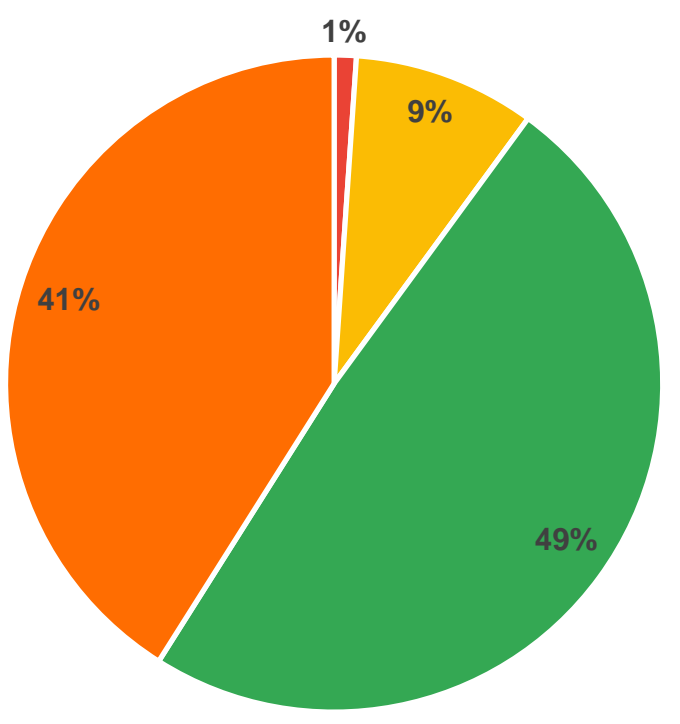

- No me identifico

- Me identifico Poco

- A veces me identifico

- Me identifico

- Me identifico en gran medida

Figura 39: Análisis de la pregunta 27 del instrumento cuantitativo.

Fuente: Resultados de investigación elaboración propia 
Se procede a analizar las afirmaciones realizadas a la variable dependiente de motivación de compra, esta variable tiene en consideración que la motivación es un estímulo que empuja al comprador a actuar de una manera concreta, basado en un conjunto de múltiples factores enfocados a la activación de una conducta de consumo para satisfacer una necesidad de la cual el comprador no es siempre consciente.

\subsubsection{Motivación de compra}

Se analiza en la figura 40 , que el $50 \%$ de personas identifican que la salud es el motivo por el cual consumen productos fitness y un $37 \%$ se identifican en gran medida. Esto indica que los consumidores consideran que su salud es muy importante como motivación para consumir estos productos, ya que la preservación de la salud es obtenible a través de hábitos saludables y el consumo de productos sanos.

P28. Mi salud es el motivo por el cual consumo productos fitness

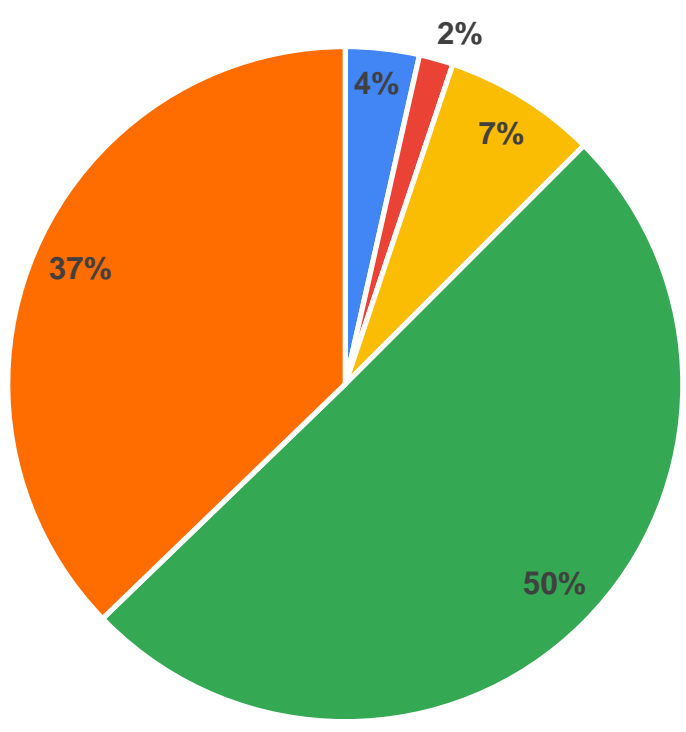

- No me identifico

- Me identifico Poco

- A veces me identifico

- Me identifico

- Me identifico en gran medida

Figura 40: Análisis de la pregunta 28 del instrumento cuantitativo.

Fuente: Resultados de investigación elaboración propia 
En la figura 41, el $42 \%$ de personas identifican en gran medida que el bajar de peso consideran es un gran factor por el cual consumen productos fitness, sin embargo, solo el $24 \%$ no se identifican con esta afirmación. Este análisis manifiesta que reducir o bajar de peso es un elemento primordial por el cual intentan llevar un estilo de vida fitness, ya que el indicador más básico de salud es el peso, sin embargo, éste puede ser muy subjetivo al error, para evaluar la salud o bienestar de un individuo; por ese motivo expertos recomiendan buscar la medición del IMC (índice de masa muscular) como factor más relevante en la búsqueda de una mejora de salud y de enriquecimiento estético.

P29. Bajar de peso es un gran factor por el cual consumo productos fitness

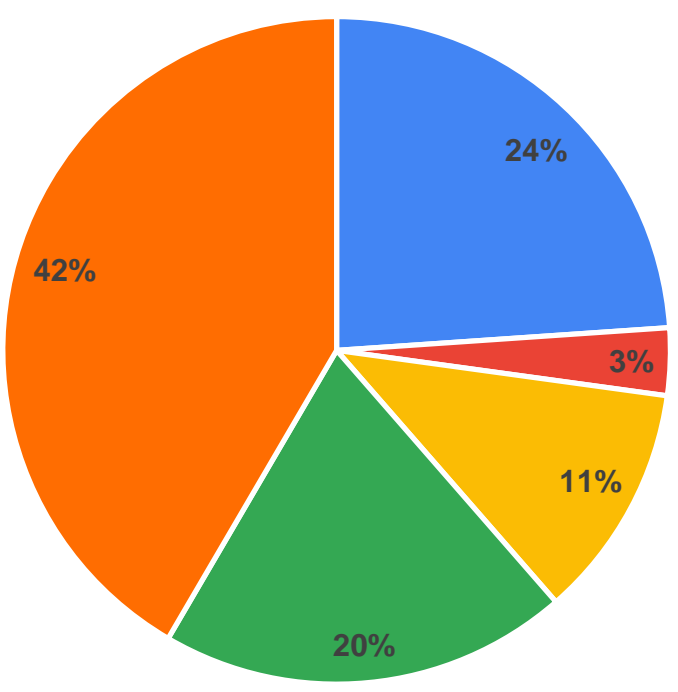

- No me identifico

- Me identifico Poco

- A veces me identifico

- Me identifico

- Me identifico en gran medida

Figura 41: Análisis de la pregunta 29 del instrumento cuantitativo.

Fuente: Resultados de investigación elaboración propia 
Se analiza en la figura 42, que el $32 \%$ de personas se identifican en gran medida al considerar que aumentar la masa muscular es una motivación por la cual consumen productos fitness, de la misma manera un $25 \%$ solo se identifican. Por otra parte, el $21 \%$ no se identifican para nada. Estos resultados exponen que aumentar la masa muscular es una motivación importante para los consumidores, pero a la vez existe gran cantidad de personas que no lo consideran tan primordial, debido a que los usuarios más inexpertos piensan que el crecimiento de masa muscular es solo para hombres, o que éste solo puede ser conseguido con el uso de anabólicos.

P30. Aumentar masa muscular es una motivación por el cual consumo productos fitness

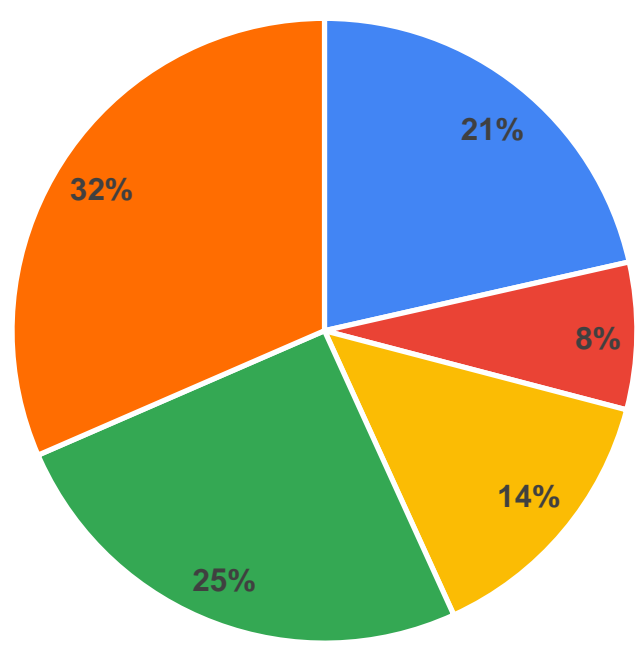

- No me identifico

- Me identifico Poco

- A veces me identifico

- Me identifico

- Me identifico en gran medida

Figura 42: Análisis de la pregunta 30 del instrumento cuantitativo.

Fuente: Resultados de investigación elaboración propia 
Se observa en la figura 43 , que el $34 \%$ de personas se sienten identificadas en aumentar su resistencia motivo por el cual consumen productos fitness, en cambio el $26 \%$ le es indiferente. Estos indicadores demuestran que no solo bajar de peso o aumentar masa muscular son las motivaciones principales por el cual consumir productos fitness sino también se considera importante tener un excelente rendimiento físico para dominar cualquier deporte.

\section{P31. Aumentar mi resistencia es el motivo por el cual consumo productos fitness}

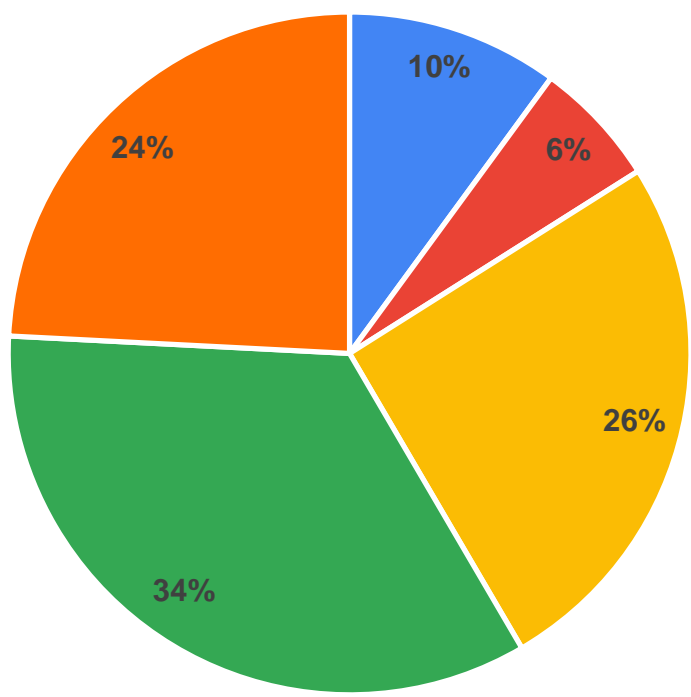

- No me identifico

- Me identifico Poco

- A veces me identifico

- Me identifico

- Me identifico en gran medida

Figura 43: Análisis de la pregunta 31 del instrumento cuantitativo.

Fuente: Resultados de investigación elaboración propia 
La figura 44 señala que el $37 \%$ de las personas se identifican en conseguir resultados más rápidos como una gran motivación por la cual consumen productos fitness y un $34 \%$ se identifican en gran medida. Según estos resultados se observa que los consumidores optan usar productos fitness debido a que desean poder acelerar sus objetivos personales de manera más rápida y eficiente.

P32. Conseguir resultados más rápidos es una gran motivación por el cual consumo productos fitness

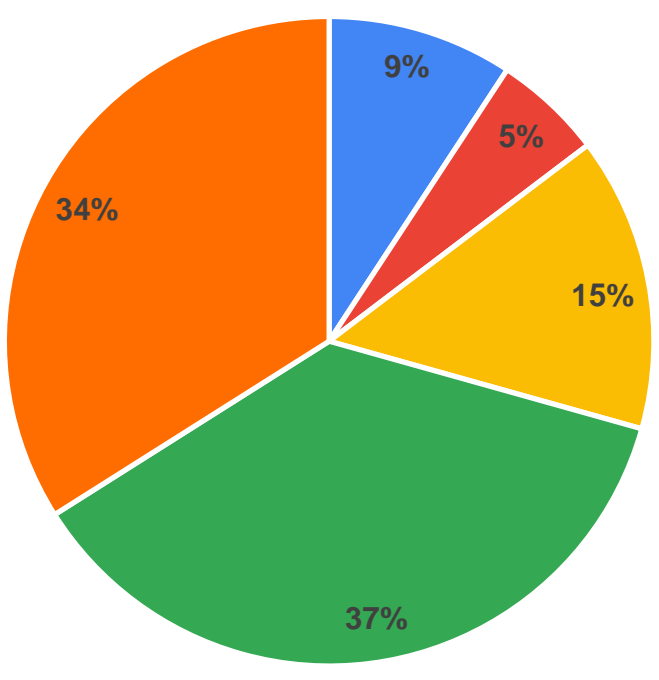

- No me identifico

- Me identifico Poco

- A veces me identifico

- Me identifico

- Me identifico en gran medida

Figura 44: Análisis de la pregunta 32 del instrumento cuantitativo.

Fuente: Resultados de investigación elaboración propia 
En la figura 45, el 44\% de personas se identifican con el asesoramiento personalizado, que los incentiva a comprar productos fitness incluso aquellos que no han consumido con anterioridad, de igual manera el $20 \%$ se identifica en gran medida. Por otra parte, el $19 \%$ son indiferentes. Este análisis demuestra que el asesoramiento personalizado es un incentivo que puede motivar a las personas a comprar productos no antes consumidos, sin generar incertidumbre ya que el asesoramiento los guiará de manera adecuada hacia los productos que aportaran mayores resultados, según el tipo de usuario.

P33. El asesoramiento personalizado en línea me incentiva a comprar productos fitness incluso aquellos que no he consumido con anterioridad

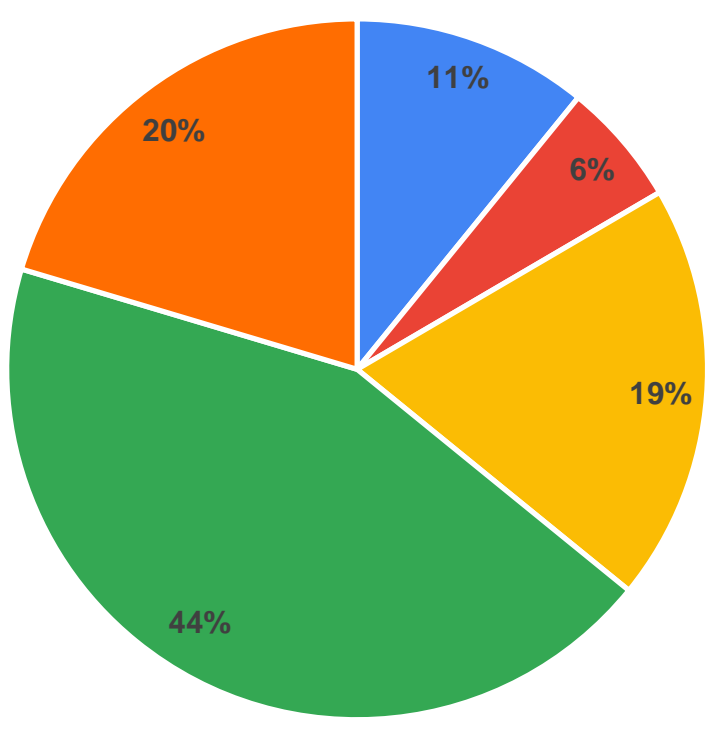

- No me identifico

- Me identifico Poco

- A veces me identifico

- Me identifico

- Me identifico en gran medida

Figura 45: Análisis de la pregunta 33 del instrumento cuantitativo.

Fuente: Resultados de investigación elaboración propia 


\subsubsection{Análisis de tablas de contingencia del estudio cuantitativo}

En esta sección se procedió a analizar la variable dependiente y la independiente a través de tablas de contingencia para poder así observar la relación entre estas variables y así poder comprobar nuestra hipótesis principal y las hipótesis de los objetivos específicos.

Tabla 15:

Tabla cruzada 1 Marketing digital * Decisión de compra.

\begin{tabular}{|c|c|c|c|c|c|c|c|}
\hline & & & \multicolumn{4}{|c|}{ Decisión de compra } & \multirow[b]{2}{*}{ Total } \\
\hline & & & $\begin{array}{c}\text { Poco } \\
\text { influyente }\end{array}$ & $\begin{array}{l}\text { A veces } \\
\text { influyente }\end{array}$ & $\begin{array}{c}\text { Influyent } \\
\mathrm{e}\end{array}$ & $\begin{array}{c}\text { Muy } \\
\text { influyente }\end{array}$ & \\
\hline \multirow{6}{*}{$\begin{array}{l}\text { Marketing } \\
\text { digital }\end{array}$} & A veces & Recuento & 0 & 24 & 15 & 0 & 39 \\
\hline & influyente & $\%$ del total & $0.0 \%$ & $6.5 \%$ & $4.1 \%$ & $0.0 \%$ & $10.6 \%$ \\
\hline & \multirow{2}{*}{ Influyente } & Recuento & 2 & 48 & 269 & 5 & 324 \\
\hline & & $\%$ del total & $0.5 \%$ & $13.0 \%$ & $73.1 \%$ & $1.4 \%$ & $88.0 \%$ \\
\hline & \multirow{2}{*}{ Muy influyente } & Recuento & 0 & 0 & 5 & 0 & 5 \\
\hline & & $\%$ del total & $0.0 \%$ & $0.0 \%$ & $1.4 \%$ & $0.0 \%$ & $1.4 \%$ \\
\hline \multirow{2}{*}{ Total } & & Recuento & 2 & 72 & 289 & 5 & 368 \\
\hline & & $\%$ del total & $0.5 \%$ & $19.6 \%$ & $78.5 \%$ & $1.4 \%$ & $100.0 \%$ \\
\hline
\end{tabular}

Fuente: Resultados obtenidos de la investigación

En la figura 46, el mayor porcentaje es un $73 \%$ es decir 269 personas consideran que el marketing digital es influyente con relación a la decisión de compra y solo el $6.5 \%$ encuentra esta relación a veces influyente; esto quiere decir que la gran mayoría del público que asiste a gimnasios en Lima moderna, considera al marketing digital como una práctica influyente a la hora de tomar una decisión de compra de productos fitness.

Los resultados demuestran una clara relación entre la variable dependiente y la independiente, permitiéndonos explorar los otros aspectos que la conforman, para evaluar cuál es la característica más influyente y así poder crear estrategias enfocadas en la capitalización de las fortalezas o el de modificar estrategias para incrementar la influencia de las debilidades. 


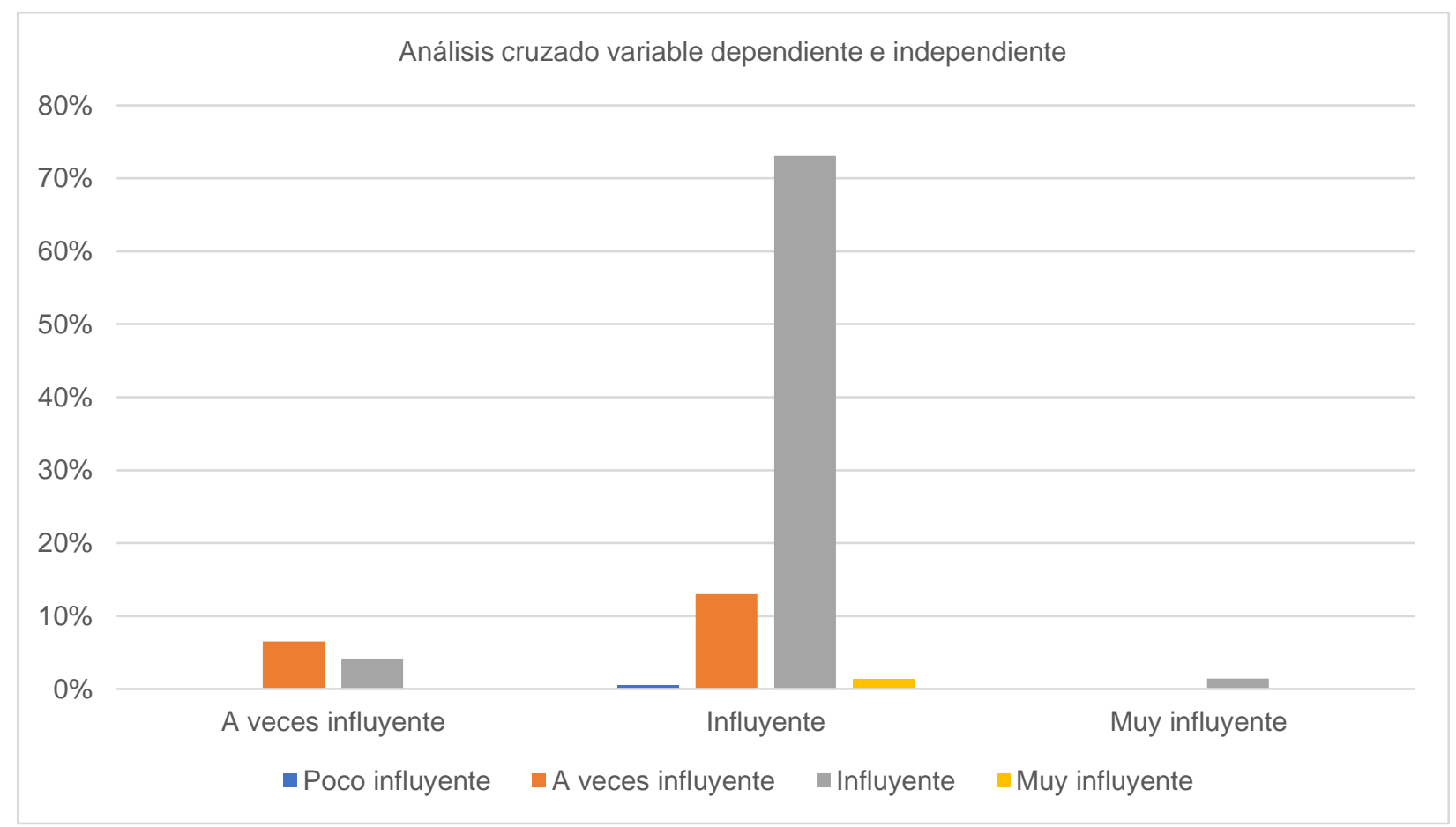

Figura 46: Análisis cruzado variable dependiente e independiente.

Fuente: Resultados obtenidos de la investigación

Tabla 16:

Tabla cruzada 2 dimensión de atracción * decisión de compra

\begin{tabular}{|c|c|c|c|c|c|c|c|}
\hline & & & \multicolumn{4}{|c|}{ Decisión de compra } & \multirow{3}{*}{ Total } \\
\hline & & & Poco & A veces & Influyent & Muy & \\
\hline & & & influyente & influyente & $\mathrm{e}$ & influyente & \\
\hline \multirow{3}{*}{$\begin{array}{l}\text { Dimensión de } \\
\text { atracción }\end{array}$} & influyente & $\%$ del total & $0.0 \%$ & $3.3 \%$ & $3.5 \%$ & $0.0 \%$ & $6.8 \%$ \\
\hline & \multirow{2}{*}{ Muy influyente } & Recuento & 0 & 9 & 33 & 1 & 43 \\
\hline & & $\%$ del total & $0.0 \%$ & $2.4 \%$ & $9.0 \%$ & $0.3 \%$ & $11.7 \%$ \\
\hline Total & & Recuento & 2 & 72 & 289 & 5 & 368 \\
\hline
\end{tabular}

Fuente: Resultados obtenidos de la investigación 
En la figura 47, el 66\%, en este caso 243 personas, consideran que el marketing digital, dimensión de atracción, es influyente en la decisión de compra, mientras que solo el 3.3\% o en este caso 12 personas consideran que es a veces influyente, es decir que la gran mayoría considera que las técnicas atracción de anuncios son influyentes a la hora de tomar una decisión de compra de productos fitness de marketing digital.

Lo cual significa que más de la mitad considera que las técnicas de atracción son efectivas; por otro lado, tienen un margen de mejora para ser más eficientes y considerando que estas estrategias forman la primera impresión en la mente del consumidor, es importante analizar cómo mejorar su nivel de aceptación.

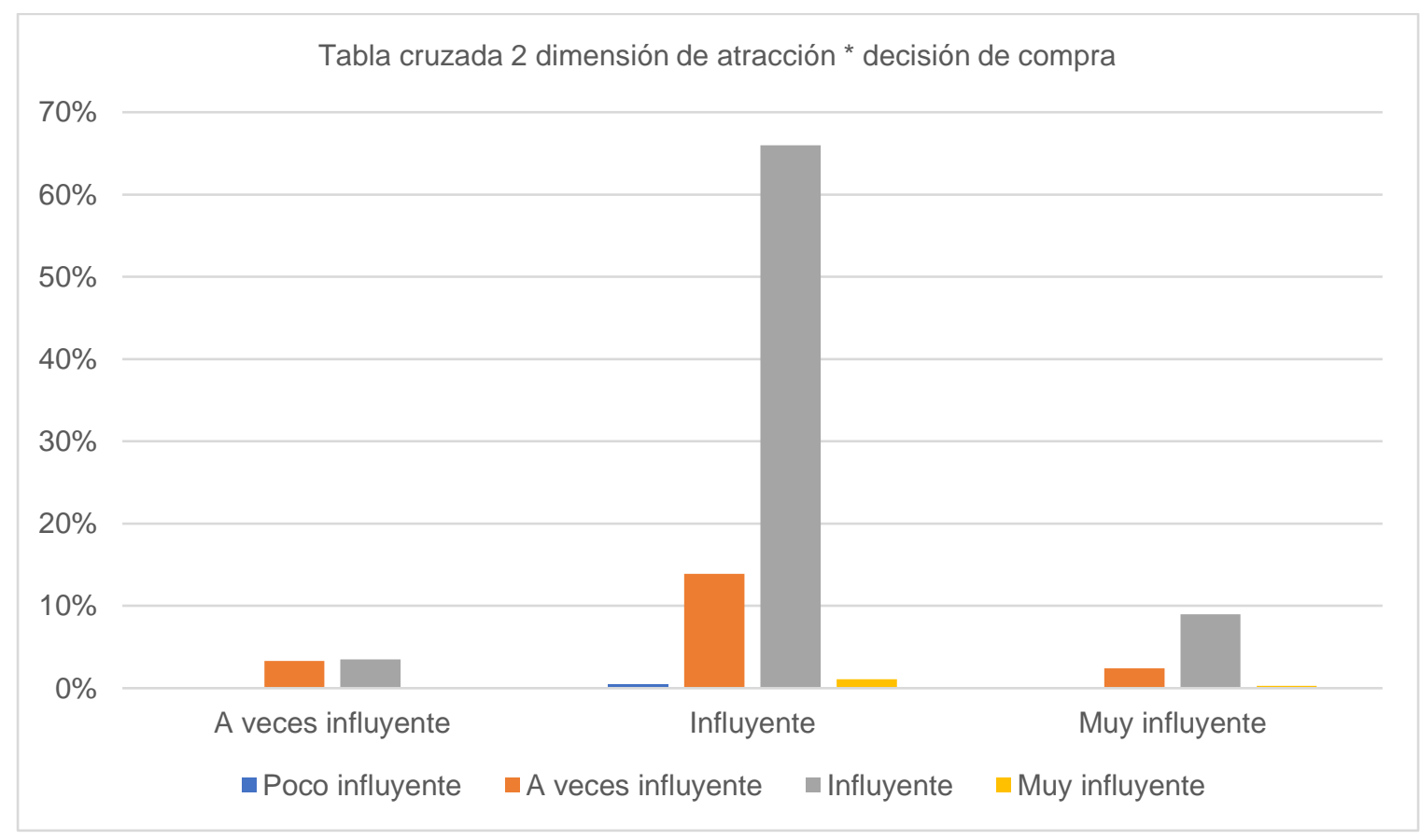

Figura 47 Análisis cruzado 2 dimensión de atracción * decisión de compra Fuente: Resultados obtenidos de la investigación 
Tabla 17:

Tabla cruzada 3 dimensión de difusión* decisión de compra.

\begin{tabular}{|c|c|c|c|c|c|c|c|}
\hline & & & \multicolumn{4}{|c|}{ Decisión de compra } & \multirow[b]{2}{*}{ Total } \\
\hline & & & $\begin{array}{c}\text { Poco } \\
\text { influyente }\end{array}$ & $\begin{array}{l}\text { A veces } \\
\text { influyente }\end{array}$ & Influyente & Muy influyente & \\
\hline \multirow{8}{*}{$\begin{array}{l}\text { Dimensión de } \\
\text { difusión }\end{array}$} & \multirow{2}{*}{ Poco influyente } & Recuento & 0 & 5 & 2 & 0 & 7 \\
\hline & & $\%$ del total & $0.0 \%$ & $1.4 \%$ & $0.5 \%$ & $0.0 \%$ & $1.9 \%$ \\
\hline & \multirow{2}{*}{ A veces influyente } & Recuento & 2 & 47 & 77 & 2 & 128 \\
\hline & & $\%$ del total & $0.5 \%$ & $12.8 \%$ & $20.9 \%$ & $0.5 \%$ & $34.8 \%$ \\
\hline & \multirow{2}{*}{ Influyente } & Recuento & 0 & 18 & 201 & 3 & 222 \\
\hline & & $\%$ del total & $0.0 \%$ & $4.9 \%$ & $54.6 \%$ & $0.8 \%$ & $60.3 \%$ \\
\hline & \multirow{2}{*}{ Muy influyente } & Recuento & 0 & 2 & 9 & 0 & 11 \\
\hline & & $\%$ del total & $0.0 \%$ & $0.5 \%$ & $2.4 \%$ & $0.0 \%$ & $3.0 \%$ \\
\hline \multirow{2}{*}{ Total } & & Recuento & 2 & 72 & 289 & 5 & 368 \\
\hline & & $\%$ del total & $0.5 \%$ & $19.6 \%$ & $78.5 \%$ & $1.4 \%$ & $100.0 \%$ \\
\hline
\end{tabular}

Fuente: Resultados obtenidos de la investigación

En la figura 48, se observa que 201 personas, las cuales representan el 54.6\%, consideran influyente al marketing digital dimensión de difusión, con relación a la decisión de compra y un $12.8 \%$ que corresponde a 47 personas, lo consideran a veces influyente, siendo este porcentaje el más bajo de influencia sobre la variable dependiente, aun así su nivel de influencia sobrepasa el 50\% lo cual es positivo. Sin embargo, se demuestra que se necesita trabajar más en la difusión para llegar a los niveles de aceptación de las demás dimensiones del marketing digital. 


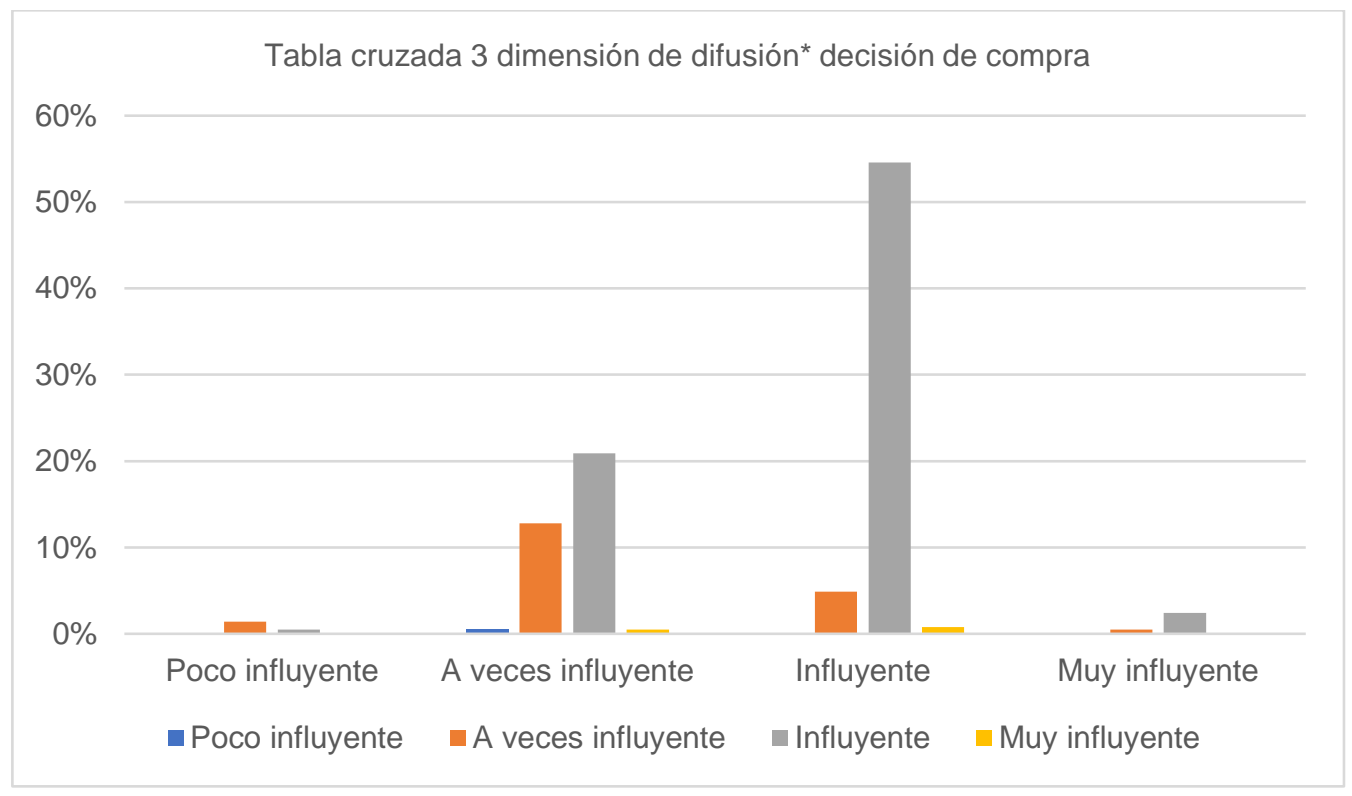

Figura 48: Análisis cruzado 3 dimensión de difusión * decisión de compra.

Fuente: Resultados obtenidos de la investigación

Tabla 18:

Tabla cruzada 4 dimensión de retención * decisión de compra.

\begin{tabular}{|c|c|c|c|c|c|c|c|}
\hline & & & & Decisión d & ipra & & \\
\hline & & & Poco & A veces & Influsonto & Muy & Total \\
\hline & & & influyente & influyente & Intuyente & influyente & \\
\hline & A veces & Recuento & 0 & 12 & 13 & 0 & 25 \\
\hline & influyente & $\%$ del total & $0.0 \%$ & $3.3 \%$ & $3.5 \%$ & $0.0 \%$ & $6.8 \%$ \\
\hline Dimensión de & Influents & Recuento & 2 & 48 & 228 & 4 & 282 \\
\hline retención & пाпиуетпе & $\%$ del total & $0.5 \%$ & $13.0 \%$ & $62.0 \%$ & $1.1 \%$ & $76.6 \%$ \\
\hline & Muy & Recuento & 0 & 12 & 48 & 1 & 61 \\
\hline & influyente & $\%$ del total & $0.0 \%$ & $3.3 \%$ & $13.0 \%$ & $0.3 \%$ & $16.6 \%$ \\
\hline Total & & Recuento & 2 & 72 & 289 & 5 & 368 \\
\hline & & $\%$ del total & $0.5 \%$ & $19.6 \%$ & $78.5 \%$ & $1.4 \%$ & $100.0 \%$ \\
\hline
\end{tabular}

Fuente: Resultados obtenidos de la investigación 
En la figura 49, se observa que 228 personas, representado por el $62 \%$, consideran influyente el marketing digital dimensión de retención sobre la decisión de compra, en un 3.3\%, que corresponde a 12 personas lo consideran a veces influyente, y en un $13 \%$ que equivale a 48 personas, tiene un nivel de aceptación de muy influyente. Esto debido a que la ideología fitness es un estilo de vida, por consiguiente, existe un consumo constante debido a una menor barrera de acceso, al haber usado previamente los productos y entender su verdadero valor.

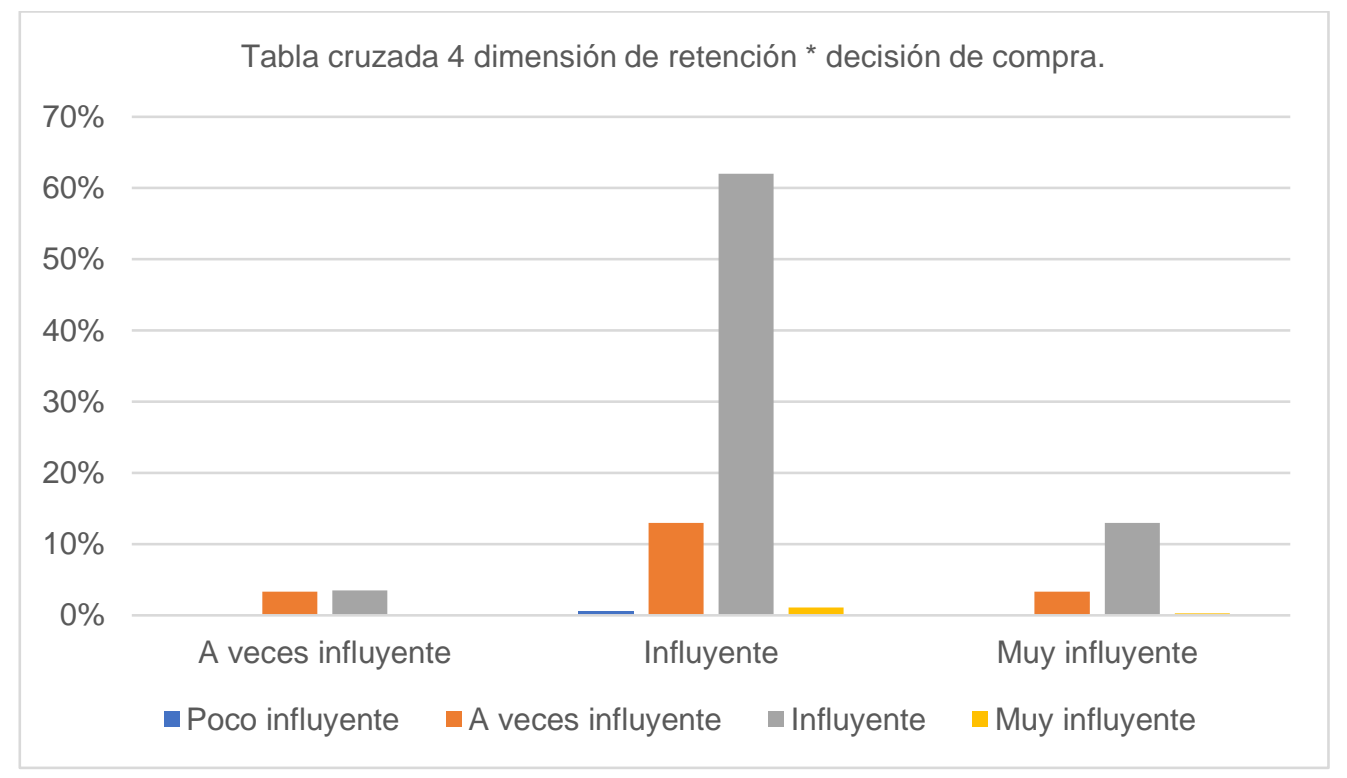

Figura 49: Análisis cruzado 4 dimensión de retención * decisión de compra. Fuente: Resultados obtenidos de la investigación 


\subsection{Comprobación de hipótesis}

\subsubsection{Prueba Rho-spearman}

Debido a que el instrumento de la escala de Likert es de tipo ordinal, ésta por consecuente tiene una distribución asimétrica, lo cual nos lleva a usar la medida de correlación de Rho-spearman "si las variables son numéricas y ordinales; en ese caso se procede a utilizar Rho-spearman para hallar la correlación entre las variables a estudiar ya que esta medida usa clasificaciones en lugar de valores absolutos de las variables" (Malhotra N. , 2020) páginas 543 y 544; permitiendo así poder determinar la existencia de una relación metódica entre las dos variables observadas y aceptando o rechazando la hipótesis nula H0, la cual propone que no existe una asociación entre las variables. 


\subsubsection{Comprobación de hipótesis general}

En este estudio participaron 368 personas, las cuales permitieron analizar la hipótesis general, así como las hipótesis específicas haciendo uso del coeficiente de correlación de Spearman:

Tabla 19:

Prueba Rho de Spearman hipótesis general.

\begin{tabular}{|c|c|c|c|c|}
\hline & & Correlaciones & & \\
\hline \multirow{7}{*}{ Rho de Spearman } & \multirow{4}{*}{ Marketing digital } & & $\begin{array}{l}\text { Marketing } \\
\text { digital }\end{array}$ & $\begin{array}{c}\text { Decisión de } \\
\text { compra }\end{array}$ \\
\hline & & Coeficiente de correlación & 1.000 & $.343^{* *}$ \\
\hline & & Sig. (bilateral) & . & .000 \\
\hline & & $\mathrm{N}$ & 368 & 368 \\
\hline & \multirow{3}{*}{$\begin{array}{l}\text { Decisión de } \\
\text { compra }\end{array}$} & Coeficiente de correlación & $.343^{* *}$ & 1.000 \\
\hline & & Sig. (bilateral) & .000 & . \\
\hline & & $\mathrm{N}$ & 368 & 368 \\
\hline \multicolumn{5}{|c|}{ **. La correlación es significativa en el nivel 0,01 (bilateral). } \\
\hline
\end{tabular}

- Ho: El marketing digital no influye en la decisión de compra de productos fitness en usuarios de gimnasios de Lima moderna.

- H1: El marketing digital influye en la decisión de compra de productos fitness en usuarios de gimnasios de Lima moderna.

$\underline{\text { Resultado: }}$

Ya que el p-valor es 0 , el cual es menor a 0.05 entonces se procede a rechazar la hipótesis nula y se acepta que el marketing digital influye en la decisión de compra de productos fitness en usuarios de gimnasios de Lima moderna. 


\subsubsection{Comprobación de la primera hipótesis especifica}

Por medio del análisis Chi-cuadrado se procedió a analizar las siguientes hipótesis:

Tabla 20:

Prueba Rho de Spearman primera hipótesis específica.

\begin{tabular}{|c|c|c|c|c|}
\hline \multicolumn{5}{|c|}{ Correlaciones } \\
\hline \multirow{7}{*}{ Rho de Spearman } & & & $\begin{array}{l}\text { Nivel de } \\
\text { atracción }\end{array}$ & $\begin{array}{l}\text { Decisión de } \\
\text { compra }\end{array}$ \\
\hline & & Coeficiente de correlación & 1.000 & $.106^{*}$ \\
\hline & Nivel de atracción & Sig. (bilateral) & . & .041 \\
\hline & & $\mathrm{N}$ & 368 & 368 \\
\hline & & Coeficiente de correlación & $.106^{*}$ & 1.000 \\
\hline & Decisión de compra & Sig. (bilateral) & .041 & . \\
\hline & & $\mathrm{N}$ & 368 & 368 \\
\hline
\end{tabular}

- Ho: La dimensión de atracción del marketing digital no influye en la decisión de compra de productos fitness en usuarios de gimnasios de Lima moderna.

- H1: La dimensión de atracción del marketing digital influye en la decisión de compra de productos fitness en usuarios de gimnasios de Lima moderna.

Resultado:

Ya que el p-valor es 0.041 , el cual es menor a 0.05 entonces se procede a rechazar la hipótesis nula y aceptar que la dimensión de atracción del marketing digital influye en la decisión de compra de productos fitness en usuarios de gimnasios de Lima moderna. 


\subsubsection{Comprobación de la segunda hipótesis especifica}

Por medio del coeficiente de correlación de Spearman se procedió a analizar las siguientes hipótesis:

Tabla 21:

Prueba Rho de Spearman para la segunda hipótesis específica.

\begin{tabular}{|c|c|c|c|c|}
\hline & & Correlaciones & & \\
\hline \multirow{8}{*}{ Rho de Spearman } & & & $\begin{array}{l}\text { Nivel de } \\
\text { difusión }\end{array}$ & $\begin{array}{l}\text { Decisión de } \\
\text { compra }\end{array}$ \\
\hline & \multirow{4}{*}{ Nivel de difusión } & Coeficiente de correlación & 1.000 & $.353^{* *}$ \\
\hline & & Sig. (bilateral) & . & .000 \\
\hline & & $\mathrm{N}$ & 368 & 368 \\
\hline & & Coeficiente de correlación & $.353^{* *}$ & 1.000 \\
\hline & \multirow[t]{2}{*}{ Decisión de compra } & Sig. (bilateral) & .000 & \\
\hline & & $\mathrm{N}$ & 368 & 368 \\
\hline & **. La correlación & significativa en el nivel 0,01 & ral). & \\
\hline
\end{tabular}

- Ho: La dimensión de difusión del marketing digital no influye en la decisión de compra de productos fitness en usuarios de gimnasios de Lima moderna.

- H1: La dimensión de difusión del marketing digital influye en la decisión de compra de productos fitness en usuarios de gimnasios de Lima moderna.

Resultado:

Ya que el p-valor es 0.0 , el cual es menor a 0.05 entonces se procede a rechazar la hipótesis nula y aceptar que la dimensión de difusión del marketing digital influye en la decisión de compra de productos fitness en usuarios de gimnasios de Lima moderna. 


\subsubsection{Comprobación de la tercera hipótesis especifica}

Por medio del coeficiente de correlación de Spearman se procedió a analizar las siguientes hipótesis:

Tabla 22:

Prueba Rho de Spearman tercera hipótesis específica.

\begin{tabular}{|c|c|c|c|c|}
\hline \multicolumn{5}{|c|}{ Correlaciones } \\
\hline & & & $\begin{array}{l}\text { Nivel de } \\
\text { retención }\end{array}$ & $\begin{array}{c}\text { Decisión de } \\
\text { compra }\end{array}$ \\
\hline \multirow{6}{*}{ Rho de Spearman } & & Coeficiente de correlación & 1.000 & .098 \\
\hline & Nivel de retención & Sig. (bilateral) & . & .060 \\
\hline & & $\mathrm{N}$ & 368 & 368 \\
\hline & & Coeficiente de correlación & .098 & 1.000 \\
\hline & Decisión de compra & Sig. (bilateral) & .060 & \\
\hline & & $\mathrm{N}$ & 368 & 368 \\
\hline
\end{tabular}

Fuente: Resultados obtenidos de la investigación

- Ho: La dimensión de retención del marketing digital no influye en la decisión de compra de productos fitness en usuarios de gimnasios de Lima moderna.

- H1: La dimensión de retención del marketing digital influye en la decisión de compra de productos fitness en usuarios de gimnasios de Lima moderna.

$\underline{\text { Resultado: }}$

Ya que el p-valor es 0.060 , el cual es mayor a 0.05, entonces se procede a aceptar la hipótesis nula y rechazar que la dimensión de retención del marketing digital influye en la decisión de compra de productos fitness en usuarios de gimnasios de Lima moderna. 


\section{Conclusiones y Recomendaciones}

\subsection{Conclusiones}

Basado en los resultados obtenidos se procede a sacar las conclusiones según los objetivos propuestos para la presente investigación:

1) El Marketing digital influye en la toma de decisión de compra, debido a que éste encierra varios factores culturales y sociales; los cuales son influenciados gracias al avance tecnológico y a las facilidades de comunicación, induciendo a nuevas prácticas de consumo.

2) El estilo de vida fitness son prácticas de comportamiento y consumo que permiten comercializar una amplia gama de productos y servicios, los cuales prometen alcanzar los objetivos del consumidor, de tal forma que, a pesar de ser un nicho de mercado pequeño, éste produce grandes dividendos. Debido a las características descritas, el marketing digital es la herramienta óptima para llegar exclusivamente al mercado objetivo, eliminando los altos costos de publicidad tradicional.

3) El comercio digital, necesita de inversión en técnicas especializadas o en profesionales que dominen éstas; así mismo un emprendedor independiente puede llegar a impulsar su negocio propio con cursos en línea sobre el tema.

4) Nivel de influencia de atracción del marketing digital en la decisión de compra de productos fitness según los resultados obtenidos de la muestra:

a. Se entiende que la dimensión de atracción del marketing digital es un factor que sí influye en la decisión de compra, debido en gran parte a que está diseñado para llamar la atención y generar interés o expectativa en la mentalidad del consumidor frente al producto o servicio que se está ofreciendo; esto quiere decir que las técnicas utilizadas actualmente son llamativas, sin embargo en este país se tiene un marketing digital que recién está empezando a adaptarse a la cultura peruana, y por ese motivo no llega a alcanzar su potencial real, el cual es alto debido a la facilidad de conexión a internet que se posee el día de 
hoy, así como a la normalización y/o adaptación de los peruanos a no separarse de sus teléfonos inteligentes, incluso teniendo facilidades de internet ilimitado en algunas redes sociales como Facebook.

5) Nivel de influencia de la difusión del marketing digital en la decisión de compra de productos fitness:

a. Se encuentra que la difusión del marketing digital es relevante en la mentalidad del consumidor, sin embargo, esta tiene un impacto moderado lo cual podría significar que las personas se sienten incomodas frente a una constante exposición de anuncios.

6) Nivel de influencia de la retención del marketing digital en la decisión de compra de productos fitness:

a. Basado en los resultados del estudio cuantitativo, la retención en el marketing digital no es influyente, podría interpretarse como la poca necesidad de volver a incentivar al consumidor a adquirir productos fitness, una vez éste se encuentre dentro del mercado ya que muchos consumidores tienden a identificar esta práctica de consumo como un estilo de vida y no como una moda. 


\subsection{Recomendaciones}

Este trabajo tiene como un gran objetivo demostrar la importancia del marketing digital y la necesidad de su uso para comercializar productos fitness principalmente para micro comercializadores, debido a que son ellos los primeros en importar y vender nuevos tipos de productos fitness al Perú, ya que grandes empresas como Nutrilab no comercializan algunos productos especializados a pesar de que sus franquicias en otros países si lo hacen.

\section{En base a la dimensión de atracción}

1) El uso de comunicación integrada es más sencillo gracias a la era digital y los bajos costos de comunicación que ésta trae, por ello se pueden usar diferentes plataformas de comunicación con el cliente, adaptándose a su canal preferido. Un ejemplo relacionado a esta práctica se encuentra en la campaña "Red bull te da alas" donde se generaba sinergia al potenciar el mensaje en todo evento relacionado con la adrenalina como carreras, deportes extremos, espectáculos aéreos, etc.

2) Usar formas creativas de publicación de contenidos, para hacer un uso correcto del marketing digital en la dimensión de atracción, ya que para que esta dimensión sea efectiva se debe utilizar una metodología inbound, evitando que la publicidad sea invasiva, molesta o que interrumpa nuestras actividades en la red. Por ello técnicas como el stoyrytelling permiten captar la atención de los clientes y compartir información sobre los productos o servicios en el menor tiempo posible, contando una historia que englobe todas sus propiedades del producto o por lo menos las más relevantes sin tomar mucho tiempo. Un ejemplo de storytelling es uso del antes y después, una técnica popularizada por el mercado fitness en donde se puede apreciar los cambios en la fisionomía de un consumidor de un producto.

3) Enfocarse en capitalizar las dimensiones con mayor aceptación como atracción y retención, debido a que invertir en una campaña de sensibilización para promover la dimensión de difusión sería muy costosa. 


\section{En base a la dimensión de difusión}

1) Posicionarse de manera positiva en redes sociales es importante, debido a que la reputación sirve para atraer nuevos clientes, los cuales sentirán desconfianza si encuentran una cantidad de comentarios negativos, o si consideran que un perfil está abandonado.

2) Existe la necesidad de invertir tiempo en aprender el correcto uso del marketing digital, ya que hoy en día la información y técnicas de ésta pueden ser encontradas en internet, permitiendo así al usuario no muy experimentado, explotar estos conocimientos para su emprendimiento personal exponiendo su contenido en los canales adecuados e invirtiendo solo los montos necesarios para asegurar sus ventas.

\section{En base a la dimensión de retención}

1) Generar una cultura de retención es importante, debido a que el empresario nunca debe descuidar a un cliente recurrente, ya que la confianza perdida es muy difícil de recuperarla. Un incentivo de retención de cliente sencillo, es implementar la reducción de costos en algunos productos o servicios al llevar volúmenes más grandes de productos, ya que a pesar de no ser necesario invertir en la retención del cliente hacia el producto, lo mismo no se puede decir del cliente al proveedor.

2) El uso de ventas privadas o VIP, permite otorgarle un sentimiento de superioridad al cliente, recibiendo acceso a productos nuevos antes de tiempo o descuentos especiales por su fidelidad; lo cual son un gran incentivo hacia los consumidores de no buscar nuevos proveedores.

3) Una técnica óptima de retención de cliente es el uso de un servicio post venta, en este caso para asegurar una correcta relación con los clientes. La empresa debe poder resolver a la mayor brevedad y mostrando el mayor interés, los problemas relacionados con un producto o servicio otorgado, generando así una gran empatía en la mentalidad del consumidor y haciendo así más difícil que el cliente busque un nuevo proveedor, aunque no se ofrezca incentivos de venta o descuentos. 
4) Identificar un patrón de solución de problemas, muchas veces un inconveniente puede ser recurrente, por ese motivo lo mejor es anticipar esta problemática instruyendo al personal para que explique esta posible interrogante al cliente al momento de generar la venta, con el fin de mostrar transparencia y evitar problemas.

5) Recompensar a los clientes recurrentes con promociones de ventas como regalos subsidiados por sus compras, una manera práctica es mediante el uso de tarjetas de stickers o sellos las cuales al llenar una cantidad definida otorgan un premio $o$ descuento en la siguiente compra. 


\section{Bibliografía}

Abdullah, M. (2019). Digital Marketing Practices at the State University of Bangladesh. Bangladesh: University of Bangladesh.

Anadolu Agency. (15 de Agosto de 2020). www.aa.com. Obtenido de https://www.aa.com.tr/es/econom\%C3\%ADa/en-el-segundo-trimestre-dela\%C3\%B1o-m\%C3\%A1s-de-6-millones-de-peruanos-perdieron-el-empleo-/1943234

Aptitus. (08 de 01 de 2017). PQS. Obtenido de https://www.pqs.pe/tecnologia/cual-es-elperfil-del-consumidor-peruano-digital

Arellano Marketing. (31 de Octubre de 2017). revistaganamas.com. Obtenido de https://revistaganamas.com.pe/arellano-marketing-desde-2015-el-98-de-peruanosutiliza-una-cuenta-de-facebook/

Baumgardner, M. (2008). Introducción a la Investigación de mercados. En N. k. Malhotra, Investigación de mercados (pág. 2). México: Pearson.

Bedoya, C. (2017). Diseño de un instrumento tipo escala Likert para la descripción de las actitudes hacia la tecnología por parte de los profesores de un colegio público de Bogotá. Bogotá - Colombia: Universidad Distrital Francisco José de Caldas.

Cabrera, G., \& Pisfil, I. (2016). PLAN DE NEGOCIOS DE COMIDA RÁPIDA SALUDABLE EN LIMA METROPOLITANA 2016. Lima: Universidad San Ignacio de Loyola, Escuela de postgrado.

Cabrera, O., \& Torres, V. (2016). La aplicación del modelo Inbound marketing para incrementar las ventas de bebida de Camu Camu en el distrito de Santiago de Surco, 2015. Lima: Universidad Peruana de Integración Global.

Campos-Freire, Yaguache, \& Ulloa. (2017). Tendencias de la industria de los medios de América del Sur en la transición digital. Revista De Comunicación, 33-59.

Cañizales, C. (2018). Genwords. Obtenido de https://www.genwords.com/blog/que-es-elmarketing-digital

Chimpén, C. (2016). Factores que influyen en la decisión de compra de los clientes a través de las estrategias de marketing con redes sociales en el sector repostero. Chiclayo Perú: Universidad Católica Santo Toribio de Mogrovejo.

ComScore. (28 de 03 de 2019). El comercio. Obtenido de https://elcomercio.pe/tecnologia/redes-sociales/facebook-utilizan-redes-socialesperuanos-noticia-620588-noticia/?ref=ecr

ComScore. (11 de 02 de 2019). Gestión. Obtenido de https://gestion.pe/tecnologia/socialmedia-peru-primer-pais-region-mayor-porcentaje-alcance-redes-sociales-258321noticia/?ref=gesr

CPI. (2017). Población 2017. Lima: Compañía peruana de estudios de mercados y opinión pública.

CPI. (2018). Inversión Publicitaria 2018. Lima: Compañía Peruana de estudios de marcados y opinion publica S.A.C.

Deloitte. (2016). La Nueva Brecha Digital. Santiago de Chile: Deloitte Consulting LLP.

Escalante, J. (07 de Diciembre de 2016). Marketing Link. Obtenido de http://marketinglink.up.edu.pe/los-principales-factores-influyen-la-conducta-delconsumidor/

Escarbajal, D. (04 de Marzo de 2017). inmotools. Obtenido de https://inmotools.wordpress.com/2017/03/04/difusion-atraccion-relacion-y-conversionlas-cuatro-dimensiones-del-marketing-digital/

Esquiven, M. (2016). Estrategias de marketing digital para la internacionalización del hotel Huanchaco Paradise en el año 2019. Trujillo: Universidad privada del norte.

Financial Times. (2015). Financial Times. Obtenido de www.ft.com/lexicon. 
Front Consulting. (05 de 08 de 2016). Gestión. Obtenido de https://gestion.pe/tendencias/39peruanos-practica-deporte-mayoria-dice-hacerlo-falta-111576-noticia/?ref=gesr

Gioshvili, G. (2019). Online Controlled Experiments in Digital Marketing Field. Berlín: Humboldt-Universität zu Berlin.

Gómez, F., \& Neri, B. (2017). Impacto de las redes sociales como herramienta publicitaria en PyMEs mexicanas. Guadalajara: Universidad de Guadalajara.

Hootsuite. (04 de Julio de 2019). Iujhon. Obtenido de https://lujhon.com/estadisticasconsumo-digital-peru-2019/

IMS (Internet Media Services). (15 de Junio de 2017). RPP. Obtenido de https://rpp.pe/blog/geek-and-chick/conoce-cuanto-tiempo-pasan-los-peruanos-en-elinternet-noticia-1057924

Ipsos. (07 de 10 de 2018). Perú 21. Obtenido de https://peru21.pe/lima/lima-moderna-vsresto-lima-comportamiento-electoral-diferente-analisis-432829-noticia/

IPSOS. (14 de 02 de 2019). IPSOS. Obtenido de https://www.ipsos.com/es-pe/generacionesen-el-peru

Jacobsen, J. (2016). The digital experience. The digital experience Vol. 107 Issue 8, p20-22.

Jobber, D., \& Lancaster, G. (2012). Administración de ventas, Octava edición. México: Pearson.

Jobber, D., \& Lancaster, G. (2012). Administración de ventas. Octava edición. México: Pearson.

Jobber, D., \& Lancaster, G. (2012). Administración de ventas. Octava edición. México: Pearson.

Kantar TNS. (21 de 08 de 2018). Perú 21. Obtenido de https://peru21.pe/economia/google94-peruanos-decide-compra-basado-investiga-internet-nndc-422567-noticia/

KidsHealth redacción. (Enero de 2015). KidsHealth. Obtenido de https://kidshealth.org/es/teens/sports-supplements-esp.html

Kochi, A., Pretell, R., \& Ynouye, J. (2017). Producción y comercialización de suplementos proteicos de concentrado de suero de leche enriquecidos con Quinua y Kiwicha. Lima: Pontifice Universidad Catolica del Perú.

Kotler, P., \& Armstrong, G. (2013). Fundamentos de marketing. México: Pearson.

Kotler, P., \& Armstrong, G. (2017). Fundamentos de marketing, Edicion 13. Mexico: Pearson.

Kulisz, A. (2018). La influencia de las redes sociales sobre la decisión de compra de alimentos orgánicos. Madrid - España: Universidad Pontificia Comillas.

Llave, M. (2016). Relación entre las estrategias de marketing digital de empresas de moda y/o entretenimiento Arequipeñas, y la decisión de compra de sus clientes, usuarios de facebook. Arequipa: Universidad Nacional de San Agustín de Arequipa.

Loza, M., \& Cobarrubias, J. (2017). Influencia del marketing digital en la compra de alimentos light sin azúcar en jóvenes adultos de México. Guadalajara - México: Universidad de Guadalajara.

Lozano, T. (22 de 11 de 2017). Gestión. Obtenido de https://gestion.pe/tecnologia/ten-73consumidores-revisaran-tiendas-virtuales-elegir-regalos-navidad-153225-noticia/

Malhotra, N. (2008). INVESTIGACIÓN DE MERCADOS Quinta edición. México: PEARSON EDUCACIÓN.

Malhotra, N. (2020). Investigación de mercados 6e. México: Pearson.

Malpica, S. (2017). Grado de eficacia de la estrategia de personalización de marketing digital de la empresa pinkberry peru en la red social instagram. Trujillo 2016. Trujillo: Universidad Privada Antenor Orrego.

Marroquín, A., Negrón, A., \& Solano, S. (2019). Plan de marketing para la empresa gen digital Perú. Lima - Perú: Universidad San Ignacio de Loyola. 
Ministerio de la producción - Gobierno del Perú. (2017). Produce.gob.pe. Obtenido de http://ogeiee.produce.gob.pe/index.php/shortcode/estadistica-oee/estadisticasmipyme

Miyoshi, C. (24 de 04 de 2017). Código.pe. Obtenido de https://codigo.pe/peru-la-inversionpublicidad-digital-la-segunda-la-torta-publicitaria/

Montoya, S. (2017). Las redes sociales virtuales y su influencia en sus hábitos saludables de alimentación y ejercicio, en los jóvenes universitarios en la ciudad de Cali. Cali: Pontificia Universidad Javeriana.

Osorio, R., Restrepo, L., \& Muños, H. (2016). Marketing digital: una mirada al pasado, presente y futuro. Bogotá - Colombia: Corporación Unificada Nacional de Educación Superior (CUN).

Patel, N. (2017). NP Digital. Obtenido de https://neilpatel.com/blog/first-page-google/

Perú21. (21 de Abril de 2018). www.peru21.pe. Obtenido de https://peru21.pe/vida/salud/universe-nutrition-marca-peruana-sorprende-mundofitness-fotos-404245-noticia/?ref=p21r

Ponce, I. (17 de Abril de 2012). Ministerio de educación y cultura de España. Obtenido de http://recursostic.educacion.es/observatorio/web/ca/internet/web-20/1043-redessociales?start $=1$

Ramírez, C., Leopoldo, A., Iriarte, A., \& Arriaga, O. (22 de Noviembre de 2017). Importancia de la Investigación Cualitativa y Cuantitativa para la Educación. EDUCATECONCIENCIA, 16(17), 169 - 171.

Redacción Gestión. (28 de 05 de 2015). Gestión. Obtenido de https://gestion.pe/economia/empresas/bodytech-tendencia-llegar-publico-sectorfitness-canal-digital-91094-noticia/?ref=gesr

Rico, A. (9 de Noviembre de 2017). Kantar Worldpanel. Obtenido de https://www.kantarworldpanel.com/mx/Noticias-/Dia-de-la-Nutricion-Como-se-cuidanlos-mexicanos.

Rodríguez, P. (2018). Redes sociales y manupulación. Madrid: Universidad Camilo José Cela.

Sanchez, J. (19 de 07 de 2017). Gestión. Obtenido de https://gestion.pe/tendencias/cincoprincipales-tendencias-consumidor-peruano-139597-noticia/

Sonora, J. (2017). Tendencias de compras en línea en los alumnos Universitarios Mexicanos al comprar productos de supermercados. Guadalajara: Universidad de Guadalajara.

Soto, A. (2019). Influencia del inbound marketing sobre la intención de compra de los potenciales estudiantes de la UM virtual. Montemorelos: Universidad de Montemorelos.

Teruel, S. (6 de Mayo de 2019). Captio. Obtenido de https://www.captio.net/blog/las-ochoetapas-en-el-proceso-de-toma-de-decisiones-de-la-empresa

Torres, R., Rivera, J., Cabarcas, R., \& Castro, Y. (2017). La efectividad del uso del marketing digital como estrategia para el posicionamiento de las pymes para el sector comercio en la ciudad de Barranquilla. Revista I+D en TIC Volumen 8 Número (2), 3-5.

Turró, S. B. (2017). El marketing de influencers en el sector fitness. Gerona - España: Universidad de Gerona.

U.S. Department of Health \& Human Services. (Octubre de 2019). National institutes of health. Obtenido de https://ods.od.nih.gov/factsheets/ExerciseAndAthleticPerformanceHealthProfessional/ 


\section{Anexos}

Anexo A:

Matriz de consistencia.

\begin{tabular}{|c|c|c|c|c|}
\hline Problemas & Objetivos & Hipótesis & Variables & Metodología \\
\hline teneral & General & General & nte & 1. Tipo \\
\hline $\begin{array}{l}\text { La interrogante } \\
\text { principal es ¿El } \\
\text { marketing digital } \\
\text { influye en la decisión } \\
\text { de compra de } \\
\text { productos fitness en } \\
\text { usuarios de gimnasios } \\
\text { de Lima moderna? } \\
\text { Específicos } \\
\text { ¿La dimensión de la } \\
\text { atracción del } \\
\text { marketing digital } \\
\text { influye en la decisión } \\
\text { de compra de } \\
\text { productos fitness en } \\
\text { usuarios de gimnasios } \\
\text { de Lima moderna? }\end{array}$ & 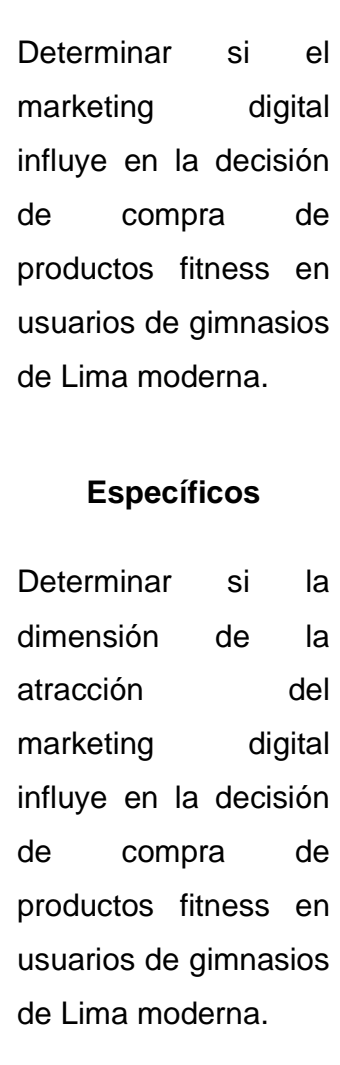 & $\begin{array}{l}\text { La dimensión de la } \\
\text { atracción del marketing } \\
\text { digital influye en la } \\
\text { decisión de compra de } \\
\text { productos fitness en } \\
\text { usuarios de gimnasios } \\
\text { de Lima moderna. }\end{array}$ & $\begin{array}{l}\text { "Decisión de compra" } \\
\text { siendo el efecto por el } \\
\text { cual las personas optan } \\
\text { o no por adquirir } \\
\text { productos fitness a } \\
\text { través de la influencia } \\
\text { del marketing digital }\end{array}$ & $\begin{array}{l}\text { Enfoque cualitativo al inicio y posteriormente } \\
\text { cuantitativo, método hipotético deductivo, de tipo } \\
\text { básica. } \\
\text { 2. Diseño de investigación } \\
\text { Para el estudio cualitativo se realizó un FOCUS } \\
\text { GROUP y } 3 \text { entrevistas de profundidad a expertos, } \\
\text { para el estudio cuantitativo el diseño fue no } \\
\text { experimental de corte transversal } \\
\text { 3. Tipo de Muestra }\end{array}$ \\
\hline
\end{tabular}




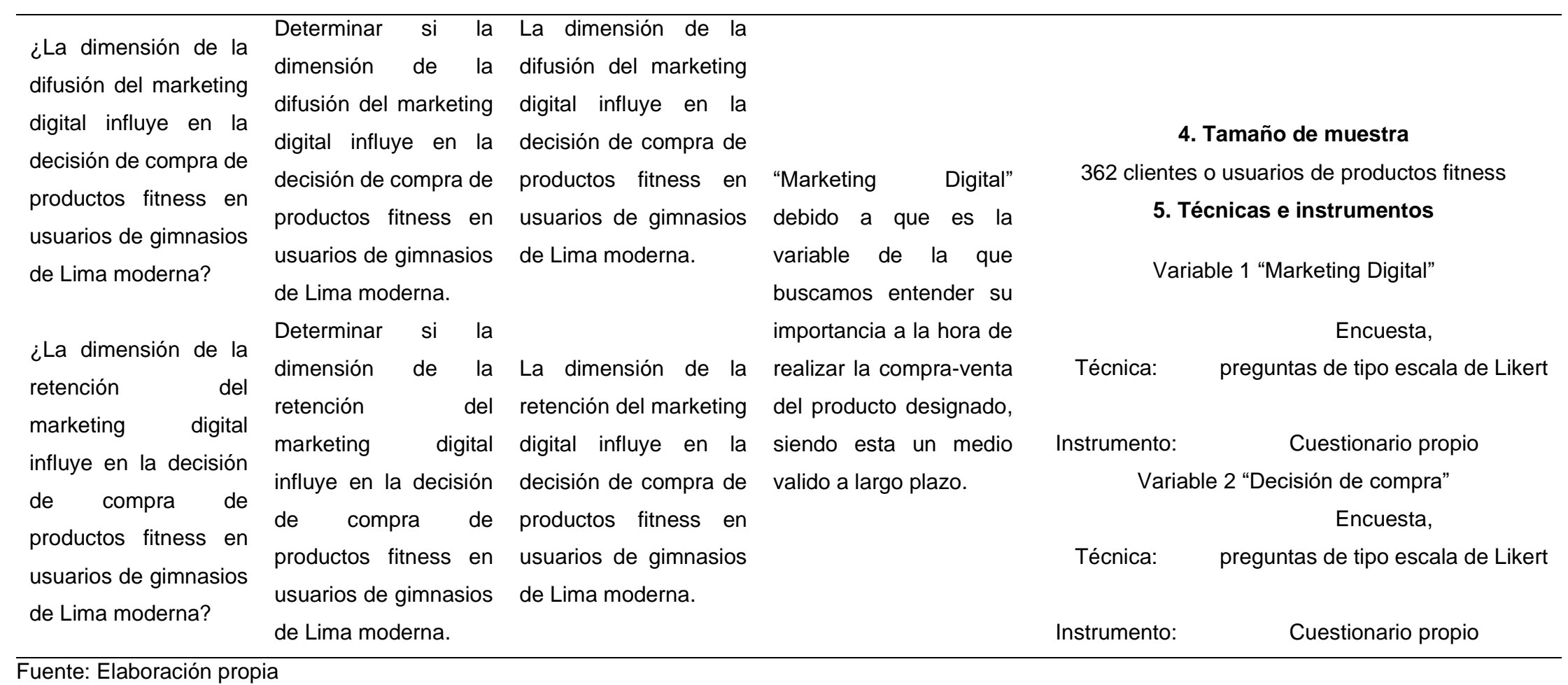


Anexo B:

Matriz operacional.

\begin{tabular}{|c|c|c|c|c|c|c|}
\hline Variables & Definición & Dimensión & Indicador & Item & Escala & Instrumento \\
\hline Marketing Digital & $\begin{array}{l}\text { Proceso de gestión } \\
\text { integral de esfuerzos de } \\
\text { venta enfocados a la } \\
\text { creación de incentivo y } \\
\text { anticipación de las } \\
\text { demandas de un } \\
\text { consumidor, por medio } \\
\text { del uso de canales } \\
\text { digitales. }\end{array}$ & Atracción & $\begin{array}{c}\text { Factores } \\
\text { considerados más } \\
\text { importantes a la hora } \\
\text { de adquirir productos } \\
\text { fitness } \\
\\
\text { Valoración de la } \\
\text { información digital } \\
\text { adquirida } \\
\\
\text { ¿Qué medios } \\
\text { enterarse de } \\
\text { productos, ofertas y } \\
\text { otras novedades? }\end{array}$ & $\begin{array}{c}\text { ¿Qué tan importante me parece la marca a la hora } \\
\text { de adquirir productos fitness? } \\
\text { ¿Qué tan importante me parece el precio a la hora } \\
\text { de adquirir productos fitness? } \\
\text { ¿Qué tan importante me parece el valor nutricional a } \\
\text { la hora de adquirir productos fitness? } \\
\text { ¿Qué tan importante me parece una recomendación } \\
\text { de amistad a la hora de adquirir productos fitness? } \\
\text { ¿Qué tan importante me parece la influencia de } \\
\text { expertos a la hora de adquirir productos fitness? } \\
\text { ¿Qué tan importante me parece la novedad de un } \\
\text { producto a la hora de adquirir productos fitness? } \\
\text { ¿Qué tan importante me parece la publicidad por } \\
\text { medios digitales a la hora de adquirir productos } \\
\text { fitness? } \\
\text { ¿Qué tan importante me parece la promoción con } \\
\text { descuento en una compra en línea a la hora de } \\
\text { adquirir productos fitness? } \\
\text { ¿Qué tan importante me parece recibir información } \\
\text { en línea para realizar compras importantes a la hora } \\
\text { de adquirir productos fitness? } \\
\text { ¿Qué tan importante me parece poder hacer } \\
\text { compras por tiendas digitales a la hora de adquirir } \\
\text { productos fitness evitando salir de casa? } \\
\text { ¿Qué tan importante me parece las páginas web de } \\
\text { los vendedores a la hora de adquirir productos } \\
\text { fitness? } \\
\text { ¿Qué tan importante me parecen los correos de } \\
\text { vendedores con novedades y ofertas a la hora de } \\
\text { adquirir productos fitness? }\end{array}$ & $\begin{array}{l}\text { No importante } \\
\text { Poco Importante } \\
\text { A veces } \\
\text { importante } \\
\text { Importante } \\
\text { Muy importante } \\
\text { No importante } \\
\text { Poco Importante } \\
\text { A veces } \\
\text { importante } \\
\text { Importante } \\
\text { Muy importante } \\
\text { No importante } \\
\text { Poco Importante } \\
\text { A veces } \\
\text { importante }\end{array}$ & Encuesta \\
\hline
\end{tabular}


¿Qué tan importante me parece la publicidad en

\section{Retención \\ Valoración de} compra

Etapa en la cual el consumidor realmente adquiere el producto fitness

\section{Frecuencia de Compra}

Frecuencia de

Compra de
Decisión de compra páginas web ajenas a la del vendedor a la hora de adquirir productos fitness?

¿Qué tan importante me parece la opinión de influencers a la hora de adquirir productos fitness? ¿Qué tan importante me parece que las marcas fitness patrocinen a mis influencers favoritos a la hora de adquirir productos fitness?

¿Qué tan importante me parece la reputación de los proveedores de productos fitness a la hora de adquirir productos fitness en línea?

¿Qué tan importante me parece la confiabilidad de distribuidores oficiales web frente al precio más bajo de proveedores minoristas no oficiales a la hora de adquirir productos fitness en línea?

¿Qué tan importante me parece facilidad de distribución del vendedor a la hora de adquirir productos fitness en línea?

\section{Importante}

Muy importante

No importante

\section{Poco Importante}

A veces

importante

¿Qué tan importante me parece tener una buena experiencia con un producto fitness a la hora de volver a adquirir otro producto similar o igual en un futuro no muy lejano?

¿Qué tan importante es realizar compras futuras con un vendedor de confianza (a quien ya compré

previamente) a la hora de adquirir productos fitness? ¿Qué tan importante me parece el asesoramiento personalizado en línea del vendedor a la hora de adquirir productos fitness?

¿Qué tan importante me parece la comunicación post compra en línea con el vendedor a la hora de adquirir productos fitness?

Consumo productos fitness más de una vez al mes

Productos Fitness

Compro productos fitness más de una vez cada tres meses

\section{Importante}

Muy importante

No me identifico

Me identifico

poco

A veces me

identifico

Me identifico

Me identifico en

gran medida 
consumo de

productos fitness?

Nivel de

motivación de

compra
Bajar de peso es el motivo por el cual consumo productos fitness.

Aumentar masa muscular es el motivo por el cual consumo productos fitness

Aumentar mi resistencia es el motivo por el cual consumo productos fitness

Conseguir resultados más rápidos es el motivo por el cual consumo productos fitness.

El asesoramiento personalizado en línea me incentiva a comprar productos fitness incluso aquellos que no he consumido con anterioridad.
Me identifico

poco

A veces me

identifico

Me identifico

Me identifico en

gran medida

Fuente: Elaboración propia 
Anexo C:

Guía de pauta de la entrevista de profundidad

\section{Selección de los expertos}

Para la selección de expertos se optó por incluir a personas con más de un año de experiencia en venta de productos fitness, que ofertan por medios digitales y por último que comercialicen en más de un distrito (ofertan o venden).

\section{Objetivo de la entrevista}

Hallar puntos claves que servirían como base para la elaboración del estudio:

- Focus group

- Encuesta para el estudio cuantitativo

\section{Guía del moderador}

Buenos días/tardes/noches. Mi nombre es Diego/Richard y estamos realizando un estudio sobre la comercialización de productos fitness por internet.

El objetivo es poder conocer distintas opiniones para colaborar con el desarrollo de la investigación. Siéntase libre de expresar sus ideas ya que no existen respuestas erradas, lo que importa es que su respuesta sea sincera. Resaltando que la información obtenida, será solo para nuestra investigación. Así mismo se procederá a grabar en video o audio la conversación, para su posterior análisis. ¿Existe algún problema en que grabemos la conversación? le recordamos que el uso de la grabación es sólo para fines de análisis.

¡Gracias por su participación!

$\underline{\text { Conocimiento del entrevistado }}$

- Nombre, edad, lugar de trabajo

- Profesión. cargo actual y trayectoria

- Experiencia actualmente 


\section{Preguntas generales}

- ¿Cómo iniciaste en este mercado?

- ¿Cuál fue el motivo?

- ¿Cuánto tiempo llevas trabajando en este mercado?

- ¿Trabajas con una sola marca o múltiples marcas?

Análisis del mercado actualmente (Productos fitness)

- ¿Cómo sabes que producto ofertar?

- ¿Cuáles son los productos que siempre tienen demanda?

- En caso de tener proveedores, ¿Cuáles son?

- ¿Consideras que este mercado es competitivo?

Análisis de los medios sociales

- ¿Qué plataforma usas para captar clientes?

- ¿Qué proceso normalmente lleva a una venta?

- ¿Cómo consigues más posibles compradores?

- ¿Cómo fidelizas a un comprador?

Presupuesto y fuentes de financiamientos

- ¿Cuál es tu porcentaje de inversión?

- ¿Cuál es tu margen de ganancia?

- ¿Qué productos ofrecen el mayor margen de ganancia?

- ¿Cuál es tu porcentaje de ventas en relación de compradores nuevos y recurrentes?

\section{Plan de mejora}

- ¿Qué consideras podrías hacer para mejorar tus ganancias o ser más competitivo?

- ¿Qué percepciones erradas son más difíciles de erradicar en la mentalidad de un comprado?

\section{Agradecimiento y despedida}

Se agradeció a los entrevistados por su tiempo, así como permitir recopilar la información obtenida por medio de una grabación. 
Anexo D:

Entrevistas de profundidad

Entrevista a profundidad \#1

Nombre: Juan Manuel Angulo Espinoza

Cargo: Entrenador de Smartfit, con más de 4 años de experiencia en ventas por internet y fundador Active Fit funtional kids (programa de entrenamiento funcional para niños)

Resumen de la Entrevista a Profundidad

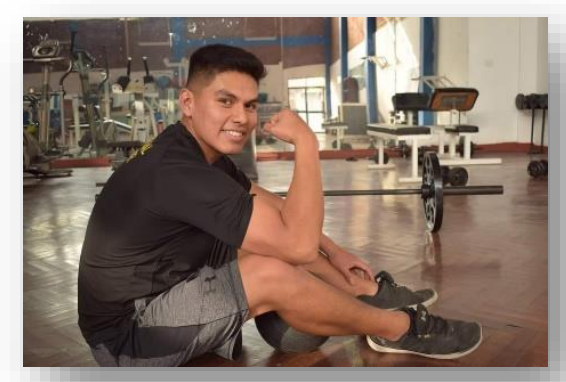

En términos generales, el entrevistado resolvió dudas generales en cuanto al sector de la industria fitness

- ¿Como averiguas que es lo que se vende y tiene más demanda?

Los distribuidores ofrecen diferente productos y alternativas que van saliendo al mercado, según los productos que impulsan a los fisicoculturistas o personas dedicadas a este mundo.

- Al mencionar proveedores, ¿a qué marcas especificas te refieres?

Trabajo con distribuidores mayoristas, se dedican a traer grandes cantidades y yo las adquiero como un tercero.

- ¿Estas personas tienen un nombre como empresa o son terceros?

Son empresas que traen diversos productos que no son tan conocidos en ocasiones, pero lo traer directamente de Estados Unidos.

- ¿Cómo captas a los clientes, cuál es su proceso y su plataforma preferida?

Principalmente uso Facebook, realizo ciertas campañas, como sorteos en vivo, a través de mis clases recomiendo mi página y hago que me sigan, captando así más clientes.

- ¿Recomiendas los productos y vas generando así un boca a boca más personal?

Así es, yo voy recomendando a las personas los productos según su objetivos y preferencias.

- ¿Como mantienes las novedades de los productos nuevos y tendencias por las páginas web? Normalmente cada fisicoculturista que va ganando campeonatos o los deportistas que recomiendan suplementos; pero siempre hay tendencia por lo clásico, se mantienen los suplementos básicos, van cambiando de insumos o marcas.

- ¿De estos insumos clásicos, que es lo que más vende?

Proteínas, quemadores de grasa y pre entreno

- ¿De estos productos, cual es que más margen de ganancia generan?

Los quemadores de grasa

- ¿En qué consisten y para qué sirven? 
Son aminoácidos con estimulantes y aditivos como la cafeína, carnitina, taurina, reforzadas con BCAA. La carnitina es la más común y el extracto de té verde. Son aminoácidos, antioxidantes que ayudan a reducir la grasa del cuerpo, en ocasiones vienen acompañados de un estimulante como taurina y cafeína que altera y acelera el proceso del metabolismo.

- ¿Estos términos son técnicos, como explicas o transfieres estos conocimientos a los clientes? Actualmente los clientes se informan, ya que el mercado es muy amplio y ya están informados.

- ¿Esa información ya no están intimidante para los clientes?

Ya no es tan intimidante, la mayoría de clientes tiene noción de lo que consume, pero hay parte de la población que desconoce y simplemente pide alcanzar un objetivo y lo cumplen.

- ¿En este mercado, también existen clientes novatos?

El mercado es muy amplio, pero también hay cierto desconocimiento; tiene nociones, pero no de manera especializada.

- ¿Cuánto tiempo le dedicas ya que no es tu actividad principal? ¿Cuál es tu monto de inversión y cuanto es tu retorno de ganancia?

Yo me dedico a ser entrenador personal de manera principal, la venta de suplementos me ayuda, le dedico solo un $20 \%$, por eso me apoyo en la página de Facebook; mi inversión mensual esta entre 1000 a 2000 soles.

- ¿Y el retorno que consigues al mes?

No solo vendo suplementos, lo acompaño con servicios como toma de medidas, evaluaciones, plan nutricional. Le doy un valor agregado. De esta forma, tengo un mayor beneficio, ganando $30 \%$ más de lo invertido.

- Los consumidores nuevos pueden ser reacios a consumir los productos, ¿cuál es la proporción de clientes nuevos en comparación de los ya conocedores?

Creo que es $50 \%$ cada uno ya que hay de todo un poco. Las nuevas generaciones están más informadas sobre el mercado fitness, pero los adultos a veces no están informados y los compran en base a recomendaciones.

- Las personas que vuelven a comprar, ¿Qué proporción de toda tu clientela es? Es un $80 \%$ ya que son clientes fieles a los que ya tiene un seguimiento y mis servicios.

- ¿Estas personas son abiertas a comprar productos nuevos o de mayor precio? Al yo ser su entrenador, confían en lo que yo les recomiendo, y voy descartando o moviendo productos, según precio y efectividad.

- ¿Cuál es el porcentaje de personas que te compran sin ser clientes?

Es de un $20 \%$

- Entonces, ¿Aprovechas esto para promover tu negocio?

Claro, principalmente a la compra de suplementos.

- ¿Ves un futuro potencial en este mercado y en qué etapa crees que están estos productos? 
Creo que está en decadencia ya que nada es como antes, los precios están bajos y el margen de ganancia es bajo. Para poder venderlo tengo que agregarle un valor para que pueda ser rentable para mí ya que los precios bajaron mucho.

- Como consumidor, ¿lo considerarías positivo?

Como consumidor, si lo consideraría positivo ya que los precios son bajos. Es una industria que evoluciona ya que hay diversas marcas en el mercado.

- ¿Qué le dirías a las personas que creen que las proteínas son anabólicas?

Las proteínas son alimentos, pre-digeridas, suero de leche, insumos naturales que fueron procesados para hacerlos más digeribles. En contraste, los anabólicos son hormonas ilegales de laboratorio. 


\section{Entrevista a profundidad \#2}

Nombre: Marco campos

Cargo: Licenciado en educación física y Especialista en el desarrollo de la musculación deportiva e incremento del alto rendimiento.

Resumen de la Entrevista a Profundidad

En términos generales el entrevistado resolvió dudas generales

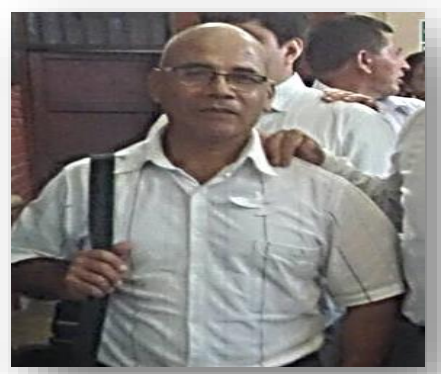

en cuanto al sector de la industria fitness

- ¿Cuántos años lleva en este mercado?

En el mercado de venta de suplementos llevo 5 o 6 años.

- ¿Qué le incentivo a entrar en este mundo fitness?

Mi movimiento personal en el mundo deportivo fue siempre la educación física y entrenamiento en el gimnasio. Me inquietó mucho la venta de estos productos y la mala información que existía.

- ¿Cuál es su experiencia?

Soy Licenciado en educación física y me enfoco en la musculación deportiva y desarrollo de entrenamiento de alto rendimiento. Eso me inquietó a saber más a fondo el tema nutricional.

- Sobre la falta de información, ¿Cuál es el mayor problema que encuentra?

En muchos gimnasios hay entrenadores que no son profesores y les recomiendan a las personas suplementos que no van acorde a su objetivo.

- ¿Qué medio de comunicación usa para impartir conocimiento?

Uso el Facebook, el volanteo en mi tienda y reparto a los gimnasios.

- ¿Como asesora a un cliente nuevo por Facebook?

Por mi página se comunican al teléfono o mercado libre, yo le respondo y le sugiero.

- ¿Después de la venta usted mantiene contacto con los clientes?

De acuerdo al interés y su satisfacción, se hace un seguimiento para que vea los efectos de los productos.

- ¿Cuál es el porcentaje de los clientes recurrentes?

20 ○ $30 \%$ clientes nuevos ya que los asesoro y les doy el alcance necesario para que logren sus objetivos.

- ¿Qué porcentaje de sus clientes son recurrentes?

Como ofrezco por mercado libre o el Facebook regresa el 70\%, pero ahora hay mucha competencia.

- ¿Cuánto invierte al mes aproximadamente?

Empecé con 10,000 soles. Con el tiempo fue invirtiendo más según el retorno.

- ¿Cuánto es su margen de ganancia?

$60 \%$ de margen. 
- ¿Cómo percibe que está el mercado?

Debe ser maduro ya que se mantiene.

- Si estos productos generan dinero y hay gente interesada, ¿por qué cree que no hay tanta publicidad en la televisión?

Pienso que es por el costo de publicitar en televisión ya que es muy alto.

- Sobre sus productos estrella. ¿Qué productos vende más?

Los quemadores y el whey protein, que es suero de leche.

- ¿Cuál le da más margen de ganancia?

Los dos tienen mucho margen de ganancia.

- ¿Cómo diferencia a un usuario nuevo o consecuente?

La persona que se inicia tiene confusión por el sistema de entrenamiento o la variedad de productos que ya están en el mercado.

Los intermedios y avanzados tienen un objetivo y ya son conocedores.

- Sobre los medios que usa para vender sus productos, ¿Fue fácil el ingreso?

En el ámbito que yo me desarrollo, me satisface tener mi marca y es un complemento de mi actividad

- ¿Qué porcentaje le dedica a su trabajo y venta de proteínas?

$50 \%$ a cada actividad.

- ¿Usted hace seguimiento a los clientes?

Hay clientes que ya tienen un entrenamiento personalizado conmigo y tienen un precio especial con el asesoramiento. A veces, los asesoramientos en los gimnasios no son los adecuados ya que no hay seguimiento y yo me diferencio de ellos. La nutrición también es importante y también me preocupo por ello, a comparación de los gimnasios que dan dietas sin ser nutricionistas.

- ¿Qué distritos son los que tienen más llegada?

El cono norte me hace más pedidos, Miraflores también y en Chorrillos también piden, poco, pero piden. Son clientes recurrentes.

Como educador y experiencia en este mundo, recomiendo buscar una alternativa adecuada, puesto que las reacciones metabólicas son diferentes, entonces la suplementación tiene q ser diferente.

- ¿Considera que otros medios también servirían para hacerse más conocido?

Con los medios que uso actualmente me va bien.

- ¿Cómo diseña su distribución?

Tengo 02 personas que me ayudan con la distribución, para que sea más efectiva mientras yo me encargo de otros temas. 


\section{Entrevista a profundidad \#3}

Nombre: Gabriel Solano

Cargo: Personal Trainer certificado en la federación peruana y nutricionista deportivo.

\section{$\underline{\text { Resumen de la Entrevista a Profundidad }}$}

En términos generales el entrevistado resolvió dudas

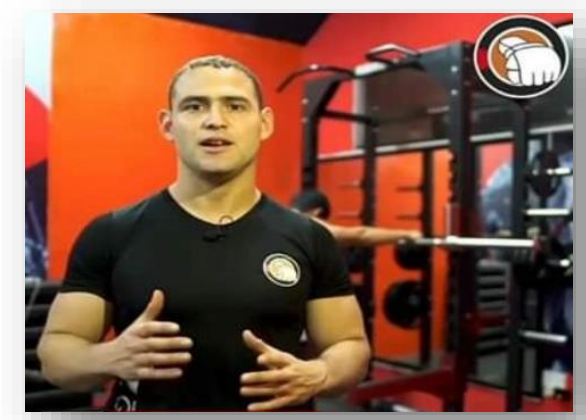
generales en cuanto al sector de la industria fitness

- ¿Cuántos años lleva en el mercado?

Llevo alrededor de 10 años en la venta de suplementos.

- ¿Qué le incentivó a entrar en este mundo fitness?

El principal motivo fue por querer tener un estilo saludable ya que es la base para cualquier deporte que quisiera desempeñar y al mismo tiempo poder ayudar a otros a alcanzar su mejor físico de manera saludable y fue así como empezar estudiar.

- ¿Cómo nació la idea de vender suplementos?

A parte de tener un ingreso más, nació por darle calidad de vida a los alumnos de los gimnasios donde yo trabajo y poder optimizar sus entrenamientos de trabajos

- ¿Cómo averiguas qué es lo que se vende y tiene más demanda?

Hago un análisis de acuerdo a los productos que más me piden los clientes, y siempre estoy al tanto de las novedades de los suplementos nuevos que salen para poder analizarlos y así poder ofrecerles a mis clientes.

- ¿Cómo capta a los clientes y cuál es tu plataforma preferida?

Hago ventas directas a mis alumnos de los gimnasios y, muy aparte, por redes sociales como Facebook.

- ¿Cómo asesora a un cliente nuevo por Facebook?

Luego que me dejan un mensaje me comunico con ellos para ver sus dudas, necesidades y así poder ofrecerles productos adecuados de acuerdo a sus objetivos.

- Después de la venta, ¿mantiene contacto con los clientes?

Así es. Les hago seguimiento para que sigan en camino a sus objetivos y siempre brindándoles apoyo o resolviendo sus dudas.

- ¿Considera los medios digitales como una buena herramienta de ingresos?

Sí, mas no dependo de ellos. Mayormente mis ventas son directas, por ejemplo, viene un cliente y yo le recomiendo su dieta y le digo que suplemento consumir como opción.

- ¿Cómo consigue nuevos clientes? 
En el mismo gimnasio, estoy como trainer y ahí le recomiendo su dieta y suplementos y por medios digitales, por preguntas.

- ¿Cuáles son tus ingresos por medios digitales?

Al mes genero 300 soles aproximadamente, en cambio directo genero entre $\mathrm{S} / 1000$ y $\mathrm{S} / 1500$ mensuales.

- ¿Consideras importante los medios digitales?

Por supuesto que sí, pero yo solo tengo interés comercial en estos.

- ¿Qué es lo que te gustaría mejorar en este mercado?

Tener un área de nutrición en el gimnasio para darle más personalización al cliente y vender más.

- ¿Qué distritos son a los que vendes más?

Los distritos que tengo más clientes son: La Molina, Ate Vitarte, Santa Anita, El Agustino, Surco.

- De estos productos, ¿Cuál es que más margen de ganancia genera?

Los quemadores y las proteínas.

- ¿Cuál es tu monto de inversión y retorno de ganancia?

Cuando empecé invertí S/. 700 a S/.1,000 en productos y ahora invierto entre S/. 10,000 a S/. 15,000 soles.

- Las personas que vuelven a comprar, ¿Qué proporción de toda tu clientela son?

La verdad es un $90 \%$. No solo vendo suplementos sino también hago asesoramientos y eso es lo que hace que mis clientes vuelvan a comprarme ya que saben la calidad y profesionalismo de mis servicios.

- ¿Estas personas son abiertas a comprar productos nuevos o de mayor precio?

Al ser su personal trainer, ellos están abiertos a seguir mis recomendaciones. De acuerdo a sus avances puedo o no sugerir otros productos.

- ¿Cuál es el porcentaje de personas que te compran sin ser clientes?

$30 \%$

- ¿Ves un futuro potencial en este mercado y en qué etapa crees que esta estos productos?

El mundo fitness cada día crece más. Hay más personas que se preocupan por su salud, pero en tema de ganancia es bajo. Por eso, lo que hago es poder ofrecer un servicio extra que vendría a ser mi asesoramiento privado. De esa manera logro captar clientes y puedo seguir generando ingresos con la fidelidad de ellos. 
Anexo E:

Guía de pauta del FOCUS GROUP

\section{Segmento a investigar}

Hombres y mujeres de 18 a 39 años, que diariamente utilicen las redes sociales, que consuman productos fitness por lo menos tres veces al mes y que vivan en los distritos de Lima moderna.

\section{Muestra}

Se realizó un focus group, el cual fue llevado a cabo en las instalaciones del hogar de Richard Madge ubicado en el distrito de Miraflores. La muestra estará conformada por 6 personas el cual se seleccionaron aleatoriamente.

\section{Guía del moderador}

1) Presentación del Moderador

2) Explicación sobre el motivo de la reunión

3) Se hará la presentación de los participantes del Focus Group de tal manera que puedan entrar en un ambiente cómodo y agradable.

4) Duración del Focus Group será de 45 minutos

\section{Explicación Introductoria}

- llustrar de qué manera se desempeña las sesiones de grupo.

- Esclarecer que no existe respuesta correcta y que solo son opiniones.

- El Focus Group se grabará con el motivo que se pueda analizar las respuestas de los participantes.

- Informar a los participantes que solo hable una persona a la vez, y si le apetece dar una opinión puede levantar la mano.

- Si un participante tiene una opinión diferente o desea aclarar algo a las demás personas del grupo, es importante que lo haga saber al moderador.

- El moderador preguntará si algún participante tiene alguna pregunta. 


\section{Rompimiento de hielo}

- Para romper el hielo se les hizo preguntas básicas como, por ejemplo, como les gusta que los llamen, en que trabajan o que estudian.

\section{Preguntas Generales o de Apertura}

1) ¿Cómo ingresaron al mundo fitness y que les llamó la atención?

2) ¿Qué tipo de productos fitness consume? considerando que todos tienen objetivos diferentes

\section{Preguntas de Transición}

3) ¿Cómo se enteraron de la existencia de los productos que consumen y si utilizaron algún medio para confirmar su utilidad?

4) ¿Ustedes siguen una celebridad o gurú del deporte que los influencia a intentar cosas nuevas relacionadas con el mundo fitness?

\section{Preguntas específicas}

5) ¿Qué valoran más el precio o la conveniencia de las nuevas facilidades de distribución?

6) ¿Qué considera más importante la confianza que tienen una marca o la reputación de una persona del mundo fitness?

7) ¿Confían en las diferentes facilidades de pago digital y el uso proveniente de las pasarelas de pago como medios de protección para el vendedor, así como el comprador?

8) ¿Dejaría su información guardada en alguno de estos medios para una compra recurrente más fácil?

9) ¿Consideran ver productos en línea y para luego buscarlos físicamente como una opción viable?

10) ¿Considera que el uso de aplicaciones móviles es un factor de retención importante para fidelizar el valor de una empresa?

11) ¿Qué necesita una marca o vendedor para ganarse su compra recurrente?, siguiendo la pregunta de todos los factores escritos, ¿sí pudieran elegir una cual sería? 
12) ¿Qué considera que las marcas o vendedores deberían hacer para traer a personas fuera de este nicho de mercado o a entusiastas que no están tan metidos en el mundo fitness?

\section{Preguntas de Cierre}

13) ¿Qué sugerirían a las marcas o vendedores a cambiar según su experiencia personal para hacer la experiencia de compra más placentera?

14) ¿Consideran que estos productos van a tener un buen desarrollo de ventas en línea o que llegará a un punto de sobresaturación de oferta, considerando el bajo nivel de dificultad para entrar en este mercado?

Agradecimiento por la participación

Se agradeció a las personas por su participación y disposición que tuvieron para venir al focus group, así mismo por las sorprendentes respuestas que se obtuvieron a las preguntas que se les realizaron. Por último, se les obsequió algunos productos fitness como barras proteicas, bebidas energizantes y agua por su participación.

Anexo F:

FOCUS GROUP

\begin{tabular}{lll}
\hline PREGUNTA & $\begin{array}{l}\text { RESUMEN BREVE/ } \\
\text { PALABRAS CLAVE }\end{array}$ & VERBATINES \\
\hline
\end{tabular}

1. ¿COMO INGRESARON AL MUNDO FIT Y QUE FUE LO QUE LES LLAMÓ LA ATENCIÓN?

2. ¿CONSIDERAN LA VIDA FITNESS, COMO UN ESTILO DE VIDA O ALGO MOMENTÁNEO?
-Estilo de vida

-Rutina

-Hábito
-Sigo a personas "famosas" en redes sociales, las cuales llevan estilo de vida saludable.... -Recomendaciones de amigos -Costumbre.
- (...) mis amigos me comentaron de la vida sana que ellos llevan ...

-Tengo personas cercanas (...) ellos son de llevar estilo de vida saludable y son veganos. 
3. ¿QUÉ CONSIDERAN AL MOMENTO DE CONSUMIR SUPLEMENTOS?

4. ¿QUÉ TIPO DE PRODUCTOS FITNESS CONSUMES?

5. ¿QUÉ MEDIOS USAS PARA CONOCER LOS PRODUCTOS?

6. ¿SIGUEN O SE BASAN EN ALGUIEN CONOCIDO DEL MUNDO FITNESS?

7. ¿POR QUÉ ES IMPORTANTE SEGUIR A ALGUIEN DE ESTE TIPO DE VIDA SALUDABLE?

8. ¿QUÉ VALORAN MAS PRECIO O CONVENIENCIA SOBRE EL TIPO DE ENTREGA?

9. ¿QUÉ CONSIDERAN MÁS IMPORTANTE, LA REPUTACIÓN DE LA MARCA O LA RECOMENDACIÓN DE ALGUIEN CONFIABLE?

10. ¿CONFÍAN EN LA COMPRA EN LÍNEA?

11. ¿DEJARÍAN GUARDADO SUS DATOS PARA COMPRAS EN LÍNEA, DE EMPRESAS EN PERÚ?
-Precio y beneficio

-Marca

-Nutrición

-Información

- La mayoría de entrevistados respondieron proteínas y quemadores de grasa.

-Redes sociales.

-Gimnasio

-Internet

-Nutricionista

-Amistades

-Todos los entrevistados dijeron que sí, entre sus respuestas estaban: "influencers", modelos y youtubers

-Todos los entrevistados dijeron que servía de motivación y guía.

-Precio

-Conveniencia

-Ver el precio en tienda

-Todos los entrevistados respondieron que tanto la marca como recomendación influyen.

- La mayoría respondió que sí. Solo una persona, dijo que no.

-Todos respondieron que no.
-Me enfoco en que el producto vaya de acuerdo a mi objetivo...

-(...) Tengo un amigo que trabaja en el gimnasio y me vende más barato...

-(...) para consumir un producto hay que saber que contiene y si son naturales ...

-(..) un amigo del gimnasio me recomendó las proteínas y él mismo me las vende.

Tomo proteína natural (...) por recomendación de un entrenador personal... - las proteínas las tomo como batido, para ganar masa muscular.

- En Facebook hay promociones de estos productos...

-Mi entrenador personal me recomienda productos y leo las recomendaciones de las personas que ya han consumido...

-(...) algunos de mis amigos toman proteínas de marcas conocidas...

- El nutricionista me recomendó algunos suplementos según mi objetivo.

-Veo a las "influencers" en Instagram, que muestran sus rutinas y comidas saludables... - (...) las modelos recomiendan tipos de suplementos...

- Veo vídeos en YouTube, donde dan tips de estilos de vida saludable y rutinas de ejercicios.

-Es como un ideal para seguir y conocer ese mundo...

-Sirve de guía para seguir un estilo de vida diferente.

-...Si me ofrecen un valor agregado, como llevarlo a mi casa, perfecto...

-..conviene que lo lleven a casa, así no pierdo tiempo en el tráfico.

-Prefiero ir a la tienda y comprarlo ahí mismo. -Pido que lo envíen a mi casa, ya que vivo lejos.

-La marca tiene que ser confiable (...) para consumir su contenido según la recomendación de alguien.

-Las personas que recién inician, confían más en las recomendaciones, en cambio los que ya llevan tiempo, ya saben y conocen... - Solo lo usaría si es a través de una transferencia bancaria directa...

- (...) confío bastante, pero también uso la contra entrega.

-Solo si se usa cuenta con página verificada, (...) en todo caso, uno la pasarela de pagos o la opción de mercado pago.

-La mayoría de veces compro por internet y es seguro.

-Un amigo si compra, pero yo no, ya que dudo de cómo podría llegar el producto.

-... prefiero poner mis datos cada vez que compro, sin guardarlos.

-Uso una tarjeta especialmente para compras en línea. 
12. ¿DEJARÍAN GUARDADO SUS DATOS PARA COMPRAS EN LíNEA, DE -Todos respondieron que no. EMPRESAS EXTRANJERAS?

13. ¿PREFIEREN VER EL PRODUCTO EN TIENDA O COMPRARLO ON LINE?

- Ir a la tienda.

-Contra entrega

14. ¿CONSIDERAN QUE ES INDISPENSABLE QUE LAS TIENDAS TENGAN APLICATIVO MÓVIL? VENDEDOR O MARCA PARA QUE USTEDES SIGAN COMPRANDO?

16. ¿DE LOS FACTORES MENCIONADOS, CUÁL ES EL MÁS IMPORTANTE?

17. ¿QUÉ TENDRÍA QUE HACER UNA MARCA PARA LLEGAR A LOS USUARIOS POTENCIALES?
15. ¿QUÉ NECESITA UN
-Todos respondieron que sí es importante y necesario.

-Buen trato.

-Promociones.

-Información.

-Precio.

-Calidad.

-Los entrevistados dijeron reputación, calidad y precio.

-Videos informativos

-Servicios personalizados.

-Resultados

-Asesoría

-Segmentación

suplementos.
-Por prevención no lo haría....

-Prefiero la seguridad de mis datos.

-Prefiero ver los precios, pagarlo y llevarme el producto...

-...si es la primera vez que compro, iría a la tienda (...) si lo compro varias veces, lo haría contra entrega.

-... lo veo por internet y pido para que lo dejen en casa.

-Da mayor confiabilidad a la marca...

- ...hay más acceso a la información.

- Si tengo dudas, puedo acceder de manera directa a un contacto.

- La misma empresa a través de la aplicación envía mensajes de promociones 0 descuentos.

-Si hay buen trato, compraría siempre.

-Si me comentan que es un buen vendedor, sin duda le compraría.

-... si es personalizado y se preocupa para hacerme un seguimiento, de hecho, sería su comprador fijo.

-... es mejor saber qué vas a consumir, más allá de ver el precio, ya que va directo a tu organismo...

-...que muestren las cualidades que contienen los productos...

- Hacer un perfil a cada cliente, según sus requerimientos ...

- Mostrar videos reales de los cambios de las personas que consumen sus productos.

-Asesoría por redes sociales y promociones a sus clientes.

-Segmentar los suplementos, de acuerdo al deporte que realiza cada persona...

18. ¿CONSIDERA QUE LA POPULARIDAD DE UN DEPORTE ES PRIMORDIAL PARA QUE SE PUBLICITEN LOS PRODUCTOS FITNESS?

19. ¿QUÉ RECOMENDARÍAN A LOS VENDEDORES SEGÚN SU EXPERIENCIA PERSONAL?

20. ¿CONSIDERA QUE LOS PRODUCTOS FITNESS TIENE FUTURO EN EL MERCADO DE VENTA EN LÍNEA?
$-\mathrm{NO}$

-Sí

-Segmentar los productos. -Decir los efectos secundarios del consumo. -Información más específica.

-Todos los encuestados respondieron que sí.
-... Todos creen que las proteínas son solo para el gimnasio, pero no es así.

-Asociar el producto con el deporte, es algo que las marcas aún no lo aplican.

-No hay información que provenga de las mismas marcas, sobre los efectos secundarios del consumo de suplementos.... - Asesoría más profunda para explicar a cada uno qué es lo que realmente necesita.

- Deberían invertir más en publicidad e información....

- La vida sana está de moda, entonces las ventas de suplementos también. 
Anexo G:

Cuestionario

\section{Marketing digital para productos fitness}

\section{Instrucciones:}

Estimado(a) participante, favor de seleccionar un numero según la importancia que les da a las siguientes afirmaciones.

1. No importante 2. Poco importante 3. A veces importante 4. Importante 5. Muy importante

\begin{tabular}{|c|c|c|c|c|c|c|}
\hline Nro. & Preguntas & 1 & 2 & 3 & 4 & 5 \\
\hline & Dimensión 1. Nivel de atracción & & & & & \\
\hline 1 & La marca a la hora de adquirir productos fitness. & & & & & \\
\hline 2 & El precio a la hora de adquirir productos fitness. & & & & & \\
\hline 3 & El valor nutricional a la hora de adquirir productos fitness. & & & & & \\
\hline 4 & Una recomendación previa a la hora de adquirir productos fitness. & & & & & \\
\hline 5 & Los comentarios de expertos a la hora de adquirir productos fitness. & & & & & \\
\hline \multirow[t]{2}{*}{6} & La innovación de un producto a la hora de adquirir productos fitness. & & & & & \\
\hline & Dimensión 2: Nivel de difusión & & & & & \\
\hline 7 & $\begin{array}{l}\text { La publicidad por medios digitales a la hora de adquirir productos } \\
\text { fitness. }\end{array}$ & & & & & \\
\hline 8 & Los descuentos en línea a la hora de adquirir productos fitness. & & & & & \\
\hline 9 & $\begin{array}{l}\text { Recepción de información en línea para realizar compras grandes a la } \\
\text { hora de adquirir productos fitness. }\end{array}$ & & & & & \\
\hline 10 & $\begin{array}{l}\text { El poder hacer compras por tiendas digitales a la hora de adquirir } \\
\text { productos fitness evitando salir de casa. }\end{array}$ & & & & & \\
\hline 11 & $\begin{array}{l}\text { Que las páginas web de los vendedores aparezcan en los anuncios } \\
\text { destacados del buscador web a la hora de adquirir productos fitness. }\end{array}$ & & & & & \\
\hline 12 & $\begin{array}{l}\text { Recibir correos de vendedores con novedades y ofertas a la hora de } \\
\text { adquirir productos fitness. }\end{array}$ & & & & & \\
\hline 13 & $\begin{array}{l}\text { La publicidad en páginas web ajenas a la del vendedor a la hora de } \\
\text { adquirir productos fitness. (SEM) }\end{array}$ & & & & & \\
\hline 14 & La opinión de influencers a la hora de adquirir productos fitness. & & & & & \\
\hline \multirow[t]{2}{*}{15} & $\begin{array}{l}\text { Las marcas fitness patrocinen a mis influencers favoritos a la hora de } \\
\text { adquirir productos fitness. }\end{array}$ & & & & & \\
\hline & Dimensión 3: Nivel de retención & & & & & \\
\hline 16 & $\begin{array}{l}\text { La reputación de los proveedores de productos fitness a la hora de } \\
\text { adquirir productos fitness en línea. }\end{array}$ & & & & & \\
\hline 17 & $\begin{array}{l}\text { Los proveedores oficiales me generan confianza que el producto } \\
\text { recibido no será adulterado de ninguna manera. }\end{array}$ & & & & & \\
\hline 18 & $\begin{array}{l}\text { La facilidad de distribución del vendedor a la hora de adquirir } \\
\text { productos fitness en línea. }\end{array}$ & & & & & \\
\hline 19 & $\begin{array}{l}\text { La experiencia positiva del producto fitness a la hora de volver a } \\
\text { adquirir otro producto similar o igual en un futuro no muy lejano. }\end{array}$ & & & & & \\
\hline 20 & Realizar compras con un vendedor de confianza. & & & & & \\
\hline
\end{tabular}




\begin{tabular}{|l|l|l|l|l|l|l|}
\hline 21 & $\begin{array}{l}\text { El asesoramiento personalizado en línea del vendedor a la hora de } \\
\text { adquirir productos fitness. }\end{array}$ & & & & \\
\hline 22 & $\begin{array}{l}\text { La comunicación post compra en línea con el vendedor a la hora de } \\
\text { adquirir productos fitness. }\end{array}$ & & & & \\
\hline
\end{tabular}

\section{Decisión de compra de productos fitness}

\section{Instrucciones:}

1. No me identifico 2. Me identifico poco 3. A veces me identifico 4. Me identifico 5. Me identifico en gran medida

\begin{tabular}{|c|c|c|c|c|c|c|}
\hline Nro. & Preguntas & 1 & 2 & 3 & 4 & 5 \\
\hline & Dimensión 1. Frecuencia de compra & & & & & \\
\hline 23 & Consumo productos fitness más de una vez a la semana & & & & & \\
\hline 24 & $\begin{array}{l}\text { Compro productos fitness más de una vez cada tres meses o al menos } \\
\text { una vez cada tres meses }\end{array}$ & & & & & \\
\hline 25 & $\begin{array}{l}\text { Prefiero comprar varios productos en conjunto, para así evitar el } \\
\text { desabastecimiento de mis productos fitness. }\end{array}$ & & & & & \\
\hline 26 & $\begin{array}{l}\text { El asesoramiento personalizado me incentiva a adquirir con mayor } \\
\text { frecuencia productos fitness. }\end{array}$ & & & & & \\
\hline \multirow[t]{2}{*}{27} & $\begin{array}{l}\text { Estoy intentando llevar un estilo de vida fitness por ello considero } \\
\text { importante, consumir productos fitness en mi día a día. }\end{array}$ & & & & & \\
\hline & Dimensión 2: Motivación de compra & & & & & \\
\hline 28 & Mi salud es el motivo por el cual consumo productos fitness. & & & & & \\
\hline 29 & Bajar de peso es un gran factor por el cual consumo productos fitness. & & & & & \\
\hline 30 & $\begin{array}{l}\text { Aumentar masa muscular es una motivación por el cual consumo } \\
\text { productos fitness. }\end{array}$ & & & & & \\
\hline 31 & $\begin{array}{l}\text { Aumentar mi resistencia es el motivo por el cual consumo productos } \\
\text { fitness. }\end{array}$ & & & & & \\
\hline 32 & $\begin{array}{l}\text { Conseguir resultados más rápidos es una gran motivación por el cual } \\
\text { consumo productos fitness. }\end{array}$ & & & & & \\
\hline 33 & $\begin{array}{l}\text { El asesoramiento personalizado en línea me incentiva a comprar } \\
\text { productos fitness incluso aquellos que no he consumido con } \\
\text { anterioridad. }\end{array}$ & & & & & \\
\hline
\end{tabular}

